NBSIR 80-2147

\title{
Daylighting, Window Management Systems, and Lighting Controls
}

S. Treado and T. Kusuda

December 1980

Center for Building Technology National Engineering Laboratory

National Bureau of Standards

U.S. Department of Commerce

Washington, DC 20234

Prepared for:

Naval Facilities Engineering Command

U.S. Navy

Washington, DC 20390

Directorate of Civil Engineering

U.S. Air Force

Washington, DC 20330 and

Office of Chief of Engineers

U.S. Army

Washington, DC 20314

U.S. Department of Energy

Jffice of Buildings and Community Systems

Nashington, DC 20585

C. 2 

S. Treado and T. Kusuda

December 1980

Center for Building Technology National Engineering Laboratory National Bureau of Standards U.S. Department of Commerce Washington, DC 20234

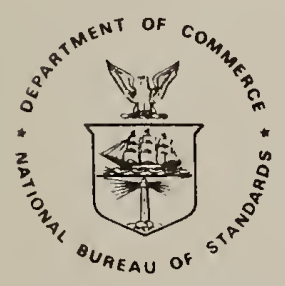

U.S. DEPARTMENT OF COMMERCE, Philip M. Klutznick, Secretary Jordan J. Baruch, Assistant Secretary for Productivity. Technology, and Innovation NATIONAL BUREAU OF STANDARDS, Ernest Ambler, Director 



\section{ACKNOWLEDGMENTS}

This project was sponsored jointly by the Tri-Services Committee, the Department of Energy and the National Bureau of Standards. The authors are grateful for the data collection and reduction assistance provided by C. Kilb. 
This report investigates major factors concerning windows in buildings and their effect on visual conditions, thermal conditions, and energy requirements. Empirically obtained data are presented for daylight illumination as a function of solar radiation, sky condition, window size and orientation, and interior reflectance. The thermal and visual effects of several window management strategies are examined, along with an analysis of automatic lighting controls. Daylight utilization is seen to offer great potential for minimizing lighting load in perimeter building areas, and careful determination of lighting needs and window management strategies can provide additional benefit.

Key words: Daylight; energy conservation; fenestration design; illumination; lighting control; solar heat gain; window management. 


\section{NOMENCLATURE}

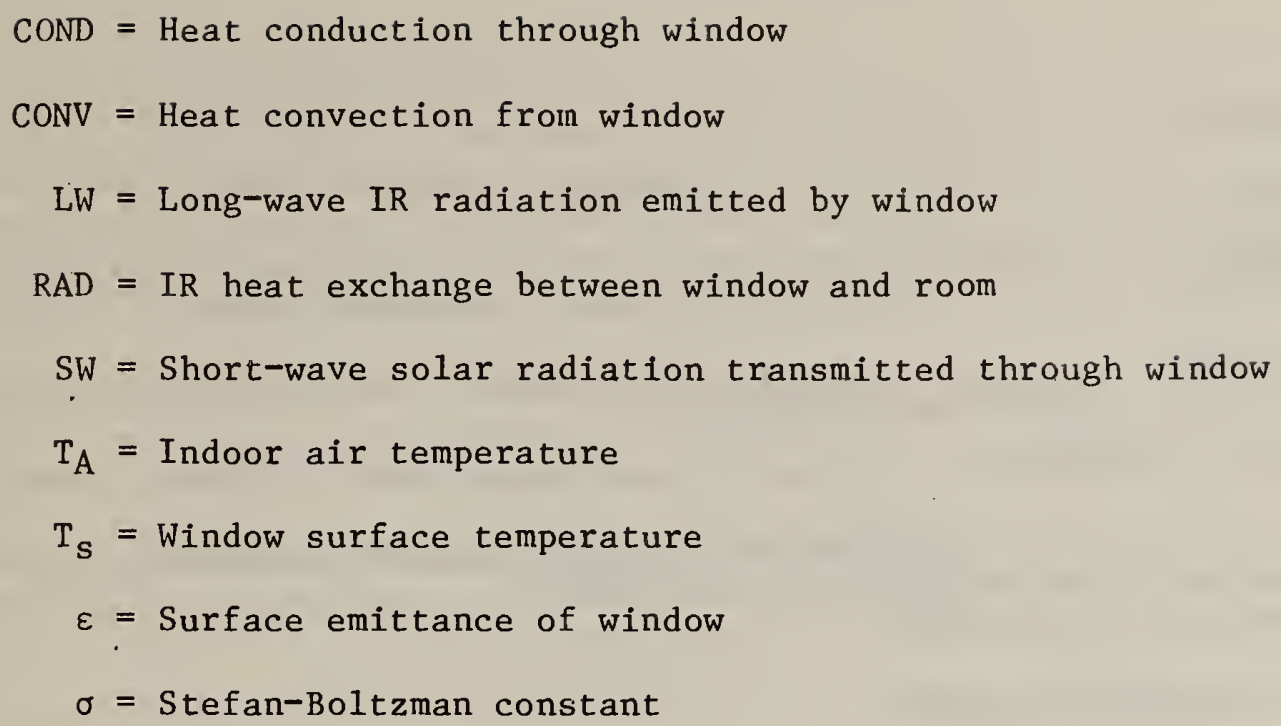


ACKNOWLEDGMENTS

ABSTRACT

NOMENCLATURE

$\mathrm{v}$

vii

LIST OF FIGURES

1. INTRODUCTION $\ldots \ldots \ldots \ldots \ldots \ldots \ldots \ldots \ldots \ldots \ldots \ldots \ldots \ldots \ldots \ldots \ldots \ldots \ldots \ldots \ldots \ldots$

2. DAYLIGHTING FACILITY AND EXPERIMENTS $\ldots \ldots \ldots \ldots \ldots \ldots \ldots \ldots \ldots \ldots \ldots$

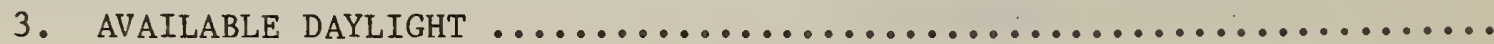

3.1 Effect of Sky Condition, Window Area and Wall Reflectance .... 6

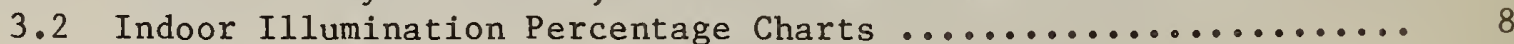

3.3 Daylight Distribution $\ldots \ldots \ldots \ldots \ldots \ldots \ldots \ldots \ldots \ldots \ldots \ldots \ldots \ldots \ldots . \ldots \ldots$

4. WINDOW MANAGEMENT SYSTEMS $\ldots \ldots \ldots \ldots \ldots \ldots \ldots \ldots \ldots \ldots \ldots \ldots \ldots \ldots \ldots \ldots$

4.1 Effect of Window Management Systems on Daylighting .......... 11

4.2 Performance of Solar Control Devices ..................... 13

5. WINDOW HEAT GAIN AND LIGHTING ENERGY ANALYSIS $\ldots \ldots \ldots \ldots \ldots \ldots \ldots$

5.1 Lighting Energy Analysis ......................... 17

5.2 Cooling Load Due to Lighting and Window Heat Gain ........... 18

5.3 Energy Consumption Due to Lighting and Window Heat Gain ...... 18

6. PERFORMANCE OF LIGHTING CONTROLS ........................ 20

6.1 Continuous Dimming System .......................... 20

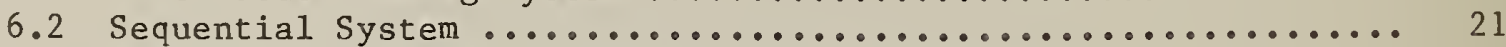

6.3 Comparison of Actual Systems with Perfect Dimmer ........... 22

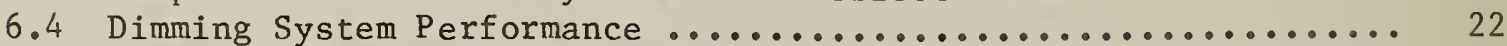

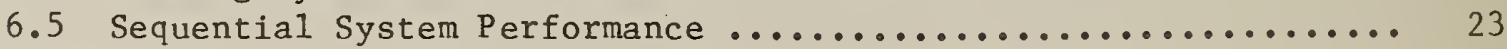

7. APPLICATION OF LIGHTING CONTROL SYSTEMS .................... 26

8. LIGHTING CONTROL/WINDOW MANAGEMENT TEST CASE $\ldots \ldots \ldots \ldots \ldots \ldots \ldots \ldots \ldots . \ldots \ldots$

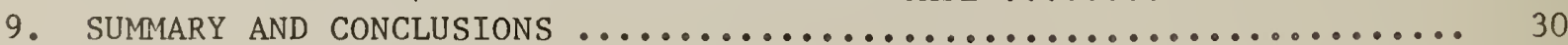

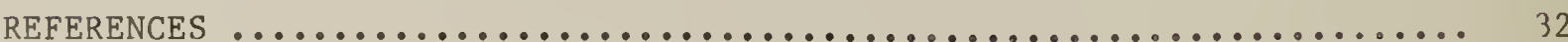




\section{LIST OF TABLES}

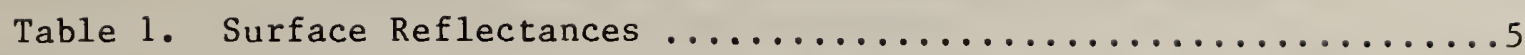

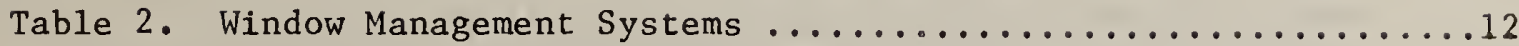

Table 3. Thermal Effects of Window Management Systems for South Exposure

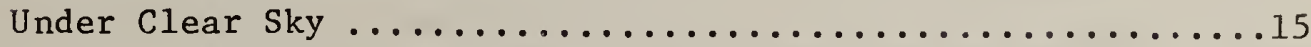

Table 4. Hourly Power Consumption of Dimming System ............23

Table 5. Hourly Power Consumption of Sequential System ..........24

Table 6. Lighting, Window Management Test Case ................... 


\section{LIST OF FIGURES}

Figure 1. Photographs of the NBS daylight research facility ...........33

Figure 2. Floor plan of Daylighting Lab ...........................

Figure 3. Effect of sky condition on indoor illumination - north-facing

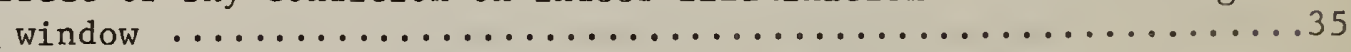

Figure 4. Effect of sky condition on indoor illumination - south-facing

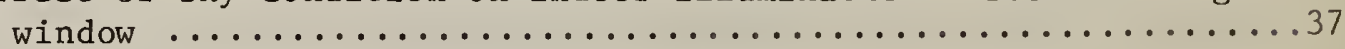

Figure 5. Effect of window area and wall reflectance - north-facing

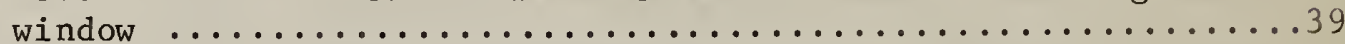

Figuré $6 . \quad$ Percentage hours of solar radiation $\ldots \ldots \ldots \ldots \ldots \ldots \ldots \ldots \ldots \ldots$

Figure 7. Percentage hours of indoor illumination -- north-facing window, $1.5 \mathrm{~m}(5 \mathrm{ft})$ and $2.7 \mathrm{~m}(9 \mathrm{ft})$ wall reflectance 0.28 , window area $22.9,15.3$ or 7.6 percent $\ldots \ldots \ldots \ldots \ldots \ldots . \ldots 42$

Figure 8. Percentage hours of indoor illumination -- north-facing window, $1.5 \mathrm{~m}(5 \mathrm{ft})$ and $2.7 \mathrm{~m}$ ( $9 \mathrm{ft})$ wall reflectance 0.50 , window area $22.9,15.3$ or 7.6 percent

Figure 9. Indoor horizontal illumination profiles for north-facing window, wall reflectance 0.28 and varying window areas. Percentages indicate ratio of illumination at each grid location to illumination immediately inside window .........44

Figure 10. Indoor horizontal illumination profiles for north-facing window, wall reflectance 0.50 , and varying window areas. Percentages indicate ratio of illumination at the center of each grid location to illumination immediately inside window

Figure 11. Daily solar radiation and illumination cycle - north and south-facing window

Figure 12. Thermal and illumination effects of windows

Figure 13. Indoor illumination with window management - south-facing window

Figure 14. Indoor illumination with roll shades - south-facing window .....50

Figure 15. Vertical solar radiation at inside surface of south-facing window, with and without management $\ldots \ldots \ldots \ldots \ldots \ldots \ldots \ldots \ldots$ 


\section{LIST OF FIGURES (Cont'd)}

Figure 16. Daily window radiation profiles - south-facing window,

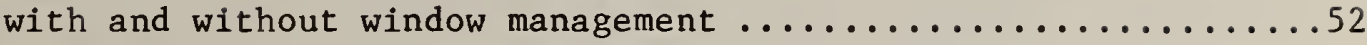

Figure 17. Short-wave solar heat gain for test case, various window

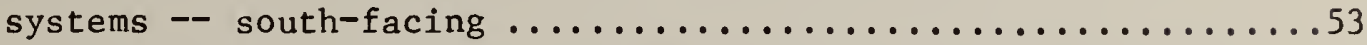

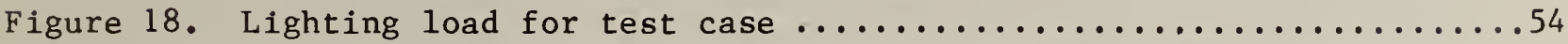

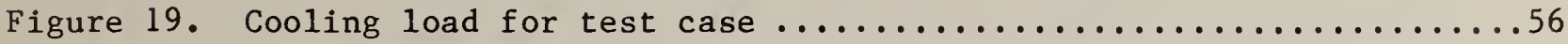

Figure 20. Cooling and lighting energy for test case $\ldots \ldots \ldots \ldots \ldots \ldots \ldots$

Figure 21. Schematic of lighting control systems.................60

Figure 22. Light output versus power consumption -- two systems ........61

Figure 23. Perfect dimmer performance comparison $\ldots \ldots \ldots \ldots \ldots \ldots \ldots \ldots \ldots$

Figure 24. Average indoor illumination for test room -- south-facing

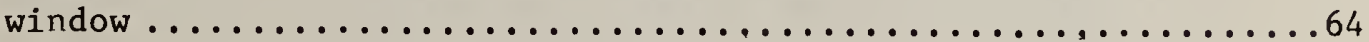

Figure 25. Lighting power consumption and energy savings -- dimming

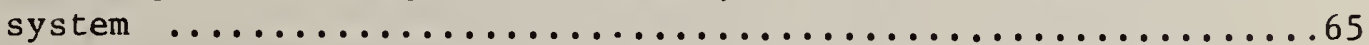

Figure 26. Lighting power consumption and energy savings -- sequential system

Figure 27. Lighting power consumption and window solar heat gain trade-off - clear window versus silver film .............69 



\section{INTRODUCTION}

The role of windows in buildings is a complex one due to the variety of ways windows affect interior illumination, artificial lighting, heating and cooling loads, and occupant comfort (both physical and psychological), as well as their integration into the overall structural design.

Windows have been estimated to account for as much as five percent of the total energy consumption in the United States, with electrical lighting accounting for an additional 5.5 percent of total energy use [1]. Thus, effective use of windows and lighting could have a significant impact on over 10 percent of the energy used in the United States. In addition, up to 50 percent of the energy used in commercial buildings has been shown to be due to electric lighting, with an additional energy expenditure of 15 to 20 percent due to increased cooling requirement to remove heat produced by lighting [2,3]. This indicates that commercial buildings in particular have great potential for energy savings through optimum design and utilization of windows and lighting systems.

Daylight utilization has been recognized as an effective way of reducing the energy required for illuminating buildings. However, attendant impact on building heat and cooling systems must also be considered before net annual benefits can be determined. Comprehensive computer programs are available for calculating natural daylighting for a specific room and window configuration. These procedures incorporate complex mathematical representations of light-ray reflections from surface to surface within a room, requiring time-consuming (and costly) calculations for a building energy analysis.

A simplified daylight calculation procedure would enable incorporation of daylight utilization, and related heating, cooling and lighting effects, to be included when undertaking building energy analyses. This in turn would promote energy-efficient building design, as well as enabling cost effective retrofit procedures to be identified. Additional information is needed concerning the performance characteristics of the various window management strategies (such as shades, films or screens) and automatic lighting control systems presently available. The use of these devices can dramatically alter energy use in buildings.

Determining the optimum design and utilization of windows in buildings is difficult due to the tradeoffs between the various window associated factors. Windows may be designed to provide natural lighting, ventilation, and visual contact with the outdoor environment for the building occupants [4] (favoring larger windows). At the same time, windows must be designed to minimize unwanted solar heat gain or cold weather heat loss [5], as well as maintaining sufficient privacy (favoring smaller windows). Of course, windows must be structurally sound and weathertight, with a long service life and low maintenance. A movable sash is needed if ventilation is desired.

Various window management systems have been proposed to selectively alter the thermal conductance and/or the solar transmittance of windows through 
the use of screens, films or shutters [6]. Special emphasis has been placed on the improvement of the thermal resistance of window systems to make them more compatible with the other portions of the building envelope. Efforts in this area include the use of multiple-pane systems, low-conductivity fill gases, internal partitions, partial evacuation of the air space, transparent heat mirror coatings and movable insulating devices [7]. These studies, along with several computer model simulations $[8,9,10]$, indicate that properly designed and operated window systems can reduce overall operating costs to the extent of making the window a net energy benefit as compared to a solid wall.

The use of daylight to replace or supplement artifical lighting through the use of automatic controls has been shown to have significant potential for energy savings, due to reduction of both lighting and cooling requirements $[10,12]$. Computer procedures have been developed to predict the amount of natural lighting available in buildings as a function of window size, type and orientation [12]. Potential energy savings through the use of automatic lighting controls have been estimated assuming a unit-for-unit replacement of interior illumination from artificial lighting, but actual savings may vary due to the light control strategy employed. This factor may be offset [13] if visual performance is better with daylight than with an equivalent level of electric lighting due to better contrast rendition.

Unlike most of the previous efforts, which are based on mathematical modeling, this report will investigate several of the major window associated building energy factors, based upon experimentally measured data. The mathematical modeling studies examined the interaction between lighting and cooling energy savings through the utilization of daylight, and undesirable window-associated thermal gains or losses, along with the resulting energy requirements.

Building energy analysis computer routines, such as NBSLD and DOE-2 use solar radiation data as an input parameter to calculate building energy performance data. In order to include the effects of daylight utilization on building energy performance, natural illumination from daylight must be calculated along with building thermal loads. Most daylight calculation routines require outdoor illumination or sky luminance data as input parameters. Illumination and sky luminance data are not available on a large scale basis nor for a wide range of geographical areas. However, solar radiation data is regularly collected at a large number of locations. An accurate correlation between indoor. 1llumination and solar radiation would enable the effects of daylight utilization to be included in building energy performance analyses. The first topic of the report is daylight availability. The amount of available interior illumination due to daylight is measured as a function of window area and orientation, internal room reflectance, outdoor solar radiation, and sky condition. Indoor illumination percentages, indicating the percent of working hours during which indoor illumination meets or exceeds a set level, are presented for a variety of room and outdoor conditions. The distribution of daylight within a room is also examined.

The second topic of the report is the effect of various window management strategies on the thermal and illumination characteristics of window systems. 
Indoor illumination with window management is examined along with measurement and analysis of the corresponding reduction in solar heat gain.

The final topic of the report concerns experimental observation of the performance of automatic lighting control systems, and their interrelation with windows and building energy requirements.

Results of several test cases are presented, with a comparison of the performance of the actual lighting controls to the performance of a 'perfect' lighting control system. Application notes for potential lighting control users are also included.

The experimental data reported herein were obtained during spring and summer of 1979, at the NBS Daylight research facility constructed on the solar test site on NBS grounds in Gaithersburg, MD. (latitude $39^{\circ} 8^{\prime}$, longitude $77^{\circ} 13^{\prime}$ ). This is an initial report which does not attempt to address the general question of the annual cost/benefits of daylight utilization, lighting controls and window management, since a full year of test data is not yet available. Additional fall and winter measurements are being performed with particular emphasis on the annual window management systems and lighting controls, results of which will be contained in a subsequent report. 


\section{DAYLIGHTING FACILITY AND EXPERIMENTS}

The NBS Daylight Research Facility consists of a specially altered mobile home, $3.7 \mathrm{~m} \times 16.3 \mathrm{~m}$ (12 ft. x $54 \mathrm{ft.})$. The home was constructed of wood framing and paneling, $7.6 \mathrm{~cm}$ ( 3 in.) glass fiber insulation and aluminum siding. Photographs of the facility are shown in figure 1. The home was partitioned into four testing modules with various combinations of window orientations and sizes. A flour plan of the lab is shown in figure 2. Three of the modules were outfitted with fluorescent electric luminaires suspended directly below the ceiling. Rooms 1 and 3 had four luminaires, while room 2 had eight. Each luminaire consisted of two-40W lamps with one ballast, either standard or dimming, with a wrap-around prismatic diffuser. The power consumption of each lighting circuit was monitored individually. The lab is cooled by a single air conditioner located in room 4 also with individually monitored power consumption. Rooms 1 and 4 can be isolated from the rest of the $1 \mathrm{ab}$ by closing their entry doors. The doorway between rooms 2 and 3 is blocked by a curtain with negligible light transmittance.

Instrumentation was installed to measure and record several parameters on an average hourly basis. These parameters included total hemispherical solar radiation and diffuse solar radiation over a horizontal surface, horizontal indoor illumination at various iaterior locations, and temperatures outdoor and throughout the lab (TYPE T thermocouples). Additional sensors were used in conjunction with the window management segment of the testing, consisting of a vertically mounted pyranometer and a similarly mounted long-wave infrared radiometer positioned at the center of the south window in room 4 (see figure 2 ).

Sensor signals were logged with millivolt integrators and a multichannel data logger. Additional measurements of illumination were performed by hand, using illuminometers. A frequent visual examination of sky condition was also performed.

The various electrical power consumptions were measured using pulsegenerating watt-hour meters connected to resetting counter/printers which could be selected to print at $0.25,0.5$ or 1.0 hours.

The reflectances of the interior surfaces and the surrounding ground surfaces are listed in table 1 . These were determined with a reflectometer. The ground surfaces on the south, west and east sides of the lab were completely asphalt, while on the north side asphalt extended approximately $10 \mathrm{~m}$ ( $33 \mathrm{ft} \cdot$ ) followed by a grassy downward slope. A small section of concrete was located adjacent to the northwest corner of the facility, increasing the amount of ground-reflected radiation impinging upon the north window of room 1 when the sun was in the west. 
Table 1. Surface Reflectances

Surface

Interior F1oor

Ceiling

Wall

Wa11

Wa11

Exterior:

Ground

Ground
Type

brown carpet

white drywal1

a) wood paneling

b) gray matte surface

c) white matte surface
Reflectance

0.38

0.84

0.28

0.50

0.85

asphalt

0.07

concrete

0.25

The views out of the windows utilized for this testing schedule were essentially unobstructed ( $<2$ percent) with the exception of the large north window in room 1. The bottom of the north window was partially blocked ( 12 percent) by the tops of large trees located approximately $122 \mathrm{~m}$ ( $400 \mathrm{ft.}$ ) north of the facility on a downward slope. Window obstruction profiles were determined by viewing out the windows at a spot $0.9 \mathrm{~m}$ high $(3.0 \mathrm{ft}$.$) located$ 2.7 or $3.1 \mathrm{~m}$ ( 9 or $10 \mathrm{ft.}$ ) from the center of each window. Rooms 1 and 4 were only deep enough to allow measurements at the shorter depth.

A11 the windows were comprised of single-pane clear glass $1.6 \mathrm{~mm}$ (1/16 in.) thick, except the large north window in room 1 , which was double-pane clear glass, each pane $3.2 \mathrm{~mm}$ (1/8 in.) thick. The measured visible transmittance of the single pane windows was 0.91 and the double pane windows 0.82 . Visible transmittances were measured with an illuminometer by consecutively positioning the sensor immediately adjacent to the inner and outer surfaces of the window.

Transmittance was computed from ratio of the measured illuminance transmitted by the window to that incident upon the outer surface of the window. 


\section{AVAILABLE DAYLIGHT}

One of the major objectives of this study was to evaluate the contribution of daylight to interior illumination as a function of window size and orientation, internal reflectances, and sky condition. North and south exposures were examined during this phase, through the use of rooms 1 and 3 , respectively. Indoor illuminance was measured and correlated as a function of total horizontal solar radiation and sky condition. This is a different approach from a previous daylight factor approach in which the indoor daylighting level was correlated with the outdoor illuminance. A key point of such an approach is the abundance of total solar radiation data available in the literature, since this data is routinely collected at many locations by the Weather Service, which enables application of this type of correlation to predict interior daylight illuminance at a wide range of locations.

Throughout this report, references to solar radiation are meant to indicate radiation power including the full solar spectrum $(0.2-3 \mathrm{~m})$. Diffuse solar radiation is simply total solar radiation less the direct component. Outdoor illumination is considered to be radiation power in the visible light band $(0.4-0.8 \mu \mathrm{m})$ as measured while shaded from direct sunlight. Indoor illumination is measured in a similar manner. All illumination measurements are filtered to respond according to the CIE standard eye curve.

\subsection{EFFECT OF SKY CONDITION, WINDOW AREA AND WALL REFLECTANCE}

Solar radiation is the source of daylight illumination, but there is no direct relation between the level of solar radiation and the illuminance levels, either indoors or out. This is because of the random effect of sky condition. The relative amounts of the infrared, visible, and ultra-violet portions of the radiant power spectrum vary as a function of sky condition (atmospheric moisture, cloud density and type). Under clear sky conditions, the level of solar radiation is high, but the illuminance level is not since a clear blue sky provides low levels of illuminance. On an overcast day, the opposite situation occurs. The level of outdoor illuminance is more dependent upon the level of diffuse solar radiation than total solar radiation, since greater levels of diffuse solar radiation indicate more overcast sky conditions. The bright white clouds which occur on partially overcast days, during which the sun is not directly obscured, provide the greatest daylight illuminance levels.

For the purposes of this study, sky conditions were defined as follows:

clear sky - essentially very few or no clouds, bright sun; partially overcast - sun visible, partially cloudy; overcast - sun not visible, completely cloudy.

Considerable variation in sky condition can occur, as combinations of overcast, partially overcast, or clear conditions may be present at the same time in different areas of the sky. This variation is greatest under partial overcast conditions since by definition the clear and overcast conditions result in nearly uniform sky conditions. However, measurements indicate a 
good relation between level of solar radiation, sky condition and indoor illumination from daylight.

Assuming equivalent levels of total solar radiation, an overcast sky will be more effective than a clear sky in providing interior illumination, due to reflected light from clouds. This is especially true for northern orientations since the sun is in the south sky causing a large amount of reflected light from any clouds in the northern sky. Figures $3 a$ and $3 b$ examine the effect of sky condition and total solar radiation on the amount of available indoor illumination for a northern exposure at depths of $1.5 \mathrm{~m}(5 \mathrm{ft.})$ and $2.7 \mathrm{~m}$ ( $9 \mathrm{ft.})$, respectively, from window at sill level. These figures were determined from many measurements performed in room 1 , with a wall reflectance of .28 , and a window area of $1.6 \mathrm{~m}^{2}\left(17.4 \mathrm{ft}^{2}\right)$, or 22.9 percent of external wall area. The ceiling and floor reflectances were measured and found to be 0.84 and 0.38 respectively.

A large difference in the amounts of available daylight is seen as a function of sky condition. Each of the lines represents a least-squares fit of handmeasured and recorded simultaneous, instantaneous values of total solar radiation and indoor illumination. An overcast sky is seen to provide approximately 2.0 times the indoor illumination as a partially overcast sky, and approximately 4.0 times as much as a clear sky, for a $1.5 \mathrm{~m}$ ( $5 \mathrm{ft.}$ ) depth at an equivalent level of total solar radiation. Similar calculations for the $2.7 \mathrm{~m}$ ( $9 \mathrm{ft.}$ ) depth indicate an overcast sky as providing 1.5 times the indoor illumination as a partially overcast sky and over 2.0 times as much as a clear sky. These figures indicate a range of expected indoor illumination values. Since low values of total solar radiation usually mean overcast days, indoor illumination levels under those conditions would probably correspond best with the overcast sky. Similarly, since high values of total solar radiation usually correlate with clear sky conditions, indoor illumination levels would probably correspond best with the clear sky. Indoor illumination at medium values of total solar radiation would probably fall at intermediate locations within the clear/overcast band, but would experience the most variation and be the most difficult to predict, without knowing sky condition or cloud cover.

Figures $4 \mathrm{a}$ and 6 provide a similar examination for a southern exposure for two depths. The window size was $1.1 \mathrm{~m}^{2}\left(12 \mathrm{ft}^{2}\right)$ or 16 percent of wall area. An overcast sky is seen to provide 1.3 times the indoor illumination as a partially overcast sky and over twice the illumination for a clear sky for the $1.5 \mathrm{~m}$ ( $5 \mathrm{ft.}$ ) depth, with smaller differences for the $3.1 \mathrm{~m}$ (10 ft.) depth, at an equivalent level of total solar radiation.

Figures $5 \mathrm{a}$ and $\mathrm{b}$ examine the effect of window area and wall reflectance on the amount of available daylight from a north window for depths of $1.5 \mathrm{~m}$ $(5 \mathrm{ft}$.$) and 2.7 \mathrm{~m}(9 \mathrm{ft}$.$) respectively. The window areas included are$ 22.9 percent, 15.3 percent and 7.6 percent, as well as wall reflectances of 0.28 and 0.50 . Window areas were altered by symmetrically reducing the width of the window. Wall reflectances were altered by changing the wall covering. The illuminances are based on an average of measurements under all sky conditions for comparison purposes. Changes in window area are seen to 
produce larger changes in illumination level than a change of wall reflectance for the shallower depth location, while the opposite effect is seen for the deeper location. This effect indicates that daylight illumination at the deeper location is more dependent upon inter-reflected light from the walls than light directly transmitted from the window.

\subsection{INDOOR ILLUMINATION PERCENTAGE CHARTS}

In analyzing the effect of daylight on illumination, it is important to know the percentage of working hours during which indoor illumination from daylighting reached various levels. Such an indoor illumination percentage would indicate the ratio of time during which the desired indoor illumination level could be achieved through daylight alone, as well as percentage contributions of daylight and artificial lighting needed to maintain the illumination set point. Since indoor illumination as a function of total solar radiation, window area, and wall reflectance has been previously presented, it is necessary to examine first the percentage of working hours for which solar radiation met or exceeded various levels. These solar radiation percentages for spring and summer are presented in figure 6 .

The work day was assumed to be from 0600 to 1800 hours. Hourly averaged total solar radiation values were examined and compiled according to their level and the percentage hours they occurred. The spring percentage was slightly lower than that for summer.

Combining the indoor illumination versus total horizontal solar radiation correlations previously presented with the percentage hours of solar radiation levels permits the determination of percentage hours of indoor illumination. These percentage hours of indoor illumination for a north window are shown in figures 7 and 8 as a function of window area, wall reflectance, depth from window, and season. These figures indicate that daylight can provide a significant portion of the desired indoor illumination level. The relative contribution of daylighting would be dependent upon the desired indoor illumination level, window size and wall reflectance.

For example, if a 700 lux (70 F.C.) indoor illumination level was desired at $1.5 \mathrm{~m}$ ( $5 \mathrm{ft.}$ ) from the window, this could be achieved through daylight alone for over 50 percent of working hours with the largest window area., as shown in figure 7 . The figures indicate that more modest contributions would be expected for the $2.7 \mathrm{~m}$ ( $9 \mathrm{ft}$. ) deep location, but still significant ones, especially for the 0.50 wall reflectance, as shown in figure 8 . Window area is seen to have a marked effect on the relative contribution of daylight. At the smallest window area, approximatley 300 lux (30 F.C.) indoor illumination occurs for 50 percent of the working hours at the shallow depth and less than half that at the deep location. As noted earlier, wall reflectance is seen to have a greater effect on the illumination at the deeper location.

\subsection{DAYLIGHT DISTRIBUTION}

Figures 9 and 10 show the effect of window area and the distribution of indoor illumination due to daylight for a north window. The two figures 
represent data taken with two different wall reflectances. These profiles were determined from consecutive measurements with different window areas, consisting of 22.9 percent, 15.3 percent and 7.6 percent of the exterior wall area, for each of the wall reflectances. The percentage illuminances were determined by comparing the illuminances in the various sub-areas of the room to the illuminance directly in front of the window. All measurements were made at a height of $0.76 \mathrm{~m}$ (30 in.) above floor level on a horizontal plane.

The significance of these profiles is in the distribution of daylight into the deeper parts of the room. As would be expected, the higher wall reflectance produced a better distribution of light into the rear of the room. The average illumination of the four deepest areas with the largest window area (22.9 percent) and wall reflectance of 0.50 was 22.1 percent. Reducing window area to 7.6 percent resulted in a drop in average illumination to 8.7 percent in the same areas. A similar illumination level, 7.8 percent, was observed at the same areas for a wall reflectance of 0.28 and a window area of 22.9 percent. In this case, increasing wall reflectance from 0.28 to 0.50 produced an increase in indoor illumination at the deepest areas comparable to that which would have been obtained by increasing window size by a factor of three. This indicates the importance of wall reflectance in influencing illumination level. This conclusion is limited to the room sizes investigated in this study.

It should be understood, however, that the distribution of daylight throughout a room will vary with time of day, season and sky condition. These illumination profiles are presented as mere examples, in an attempt to evaluate the effect of window area and wall reflectance on indoor illumination.

Figure 11 presents typical diurnal profiles of total solar radiation, outdoor illumination, and indoor illumination for a north and south exposure. Indoor illumination was measured $1.5 \mathrm{~m}(5 \mathrm{ft.})$ from the center of the windows, at a height of $0.76 \mathrm{~m}$ (30 in.). The north-facing window area was 22.9 percent of the wall area and the south-facing window area was 16 percent. Sky condition was partially overcast. Indoor illumination is seen to be higher in the morning, corresponding to a higher level of outdoor illumination at that time due to sky conditions. 


\section{WINDOW MANAGEMENT SYSTEMS}

The results in the previous section were obtained using clear glass, unaltered or shaded. Many varieties of window management devices are available to alter the thermal and/or visual performance of window systems. Some of these take the form of sun control screens, films or shades, and are designed to reduce unwanted solar heat gain during the cooling season by reflecting incident solar radiation. Additional benefits of glare control, cosmetic appearance and reduced solar-induced material fading are attributed to these types of window management systems.

In this section the effect of several window management systems on the interior illumination level due to daylight will be examined. Some of the thermal aspects of the sun control devices are also presented.

As compared to an opaque wall, a window in a room will affect the thermal and visual characteristics of that room in several significant ways. First the window will provide natural illumination through transmission of daylight. Heat may be transferred into the room due to the admittance of solar radiation through the window. This can be termed short-wave solar radiation. Radiation exchange in the long-wave infrared region will occur between the window glass and the room, the net magnitude dependent upon the temperature difference between the glass and the room, and their respective surface emittances. Heat transfer through the window will also occur due to temperature differences between the interior and exterior air tempertures, by way of conduction and convection. The amount of total solar radiation, sun angle, time of day, sky condition, and wind conditions will all influence the thermal or visual performance of windows. These factors are summarized in figure 12 .

Heat gain through a window can be expressed by the following relation:

$$
\text { Window Heat Gain }=\mathrm{SW}+\mathrm{LW}+\mathrm{CONV}+\mathrm{COND}
$$

\footnotetext{
where $\quad \mathrm{SW}=$ short-wave solar radiation transmitted through window $(0.2-3 \mathrm{rm})$,

$\mathrm{LW}=$ long-wave radiation emitted by window $(4-50 \mathrm{\mu m})$,

CONV = convection from window,

COND = conduction through window.
}

For the sake of simplicity, only those factors pertaining to summer conditions will be examined. The short wave component is composed of direct and diffuse solar radiation as well as ground-reflected solar radiation. The magnitude of the short-wave component is dependent upon the level of solar radiation, sky condition and ground reflectance. Most of the incident short-wave radiation will be absorbed by the floors, walls and furniture of a room, raising their temperatures. Since glass is opaque to long-wave radiation emitted by surface less than $121^{\circ} \mathrm{C}\left(250^{\circ} \mathrm{F}\right)$, this energy cannot be transmitted back out of the room through the window. The temperature of the glass will determine the net transfer of heat due to radiation between the room and window. The glass temperature is in turn dependent upon the indoor and outdoor air temperature, level of solar radiation, wind conditions and window management 
system. Heat exchange due to conductive and convective processes is essentially dependent upon the glass and air temperatures and air flow conditions at the window surface.

Window management systems can reduce unwanted summer window heat gain by rejecting short-wave radiation directly, and by reducing window temperature, thereby reducing the long-wave radiation component, as well as the convection component. Since window temperature is primarily dependent upon air temperature, the magnitude of the last effect may be small for a non-heat-absorbing glass. This is because the amount of radiation emitted by a surface is dependent upon ițs absolute temperature, so the temperature variations normally encountered with standard glass have a relatively small effect.

An increase in window temperature may occur if a film with a significant solar absorptance or an interior shade is utilized for solar control. This phenomenon may be beneficial under winter conditions, increasing the heat gain as well as reducing heat loss to the window by radiation, although window conduction heat "losses may increase.

It is difficult to selectively suppress solar heat gain through windows without also reducing daylight transmission. Because of this, a trade-off must be made between reducing cooling load through rejection of solar radiation with window management systems and increasing lighting load because of lower levels of daylight lumination available with window managment systems installed. Window management techniques which allow sun control only when needed, enabling full utilization of daylight at other times, would partially reduce the negative aspects of this tradeoff. However, many of the sun films and screens presently available are designed for relatively permanent installation, at least on a seasonal basis, and would be difficult to remove during the portion of the day when they are not needed for solar control purposes. Several types of adjustable shades and. louvers are available that can be quickly and easily positioned in response to sun control or daylight transmission requirements determined by the user. Adjustment may be designed to occur manually or automatically, depending on the system, so the window will be completely clear of obstructions.

Table 2 lists the various window management systems and devices examined during this study. All the equipment listed is available commercially. While many more types of window management systems are available, the ones presented here were chosen to demonstrate the performance which might be expected through utilization of typical systems.

\subsection{EFFECT OF WINDOW MANAGEMENT SYSTEMS ON DAYLIGHTING}

Figure 13 presents the indoor illumination levels observed in a room with a south-facing window (area 13 percent) as a function of total outdoor hemispherical radiation for different window management systems. Illuminance was measured $1.5 \mathrm{~m}(5 \mathrm{ft}$.$) and 3.0 \mathrm{~m}(10, \mathrm{ft}$.$) from the center of the window at a$ height of $.76 \mathrm{~m}$ (30 in.). Illumination levels for the roll shades are presented in figure 14. In these figures, the illuminance plots are given for overcast 
and partially overcast sky conditions for all the window management systems, with additional clear data for the roll shades.

The screens and shade with film are seen to reduce natural illumination significantly as compared with clear glass. Use of either the bronze screen or the shade with film would provide very little natural illumination, even at high levels of solar radiation. The reflective films and shade without f $11 \mathrm{~m}$ produce a more moderate reduction in illumination levels. Indoor illumination on overcast days is seen to be higher than on partially overcast days, for an equivalent level of solar radiation. Illumination provided by the roll shade without $\mathrm{fllm}$ is higher on clear days than on partially overcast days, due to the direct solar radiation falling on the shade being dispersed into the room.

\section{Table 2. Window Management Systems}

Item

Bronze Screen

Aluminum Screen

Glass Fiber Screen

Silver Reflective Film

Grey Reflective Film

Bronze Reflective Film

Roll Shades, Single

Roll Shades, Dual

\section{Description}

Small horizontal louvers of bronze bands; flat black; attached to exterior window frame.

Small horizontal louvers stamped from aluminum sheet; natural unpainted; attached to exterior window frame.

Open weave fabric; dark brown; attached to exterior window frame.

60 percent reflection, 17 percent visible transmission; polyester base; adhered to glass.

30 percent reflection, 20 percent visible transmission; polyester base; adhered to glass.

17 percent reflection, 28 percent visible transmission; polyester; adhered to glass.

Varlous colors (white, grey) and weaves; vinyl; interior use.

Same as single but with one layer of fabric and one layer of reflective $\mathrm{f} 1 \mathrm{~lm}$ seprated by small alr space $(1.3 \mathrm{~cm}$, 0.5 in.); installed with film facing window side. 


\subsection{PERFORMANCE OF SOLAR CONTROL DEVICES}

To evaluate the effectiveness of the different window management strategies in reducing solar heat gain through the window, measurements were made of the level of solar radiation incident upon a vertical plane inside the window surface. These measurements are summarized in figure 15 as a function of exterior horizontal total solar radiation and window management system. These data were obtained by a linear least-squares fit of hourly averaged data for each window management system. All measurements were made during a one-month period, and no correction was made for the small differences in sun angle due to seasonal changes in solar altitude.

The window utilized had an area of $0.66 \mathrm{~m}^{2}\left(7.1 \mathrm{ft}^{2}\right)$ or 9.7 percent of wall area. The bronze screen and the roll shade with film are seen to be the most effective in reducing the transmission of solar radiation into the room, with the other screens and silver film transmitting slightly higher amounts. All the systems except the grey film, which did not have a high reflectance, provided at least a 50 percent reduction in short-wave solar transmittance into the room.

Typical daily profiles of outdoor horizontal solar radiation, indoor vertical solar radiation, indoor vertical long-wave IR radiation and outdoor temperature for a sunny summer day are given in figure 16 for a clear window and for a window with a sun control screen, for a south orientation. The indoor radiation levels were measured immediately adjacent to the window surface. The level of long-wave radiation emitted from the window is seen to remain fairly constant, with only a slight increase in outdoor temperature during the day. The level of indoor vertical solar radiation is significntly reduced through the utilization of the sun control screen. This indicates that the most significant benefit of the solar control devices is reduction. in the amount of solar radiation transmitted through the window, rather than a reduction of the long-wave radiation emitted from the window surface, since window surface temperature does not change much as a function of solar radiation.

It is difficult to analyze the thermal effects of the different window management systems because of the variety of factors which influence their performance. It was not possible to perform side-by-side comparison testing of all the window management systems under identical conditions. Each of the systems was installed for a set time interval, and"its performance continuously monitored. For comparison purposes, only a limited set of data was shown which had been obtained under relatively equivalent time-of-day, solar and temperature conditions. Some variations in conditions did occur, especially temperature during the later stages of testing.

Table 3 lists the measured levels of window heat gain along with a breakdown of the individual components. Heat transfer due to conduction is not included, since it is essentially a function of the indoor-to-outdoor temperature difference and the thermal transmittance (U-factor) of the window. Use of window management systems may alter the U-value of a window, but this phenomenon was not investigated. Under summer conditions, the U-value of a window management 
system does not have as great a thermal influence on a room as the reduction in solar heat gain due to reduced solar transmission. Air infiltration was also neglected, since it was assumed to be approximately the same regardless of the window management system.

The significance of table 3 is in the breakdown of percentage contributions of the short-wave, long-wave and convection components. The convective heat transfer is dependent upon the temperature difference between the window surface and the indoor air. This parameter was calculated from the following relation [14]

$$
\operatorname{CONV}=0.19\left(\mathrm{~T}_{\mathrm{S}}-\mathrm{T}_{\mathrm{A}}\right)^{1 / 3}\left(\mathrm{~T}_{\mathrm{S}}{ }^{-\mathrm{T}_{A}}\right)
$$

where

$$
\begin{aligned}
& \mathrm{T}_{S}=\text { window surface temperature } \\
& \mathrm{T}_{\mathrm{A}}=\text { indoor air temperature. }
\end{aligned}
$$

Indoor air temperature was measured directly and the window surface temperature was determined from the long-wave radiometer readings and the Stefan-Boltzman relation [14]. The total radiation incident upon the radiometer (LW) is equal to the sum of the energy emitted and energy reflected by the window, or:

$$
L W=\varepsilon \sigma T_{S}^{4}+(1-\varepsilon) \sigma T_{A}^{4}
$$

where

$$
\begin{aligned}
& \varepsilon=\text { surface emittance of window } \\
& \sigma=\text { Stefan-Boltzman constant, } 5.67\left(10^{-8}\right) \frac{\mathrm{W}}{\mathrm{m}^{2} \cdot{ }^{\circ} \mathrm{K}^{4}}\left(0.1713\left(10^{-8}\right) \frac{\mathrm{Btu}}{\mathrm{h} \cdot \mathrm{ft}^{2} \cdot{ }^{\circ} \mathrm{R}^{4}}\right)
\end{aligned}
$$

Rearranging the terms of this relation yields:

$$
\mathrm{T}_{\mathrm{S}}=\left[\frac{L W}{\varepsilon \sigma}-\mathrm{T}_{A}^{4}\left(\frac{1}{\varepsilon}-1\right)\right]^{1 / 4}
$$

The surface emittances of the glass and films were determined through measurement, also utilizing the radiometer.

$$
\varepsilon=\frac{L W-\sigma T_{A}^{4}}{\sigma\left(T_{S}^{4}-T_{A}^{4}\right)}
$$




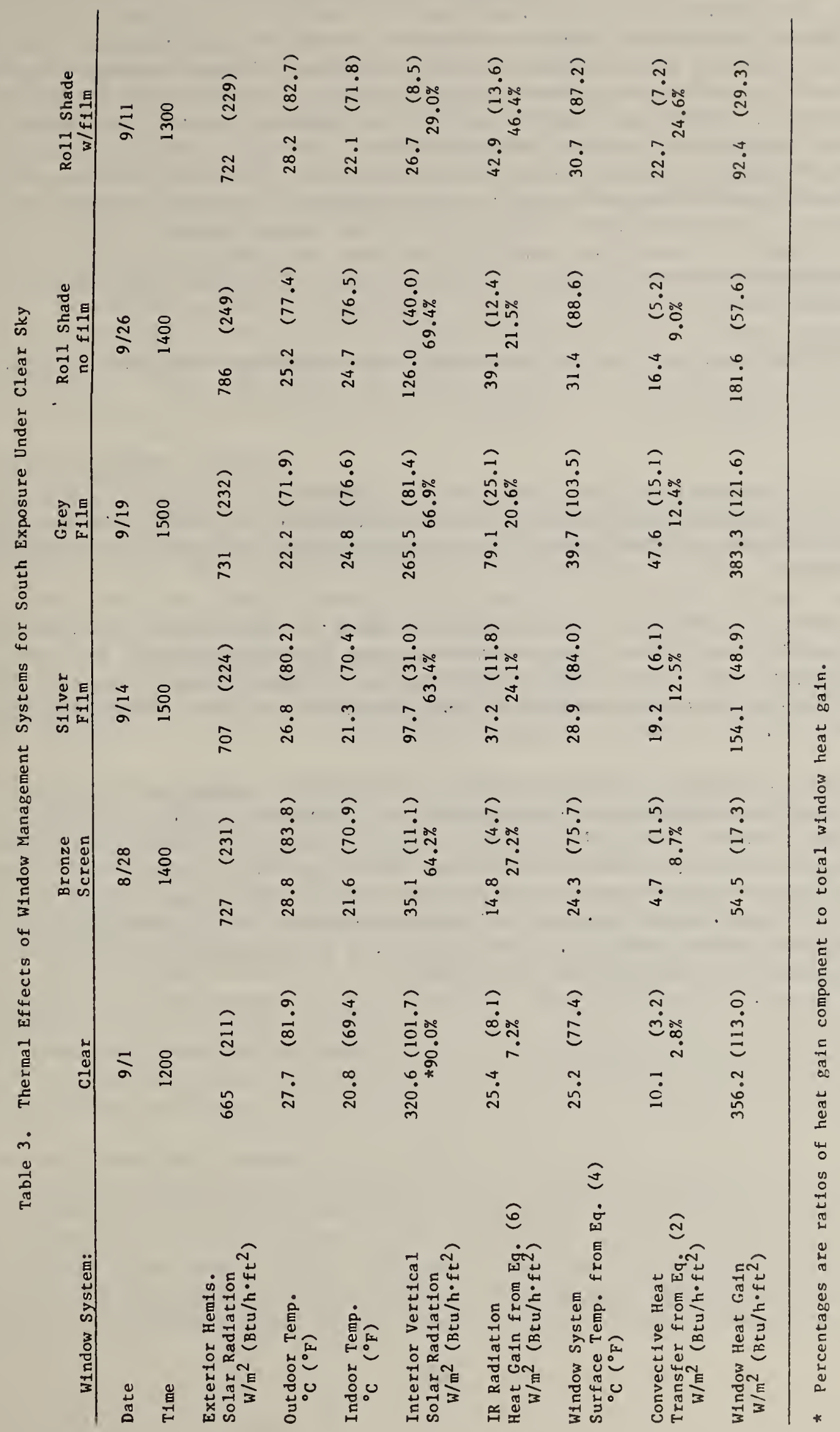


A surface thermocouple was attached to the window surface with a thin piece of tape, and measurements were performed at night to eliminate solar absorption effects which might induce inaccuracy. Simultaneous measurements were made of $\mathrm{T}_{S}, \mathrm{~T}_{\mathrm{A}}$ and $\mathrm{LW}$, allowing $\varepsilon$ to be computed. These measurements indicated surface emittance values of 0.94 for the glass and 0.82 for the films. When the roll shades were installed, the radiometer viewed the shade surface, which was composed of an open weave material. It was difficult to determine an exact surface emittance value for this system, since the shade and glass or film surface both contributed to the radiation intensity sensed by the radiometer. Therefore, the surface emittances were assumed to be 0.94 for the roll shade without film, and 0.82 for the roll shade with film, since these were the measured values for the surfaces which were opaque to long wave IR radiation.

IR radiation heat gain to the room ( $R A D$ ) was estimated from the relation:

$$
R A D=\varepsilon \sigma\left(T_{S}^{4}-T_{A}^{4}\right)
$$

based on the assumption that the room air temperature represents the mean radiant room temperature (since walls were highly insulated) and assuming that the room is performing as a black body (since the window views the room as a cavity).

In al1 cases, convective heat transfer is seen to make a small contribution to the overall heat gain. The window surface temperature with the grey film is the highest, due to the solar absorptance of the tinted film. The surfaces of the roll shades also reached a higher temperature, due to the long-wave radiation trapped between the shade and glass.

As would be expected, the main effect of the window management systems is seen to be the reduction of transmission of short-wave solar radiation. Significant reductions in window heat gain are seen, especially with the bronze screen and roll shade with film. The grey film, which does not have a high reflectance, produced a small reduction in short-wave solar radiation which was offset by an increase in long-wave radiation, producing no net reduction in window heat gain. The long-wave components from the other systems were not significantly affected. 


\section{WINDOW HEAT GAIN AND LIGHTING ENERGY ANALYSIS}

To examine the tradeoff between natural and artificial illumination and solar heat gain through the window system, several examples were considered. A south facing window was chosen, since this orientation is of most interest during the summer cooling season. Two window areas were examined, 26 percent and 13 percent, along with three window systems; clear, fiber glass screen, and bronze screen. These three window systems were chosen because their solar rejection performance covers a large range, from high (bronze screen), to medium (fiber glass screen), to low (clear).

Using the data from figure 15, which indicated short-wave solar radiation levels at the inside window surface per unit area, short wave heat gain into the room was determined for the two window areas with each window system. This data is presented in figure 17, again as a function of outdoor horizontal solar radiation. These relations were utilized in subsequent analysis of cooling load due to solar heat gain and lighting.

\subsection{LIGHTING ENERGY ANALYSIS}

To integrate the effect of natural and artificial illumination on energy consumption, as a function of window area and window system, several factors must be considered. The required indoor illumination level must be determined, as well as the location within the room of that illumination level. The contribution of daylight is much greater nearer the window than deep in a room. The illumination set point is determined mainly by occupant needs. Some users require high illumination levels throughout the room, others are satisfied with high levels only in the center of the room or at another specific location.

For the purpose of example, the locations of the illumination set points were chosen to be $1.5 \mathrm{~m}(5 \mathrm{ft}$.$) and 3.1 \mathrm{~m}(10 \mathrm{ft}$.$) in from the window center, and$ the illumination levels chosen to be 500 lux and 1000 lux. These illumination levels were considered to be moderate and high, respectively. Illumination levels will usually be higher for locations nearer to the window than at the set point locations, due to daylight entering through the window. Size and type of artificial lighting must be chcsen also. Fluorescent lighting systems were chosen since they were used throughout the testing and are commonly found in buildings. Lab measurements indicated that four $80 \mathrm{~W}$ double-lamp fluorescent luminaires provided approximately 1000 lux illumination at the center of the test modules. Considering additional power consumption by lamp ballasts and control systems, total lighting power consumption was assumed to be $400 \mathrm{~W}$ for the 1000 lux condition and half that, $200 \mathrm{~W}$, for the 500 lux condition.

Based on the foregoing assumptions, lighting loads were calculated for the various conditions assuming the operation of a perfect dimming system. A perfect dimming system is defined here as one which varies lighting level in direct proportion to the lighting power consumption while maintaining constant indoor illumination level. This is done by reducing artificial lighting in response.to the available interior daylight. A perfect system maintains this linear relationship down to zero light output. Perfect dimming systems 
do not exist in reality, so reductions in lighting load could be less for actual system. However, the assumption of a perfect dimming system is used in this analysis. System performance of several lighting control systems is examined in a later section.

Figure 18 examines lighting load as a function of outdoor horizontal solar radiation for the various window areas, window systems, and illumination setpoint levels and locations. The contributions of daylight were determined based on the illumination levels for partially overcast conditions presented in figure 13. Partially overcast conditions were used since they reflect average data. Significant reductions in lighting load are seen for most conditions, especially with 500 lux illumination set point and the window sytems with higher visible transmission. Window area does not influence lighting load as strongly as does the type of window system. For the clear window, 26 percent of the wall area, 500 lux setpoint condition, daylight is seen to fully satisfy total illumination requirements at the $1.5 \mathrm{~m}$ ( $5 \mathrm{ft.}$ ) location whenever horizontal solar radiation exceeds $200 \mathrm{~W} / \mathrm{m}^{2}$. From figure 6 , this is seen to occur 76 percent of the working hours in spring and 79 percent in summer. However, under the same conditions at the $3.1 \mathrm{~m}(10 \mathrm{ft.})$ location, some artificial lighting is always needed to maintain the illumination set point, although significant reductions in lighting load are seen (35 percent at moderate solar radiation level of $400 \mathrm{~W} / \mathrm{m}^{2}$ ) for the clear windows. As a worst case, lighting load is only reduced approximately 6 percent for the $3.1 \mathrm{~m}$ (10 ft.) 1000 lux condition with the window screens, at a $400 \mathrm{~W} / \mathrm{m}^{2}$ solar radiation level.

\subsection{COOLING LOAD DUE TO LIGHTING AND WINDOW HEAT GAIN}

Lighting operation affects energy consumption in two ways. First, energy is used to provide illumination. Second, heat dissipated must then be removed from the conditioned space, increasing the cooling load by a factor dependent upon the heat absorption and conduction capacity of the structure, as well as the COP (coefficient of performance) of the cooling system. A COP of 2.5 was chosen as a representative value for typical systems for use in this analysis.

Neglecting the conduction and absorption effect of the structure, cooling load due to solar heat gain and lighting is given in figure 19 drawing from figures 17 and 18, as a function of horizontal solar radiation. At low levels of solar radiation, the majority of the cooling load is due to lighting, but with increasing solar radiation levels, short-wave heat gain begins to dominate. Cooling load remains fairly constant at normally encountered levels of solar radiation for the $1.5 \mathrm{~m}$ ( $5 \mathrm{ft.}$ ) set-point location, except for the clear windows. For the $3.1 \mathrm{~m}$ (10 ft.) set-point location, cooling load is seen to increase with increasing solar radiation, as solar heat gain increases faster than the cooling load due to lighting decreases.

\subsection{ENERGY CONSUMPTION DUE TO LIGHTING AND WINDOW HEAT GAIN}

Energy consumption due to lighting and cooling to offset solar heat gain is presented in figure 20. These plots are a combination of the previous two sets of figures, and indicate the net effect of the window areas and window 
systems on energy consumption. Results are very different for the $1.5 \mathrm{~m}$ ( $5 \mathrm{ft.}$ ) and $3.1 \mathrm{~m}$ (10 ft.) set-point locations. For the 1000 lux condition at the shallow depth, figure $20 \mathrm{a}$, the contribution of daylight causes the clear window to provide the least energy costs at normally encountered levels of solar radiation. For the 500 lux condition, the medium screen (fiber glass) is seen to be most effective when solar radiation exceeds low moderate levels $\left(400-600 \mathrm{~W} / \mathrm{m}^{2}\right)$, depending on window area.

At the deeper location, figure $20 \mathrm{~b}$, energy consumption is least for the screen with highest solar rejection, and either screen is preferable to clear glass for the larger window area. This is due to the fact that the contribution from daylight is low at this room depth as compared with the shallower depth, while solar heat gain remains the same. Therefore, increases in artificial lighting load are more than offset by reduction in cooling load for this configuration. Energy consumption for cooling and lighting is seen to remain almost constant regardless of solar radiation level for all systems except the clear glass 26 percent window rea, indicating that for these situations the various trade-offs virtually balance out. 


\section{PERFORMANCE OF LIGHTING CONTROLS}

In this section, the performance of actual lighting controls will be examined, to investigate their energy savings potential. In addition, information is presented with respect to installation and operation of two typical lighting control systems. Finally, the interaction between lighting power consumption and window management system is examined with presentation of results from a test case using a dimming system in combination with a clear window or a solar screen.

In the previous section, the energy savings potential of automatic lighting controls was examined assuming a "perfect" dimming system. No actual lighting control system can perform identically to a perfect system due to several factors. These factors include power consumed to operate the control system, inability of the control system to maintain a constant level of illumination due to sensor characteristics or room/window configuration, and power consumption of lighting not varying linearly with light output. Thus, the lighting power consumption of actual systems could be different, probably higher than for a perfect system. The magnitude of this difference would be dependent upon lighting control system operation, amount of available daylight and illumination set point.

Two commercially available lighting control systems were examined. One system was a continuous dimming control and the other a sequential control which switched individual fixtures on or off. Both control systems utilized a photo-sensitive detector to monitor indoor illumination, and an internal comparison circuit which determined if illumination level was not at the required level. The control systems automatically adjusted the light output of the electric lighting to maintain the illumination set point. A schematic diagram of the two systems is presented in figure 21.

\subsection{CONTINUOUS DIMMING SYSTEM}

With the dimming system, each luminaire was a complete system, including photo sensor, controller and level adjustment. The photo sensor aperture was mounted on the fixture facing downwards, and was covered with a lens approximately $0.8 \mathrm{~cm}(5 / 16 \mathrm{in.)}$ in diameter. A short piece of fiber optic cable transmitted incident light from the lens to the actual photo detector located within the controller. The controller was located adjacent to the standard ballast. A comparator circuit within the controller determined if the illumination level sensed by the photo detector was at the required level. If not, light output was varied until the illumination level was met. Light output was varied through the use of a current limiting technique. Due to the operating characteristics of fluorescent lighting, a minimum power level of approximately 32 percent is required for proper operation. Reducing power below that amount causes flickering, reduced lamp-life or no light output. This minimum power level is maintained automatically by the controller. The level adjustment control was a variable resistor which enabled any lighting level to be chosen between full and the level at the minimum power point. Figure 22a presents light output of a typical dimmer control unit as a function of power consumption for a single luminaire. Illumination is roughly 
linear as a function of power consumption above the minimum power point. At 50 percent light output, power consumption is seen to be 68 percent.

To install and operate this particular system, it is simply necessary to locate the luminaires and adjust the light level control to the desired illumination level. The number of luminaires should be chosen such that the illumination level desired in the absence of daylight is achieved with the level adjustment fully or nearly at its maximum. In this manner, the full dynamic range of the control system can be utilized.

\subsection{SEQUENTIAL SYSTEM}

The sequential system is essentially an automatic switching system. Rather than continuous dimming, light output is controlled by switching luminaires on or off in response to the photo sensor. A single controller, level adjustment and photo sensor can accomodate multiple fixtures. The photo sensor and level adjustment are wall mounted. The sensor is covered with a hemispherical translucent white dome, approximately $3.5 \mathrm{~cm}$ (1.25 in.) in diameter, which is oriented upward. Sensor positioning is critical for optimum performance..

The output of the photo sensor passes through the level adjustment to the controller. The controller activates the triac switches wired in series with each luminaire. An internal comparator in the controller determines if luminaires should be switched to maintain a constant illumination level within a band. Since switching is used rather than continuous dimming, light output can be varied only in discrete steps, so illumination is not constant. The illumination level is maintained at or above the set point. Since all the fixtures can be switched off, the minimum power level is simply the controller power, approximately 12 watts.

Figure $22 \mathrm{~b}$ presents light output of a typical sequential unit as a function of power consumption for a sequential system controlling four luminaires. The increments of illumination corresponding to the activation of each individual luminaire are dependent upon fixture placement and room configuration. This case represents a typical example. Each luminaire activated provides an additional 210 to 320 lux increase in illumination at the center of the room. Illumination levels for the discrete points fall very near the line for a perfect dimmer, as would be expected. There is no continuous relation between light output and power consumption, since the controller operates in discrete steps.

To install and operate this particular system, the luminaires must be placed and the triac switches connected in series with the ballast. A low voltage line connects the controller to the triacs and provides the control signal. The photo sensor must be mounted at a suitable location, dependent upon window and lighting configurations. Several operations must be performed with the level adjustment. The illumination set point must be adjusted to the desired leve1. A second adjustment controls the magnitude of the illumination difference (set point minus observed) that will trigger a switching function. A third adjustment controls response time to variations in illumination. Since each luminaire adds or subtracts a step of illumination, the controller 
should be adjusted so a change in illumination of the same magnitude as the lighting step will trigger a switching action. In this case, since activation of an individual luminaire changes illumination level by as much as 320 lux, the controller should be adjusted to initiate switching when a change in illumination of approximately $320 \mathrm{lux}$ is observed. If the illumination difference sensitivity is any less, the increment of illumination from the activated fixture will cause the illumination level to overshoot the setpoint, and illumination will be sensed by the controller as being greater than the set point, causing the luminaire to be switched off. At that point, the illumination level will be sensed as being too low and the fixture will be reactivated. This cycle will continue repeatedly until illumination conditions change substantially.

As with the dimming control system, the number of fixtures should be chosen such that the desired illumination level in the absence of daylight is achieved when all fixtures are activated.

\subsection{COMPARISON OF ACTUAL SYSTEMS WITH PERFECT DIMMER}

Figure 23 compares the performance of the dimming system and sequential system with that of a perfect dimmer. Daylight illumination percentage on the abscissa refers to the contribution of daylight to the illumination set point. Whenever this percentage meets or exceeds 100 percent, daylight is supplying all the required illumination and lighting power consumption should be zero. Both systems continue to consume lighting energy above the 100 percent point, 32 percent for the dimmer and 3 percent for the sequencer. Power consumption for both systems below 100 percent daylight illumination also exceeds that for a perfect dimmer.

\subsection{DIMMING SYSTEM PERFORMANCE}

The dimming system was installed in a room with a south window (area 16 percent, $1.2 \mathrm{~m}^{2}, 13 \mathrm{ft}^{2}$ ). Indoor illumination as a function of solar radiation for the room is presented in figure 24, for average solar conditions. The level adjustment on each of the four luminaires was adjusted to be at maximum light output in the absence of daylight, approximately 1300 lux at $1.5 \mathrm{~m}$ (5 ft.) from the window.

Lighting power consumption was monitored on an average hourly basis for a one week period. Figure 25a presents hourly lighting power consumption versus average hourly solar radiation for the same hour. Figure 24 indicates that the 1300 lux set point will be achieved when solar radiation exceeds $500 \mathrm{~W} / \mathrm{m}^{2}$, for the $5 \mathrm{ft}$. location. Thus, a perfect dimmer would shut off the lights completely at that point. Based on that, a perfect dimmer power consumption line was plotted. In the case of the actual dimmer, the minimum power level is $120 \mathrm{~W}$, due to factors described earlier.

Actual lighting power consumption is seen to follow the perfect dimmer line until the minimum power level is reached. In general, actual power consumption exceeds that of a perfect dimmer for most hours, but not by much. 
A daily breakdown of hourly average power consumption and solar radiation is given in table 4, for the hours 0700-1700.

Table 4. Hourly Power Consumption of Dimming System

\begin{tabular}{lccc} 
Day & $\begin{array}{c}\text { Solar Radiation } \\
\text { W/m }{ }^{2} \text { per hour* }\end{array}$ & $\begin{array}{c}\text { Lighting Power } \\
\text { Consumption W/h }\end{array}$ & $\begin{array}{c}\text { Lighting Power } \\
\text { Savings \% }\end{array}$ \\
\hline 1 & 199 & 279 & 27 \\
2 & 107 & 322 & 15 \\
3 & 282 & 210 & 45 \\
4 & 181 & 262 & 31 \\
5 & 260 & 222 & 42 \\
6 & 280 & 199 & 38 \\
7 & 262 & 237 & Average $35 \%$
\end{tabular}

* average of hourly readings between $0700-1700$ hours

The average solar radiation levels were low during this test period, the hourly average for the week being $224 \mathrm{~W} / \mathrm{m}^{2}$. There is a strong correlation between lighting energy savings and level of solar radiation, as demonstrated in figure $25 \mathrm{~b}$. If the level of solar radiation had been higher, more savings would have occurred. The maximum possible savings with this system would be 68 percent, due to the minimum power level required for operation. The minimum power level would have been reached at a solar radiation level of approximately $390 \mathrm{~W} / \mathrm{m}^{2}$ or greater.

The amount of lighting energy savings is essentially dependent upon daylight contribution and lighting control operation. If the operation of a lighting control approximates the performance of a perfect dimming system, the maximum lighting energy savings will be achieved. In this case, the actual dimming system did perform similarly to a perfect system, until the minimum power level was reached. If solar radiation levels (and consequently daylight illumination levels) had been higher, the performance of the dimming system would have deviated more from that of a perfect system, although lighting energy savings would have increased due to the larger contribution. of daylight to the indoor illumination level.

\subsection{SEQUEN'TIAL SYSTEM PERFORMANCE}

A similar test procedure was performed using the sequential system in a room with a north window (area 22.9 percent $1.6 \mathrm{~m}^{2}$ ) $\left(17.3 \mathrm{ft}^{2}\right)$. Indoor illumination as a function of solar radiation was previously presented in figure 5 . Wall reflectance was 0.50 . Illumination level, in the absence of daylight with all four fixtures energized, was approximately 1000 lux at the center of the room. The configuration of the lighting fixtures was identical to that presented in figure $22 \mathrm{~b}$. The level adjustment was set to maintain this illumination level. 
Lighting power consumption was averaged on an hourly basis for a one-week period. Figure 26a presents average hourly lighting power consumption versus average hourly solar radiation for the same hour. Figure 5 indicates that the 1000 lux set point will be achieved when solar radiation exceeds 500 $\mathrm{W} / \mathrm{m}^{2}$, for the $1.5 \mathrm{~m}$ ( $5 \mathrm{ft}$. ) location.

A perfect dimmer would shut off the lights completely at that point. The lighting power consumption for a perfect dimmer was plotted, similar to figure 25.

Performance of the sequential system is seen to approximate that of a perfect dimmer. The minimum power level is approximately $12 \mathrm{~W}$, the power needed to operate the controller. Lighting energy consumption is seen to be much lower than for a perfect dimmer for some levels of solar radiation near $200 \mathrm{~W} / \mathrm{m}^{2}$. Most of these points represent the late afternoon hours, when indoor illumination levels received a larger contribution of ground reflected daylight from the concrete surface located to the west of the lab. A plateau is seen at approximately $100 \mathrm{~W}$ lighting power consumption. This is due to the operation of a single lighting fixture which was sometimes needed to maintain indoor illumination level even at high solar radiation levels. These points occurred on a very clear day. A daily breakdown of hourly average power consumption and solar radiation is given in table 5 .

Table 5. Hourly Power Consumption of Sequential System

\begin{tabular}{|c|c|c|c|}
\hline Day & $\begin{array}{l}\text { Solar Radiation } \\
\mathrm{W} / \mathrm{m}^{2} \text { per hour } \\
\end{array}$ & $\begin{array}{l}\text { Lighting Power } \\
\text { Consumption } \mathrm{W} / \mathrm{hr} \\
\end{array}$ & $\begin{array}{c}\text { Lighting Power } \\
\text { Savings } \% \\
\end{array}$ \\
\hline 1 & 415 & 108 & 72 \\
\hline 2 & 452 & 58 & 85 \\
\hline 3 & 412 & 54 & 86 \\
\hline 4 & 569 & 114 & 71 \\
\hline 5 & 522 & 57 & 86 \\
\hline 6 & 432 & 66 & 83 \\
\hline 7 & 385 & 91 & 77 \\
\hline
\end{tabular}

Average $80 \%$

The average solar radiation levels were high for this test period $\left(445 \mathrm{~W} / \mathrm{m}^{2}\right)$, as was the contribution of daylight. During many hours of most days, daylight completely satisfied indoor illumination requirements and all fixtures were switched off by the controller. Figure $26 \mathrm{~b}$ presents daily lighting energy savings as a function of solar radiation level. This relationship is very similar to figure $25 \mathrm{~b}$ except for slight difference due to window size and orientation, and the minimum power level for the dimming system. System performance for both the sequencer and the dimmer are nearly identical, until the minimum power level is reached, in terms of lighting energy savings. If solar radiation levels during the sequencer test period had been similar to the levels during the dimmer test period, energy savings for the sequencer probably would have been similar to the savings measured for the dimmer. On 
the other hand, if the higher solar radiation levels had occurred during the dimmer test period, energy savings would probably have approached 68 percent, the maximum possible for that system. 


\section{APPLICATION OF LIGHTING CONTROL SYSTEMS}

Lighting control system requirements for a building are determined by several factors, the main one being daylight contribution. If large daylight contributions are expected, more energy savings could be achieved through the utilization of a system which can completely shut off the lighting fixtures, as opposed to a dimming system which must remain at or above a minimum power level. Of course, if high contributions of daylight are available, a dimming system, or any lighting system, can simply be switched off manually. If more modest daylight contributions are expected, either type of system would achieve reductions in lighting energy.

Another factor is uniformity of illumination. A dimming system will provide fairly uniform distribution of illumination throughout the room, while a sequential system will provide more light directly beneath the luminaires energized. Proper luminaire location, in respect to. windows and work areas, can minimize this effect. Also, a dimming system provides fairly constant indoor illumination over time, due to its ability to vary light output over a continuous range. Operation of a' sequential system will cause illumination levels to change in steps as luminaires are energized or de-energized. In some cases, that factor may be a problem or distraction, although it was not felt to be one in this case.

With any type of lighting control system, proper sensor placement and level adjustment is essential for maximum energy savings and proper system operation. The lighting controller should not respond to changes caused by people walking through a room, or reflected glare or a cloud quickly passing in front of the sun. Frequent and drastic changes in light output may be unacceptable to building occupants.

Many existing buildings are targets for lighting control retrofit. As compared with new buildings where illumintion levels can be specified and met by choosing the proper number of lighting luminaires as well as their location, existing buildings may be currently over or under-illuminated, most probably the former. Potential lighting energy savings would be greater due to the possible elimination of overlighting in addition to daylight utilization. The economics of lighting control retrofit procedures are not examined here, as each potential building would be an individual case requiring detailed analysis of energy costs due to lighting, availability of daylight, and cost of controls. It is noted, however, that the control systems examined herein are not costly devices compared to the cost of the total lighting system and the cost of lighting energy. If lighting fixtures are old and ready for replacement anyway, lighting controls may be viable retrofit procedure.

Maintenance costs should not be significantly different for lighting systems with and without controls, although long-term durabilty tests have not yet been performed. The two control systems utllized for this testing have been, and still are, operating properly after approximately one year. 


\section{LIGHTING CONTROL/WINDOW MANAGEMENT TEST CASE}

The dimming system was utilized in conjunciton with a solar control film to present an example of the lighting and cooling energy tradeoffs examined earlier. A room with a south window exposure (area 16 percent, $1.2 \mathrm{~m}^{2}$, $13 \mathrm{ft}^{2}$ ) was outfitted with 8 luminaires. Indoor illumination, solar radiation and lighting power consumption were monitored for two test periods, first with clear glass and then with a silver reflective film (item 4 from table 2) installed.

The levels of each of the parameters were averaged for each hour of the day for a five-day test period. Figure 27 a presents an average profile for the test period with a clear window, indicating the average level of solar radiation, lighting power consumption, and indoor illumination which was observed for each hour of the day. Figure $27 \mathrm{~b}$ presents similar data for the test period with the silver reflective film. With the clear window, indoor illumination greatly exceeds the 760 lux set point during the middle of the day, although lighting power consumption levels off. This occurs because the luminaires in front of the window are at the minimum power level and the luminaires to the side of the window do not see the daylight as much. In any case, lighting power consumption must be at least $220 \mathrm{~W}$ if all light fixtures are at the minimum power level.

Installation of a solar control film would be expected to produce two effects, namely reduction in daylight contribution and reduction in short-wave solar heat gain through the window. As is seen in figure $27 \mathrm{~b}$, indoor illumination remains fairly constant. This is because although daylight contribution is reduced, most of the reduction eliminates the over-illumination observed with the clear window. Lighting power consumption remains nearly the same. A comparison of lighting and cooling energy for these two cases plus a non-dimmer case are presented in table 6, for the hours 0600 to 1800 .

Lighting power consumption for the non-dimmer case was calculated assuming constant power consumption for the 12-hour test days at the measured $460 \mathrm{~W}$ level in the absence of daylight. A 28 percent savings in lighting energy is seen for the dimmer with clear window case, and a 22 percent savings for the silver film case. Solar heat gain was calculated for each condition using the indoor vertical solar-outdoor horizontal solar data presented in figure 15 on an hour-by-hour basis. The solar radiation levels observed during the silver film test period were used for all three cases, for comparison purposes. A 75 percent reduction in solar heat gain is seen for the silver film test period. Cooling energy required to remove lighting and solar heat gain indicates a 43 percent savings for the silver film and 17 percent for the clear window, as compared with the non-dim situation. Energy for lighting and cooling (due to lighting and solar heat gain) is seen reduced by 24 percent for the clear window and 30 percentfor the silver film, as compared to no-dim, clear window.

A comparison was made between the observed lighting energy savings and that which might be predicted based on the analysis presented in the window management section of the report. Figure 18 indicates lighting power 


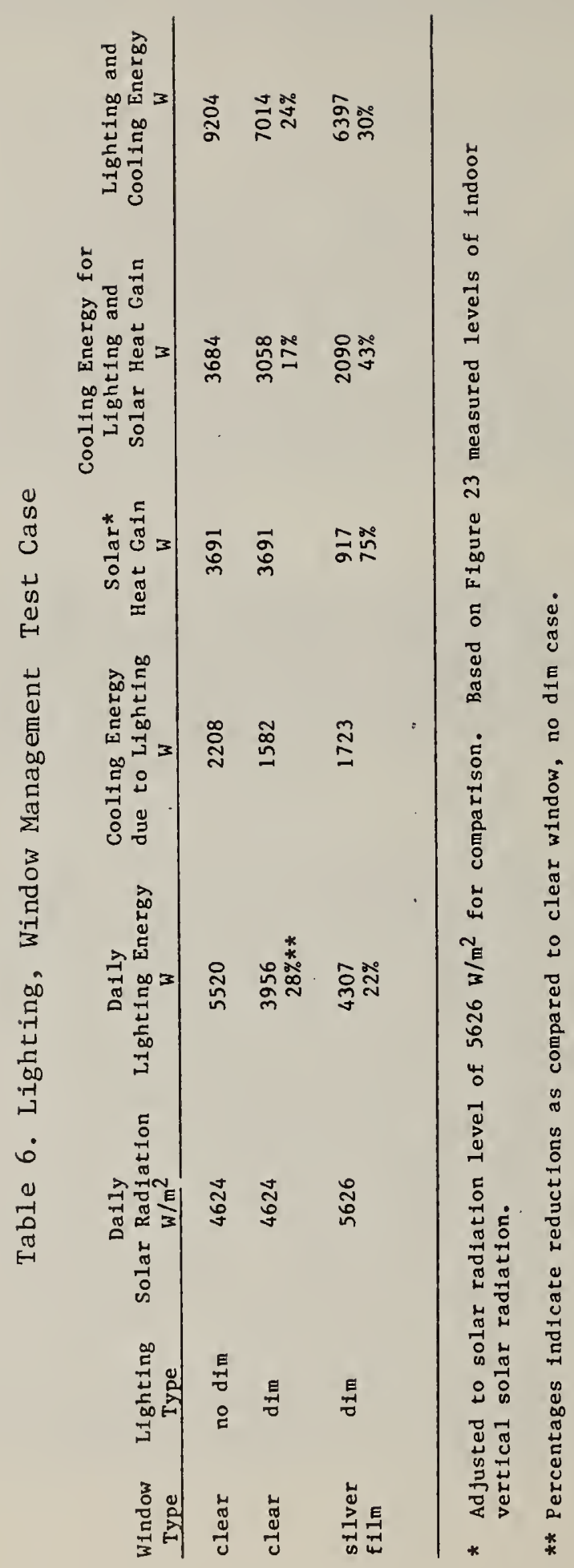


consumption as a function of solar radiation. Using the solar radiation levels observed during each portion of the test on an hour-by-hour basis, predicted lighting power savings would be 37 percent for the clear window and 20 percent for the silver film. Actual lighting energy savings compared to predicted was less for the clear window by 11 percent and more for the silver film by 2 percent.

This indicates that in the clear window phase of the test, the dimming system did not take full advantage of the available daylight, due to minimum power requirement for proper operation of fluorescent lighting. 
The proper utilization of window and lighting systems requires consideration of many factors relating to building use, orientation and configuration. Natural illumination from daylight can make an important contribution to indoor illumination levels. Measurements indicate that significant levels of daylight illuminance occur a high percentage of working hours. An indoor illumination level of over $7001 \mathrm{ux}$ ( $70 \mathrm{~F} . \mathrm{C}$. ) was observed more than 50 percent of the hours between 0600-0800 during the spring and summer test period for a location $1.5 \mathrm{~m}$ ( $5 \mathrm{ft.}$ ) from the window. Similar measurements at a $3.1 \mathrm{~m}$ (10 ft.) location showed daylight levels of 400 lux ( $40 \mathrm{F.C.})$ occurring 50 percent of the working hours.

Sky condition and solar radiation level were seen to be the main determinants of available daylight illumination, with window area and internal reflectance controlling the actual indoor illumination at a particular location within a room. In particular, higher wall reflectances provided signficantly higher levels of indoor illumination for the locations at greater depth from the window than that provided by lower wall reflectances.

Photo-sensitive lighting controls can take advantage of daylight to reduce lighting energy while maintaining required illumination levels. Measurements indicate lighting energy savings from 35 percent to 80 percent or more are possible in perimeter offices, depending upon window size and orientation and required illumination level. Although actual lighting control systems do not operate exactly as a perfect dimming system, analysis of potential energy savings through the utilization of actual lighting controls based on the operation of a perfect dimming system can adequately depict actual savings in many cases.

Window management devices are seen to be of value under summer conditions, although their use requires trade-offs to be made between daylight utilization ind solar heat gain. Solar control devices such as screens, films and shade's can reduce solar heat gain dramatically. Even though lighting energy may increase due to a reduction in daylight contribution after installation of a solar control device, this increase can be offset by the reduction in cooling energy associated with the reduction in solar heat gain under summer conditions. It should be noted however, that these results pertain only to summer conditions. To examine the annual effect of window management strategies, winter conditions must also be considered. Solar heat gain in winter can be effective in reducing building heating load as long as overheating of perimeter areas does not occur. Adjustable window management devices would be more beneficial in this respect since their flexibility would allow window system characteristics to be altered selectively. Analysis of daylight contribution and lighting needs for a building will enable proper selection of lighting control system and winclow management system to naximize energy savings. The correlation between level of solar radiation and level of natural indoor illumination is seen to be sufficient to permit analysis of the performance of lighting control systems, for the purpose of predicting energy savings through their utilization. Althougil significant variation 
exists for indoor illumination from daylight as a function of solar radiation, due to variations in sky condition, utilization of average sky conditions (or partially overcast conditions) can be useful in predicting average illumination levels within a room.

Significant potential exists for energy savings in existing buildings through the use of lighting controls and window management devices. In new construction, careful analysis of illumination needs, window design and lighting controls can result in optimum utilization of these factors to minimize energy consumption. 


\section{References}

1. King, W.J., High Performance Solar Control Office Windows, Lawrence Berkeley Laboratory Report $7825,1977$.

2. Bitterice, M.G., McKinley, R.W., Use Solar Daylight and Heat from Windows to Save Fossil Fuel, PPG Industries, Inc.; 1978.

3. Owens, P.G.T., Energy Conservation and Office Lighting, Pilkington Bros. Ltd., Technical Advisory Service; 1976.

4. Collins, B.L., Windows and People: A Literature Survey, National Bureau of Standards BSS 70; 1975 .

5. Ruegg, R.T., Chapman, R.E., Economic Evaluation of Windows in Buildings: Methodology, National Bureau of Standards BSS 119; 1979.

6. Yellott, J.I., The Phoenix Fenestration Tests of 1977 - Thermal Aspects, ASHRAE TRANSACTIONS, Vo1. 85, Part 2; 1980.

7. Selkowitz, S.E., thermal Performance of Insulating Vindow Systems, ASHRAE TRANSACTIONS, Vo1. 85 , Part 2; 1980.

8. Kusuda, T., Collins, B.L., Simplified Analysis of Thermal and Lighting Characteristics of Windows: Two Case Studies, National Bureau of Standards BSS 109; 1978.

9. Owens, P.G.T., Analysis of the Energy Requirement of Buildings with Particular Reference to the Window, Glass in Buildings Conference, International Council for Building Research, Studies and Documentation (CIB); 1977.

10. Crisp, V.H.C., a Preliminary Study of the Use of Automatic Daylight Control of Artificial Lighting, Lighting Research and Technology; Vol. 9 , 1977 .

11. Smith, M.N., Automatic Light Sensing and Control of Lighting Systems for Energy Conservation, Civil Engineering Laboratory, Tech. Note $\mathrm{N}-1486,1977$.

12. Kusuda, T., Bean, J.W., Comparison Between a Simplified Daylighting Calculation Procedure and a Comprehensive Interreflection Model CaIculation Procedure, Proc. 3rd Int1, Symposium on Use of Computers for Environmental Engineering Related to Buildings, Aug. 1978, National Research Council of Canada, Report CNRC 17376.

13. Pierpoint, P.E., Intelligent Lighting Control Principles, Civil Engineering Laboratory, Tech. Note N-1558; 1979.

14. ASHRAE Handbook of Fundamentals, published by ASHRAE New York, 1977. 


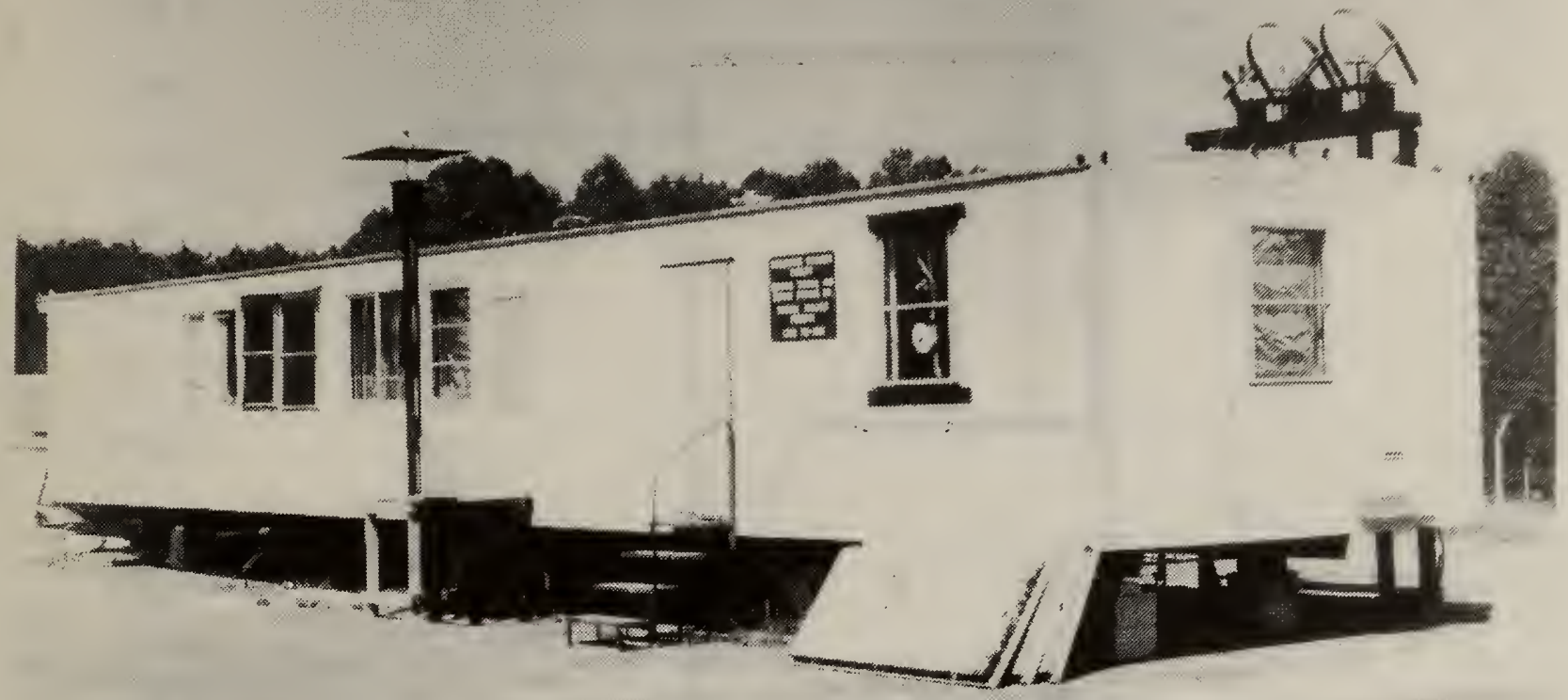

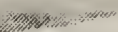

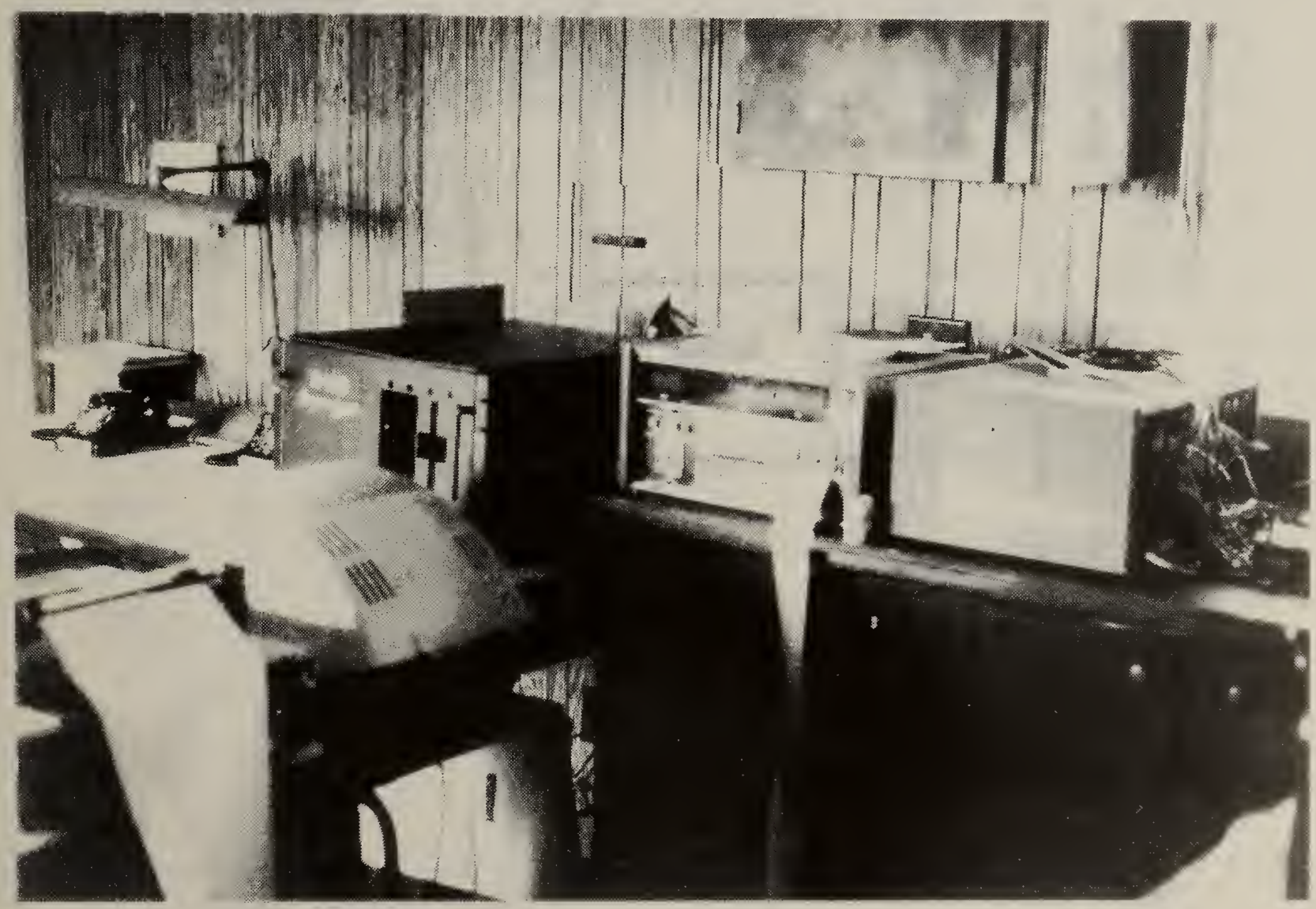

Figure 1. Photographs of the NBS daylight research facility 


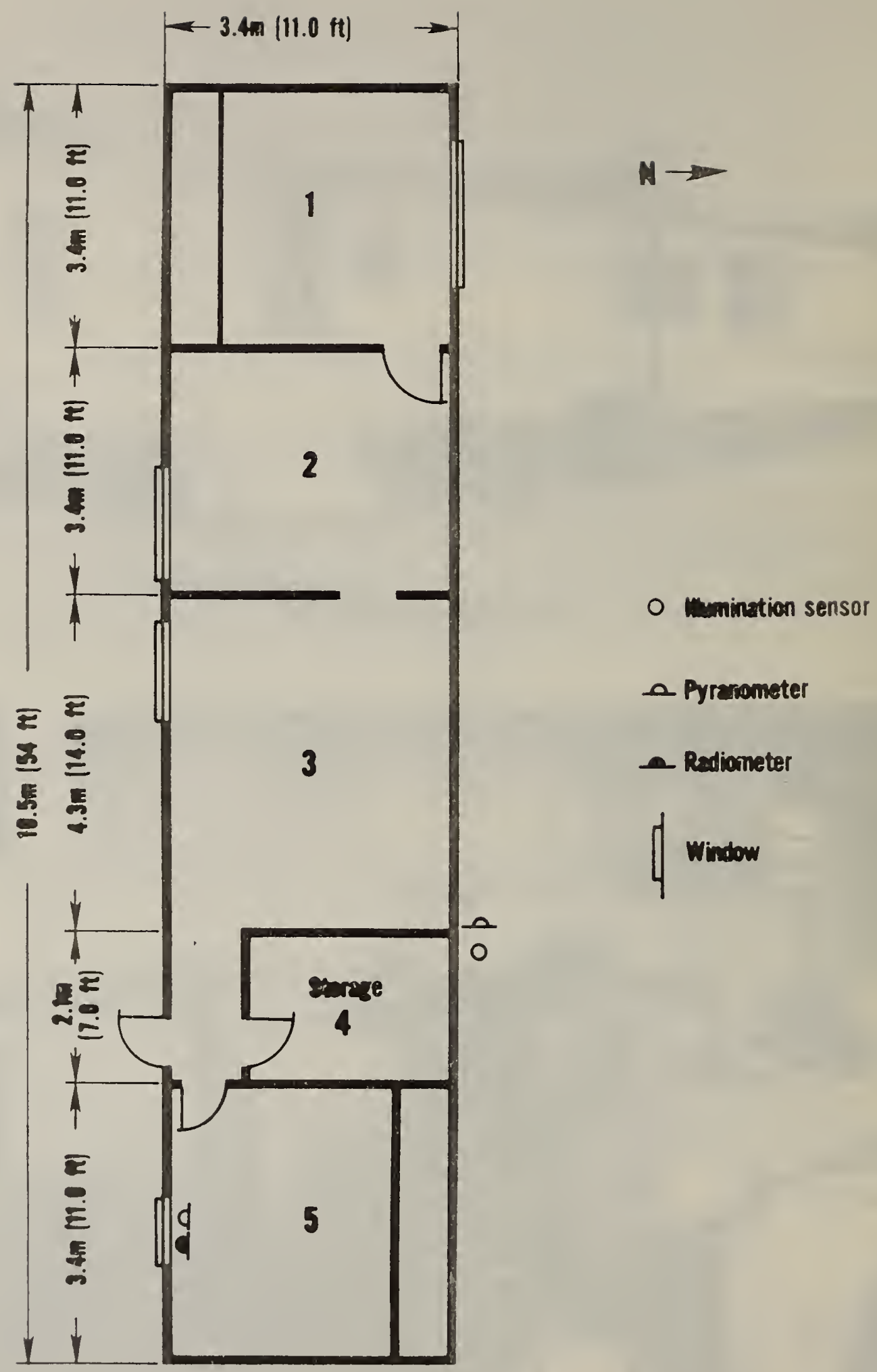

Figure 2. Floor plan of Daylighting Iah 


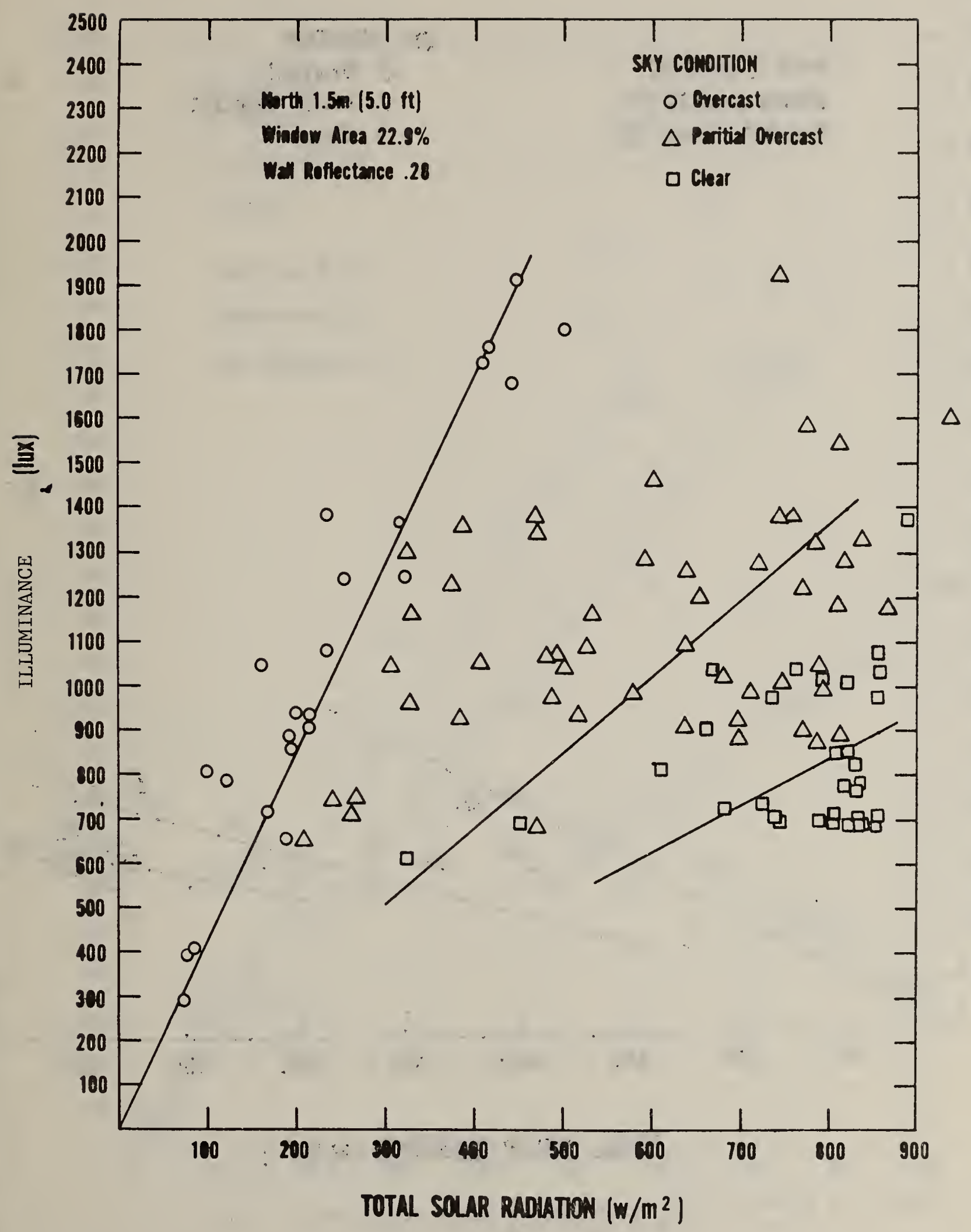

Figure 3.a Effect of sky condition on indoor illumination - north-facing window, depth $1.5 \mathrm{~m}$ 


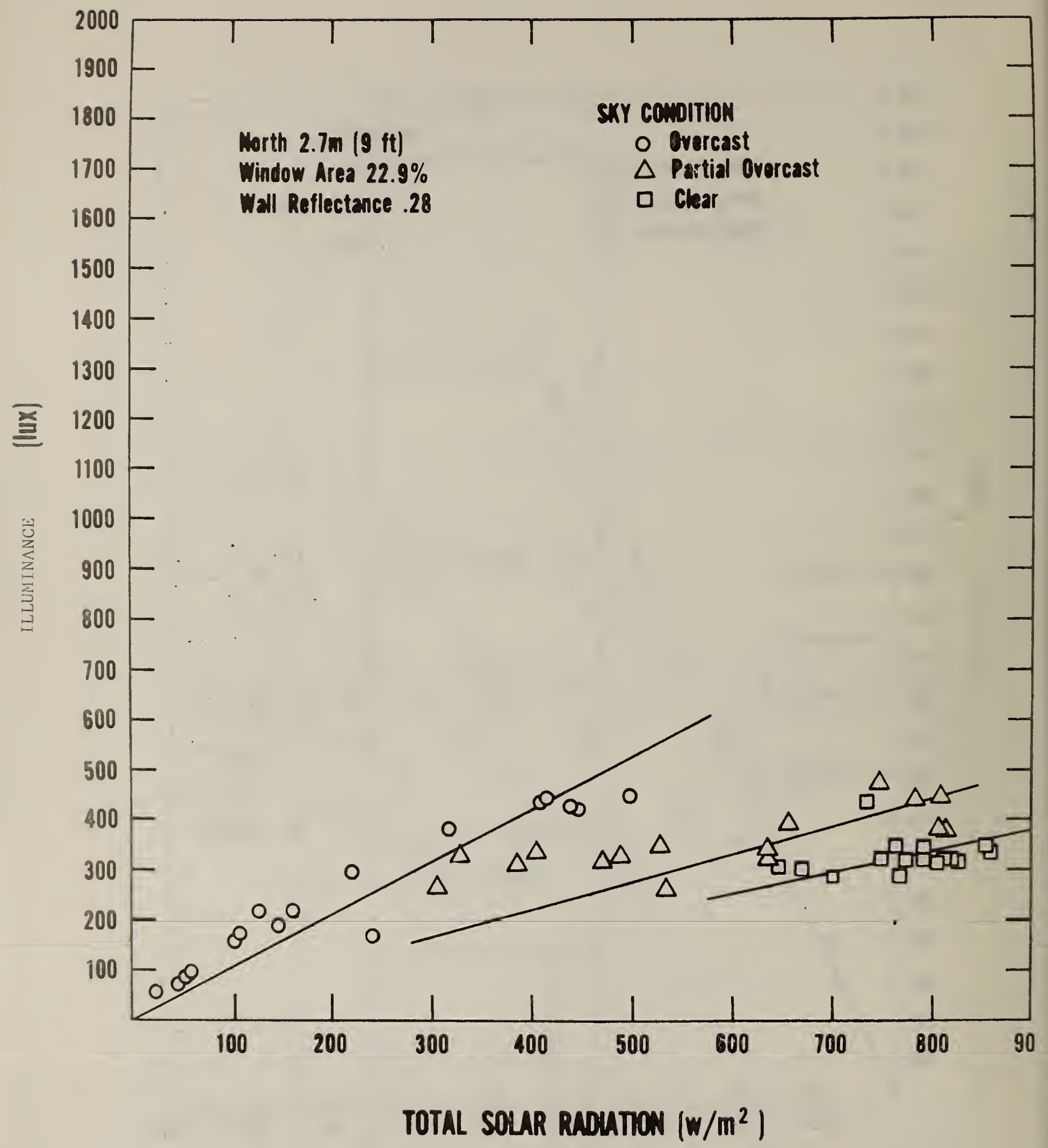

Figure 3.b Effect of sky condition on indoor illumination - northfacing window, depth $2.7 \mathrm{~m}$ 


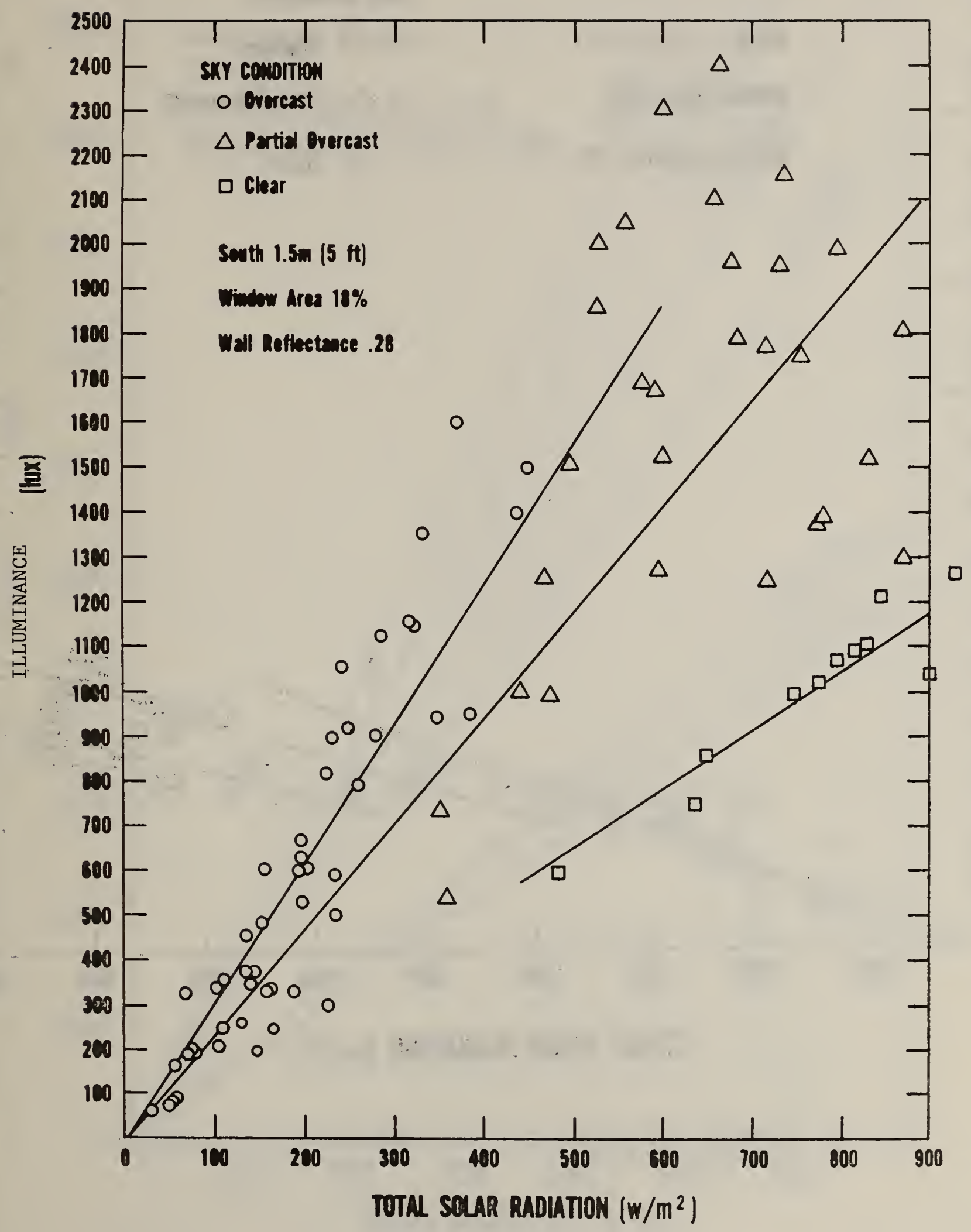

Figure 4.a Effect of sky condition on indoor illumination - south-facing, window, depth $1.5 \mathrm{~m}$ 


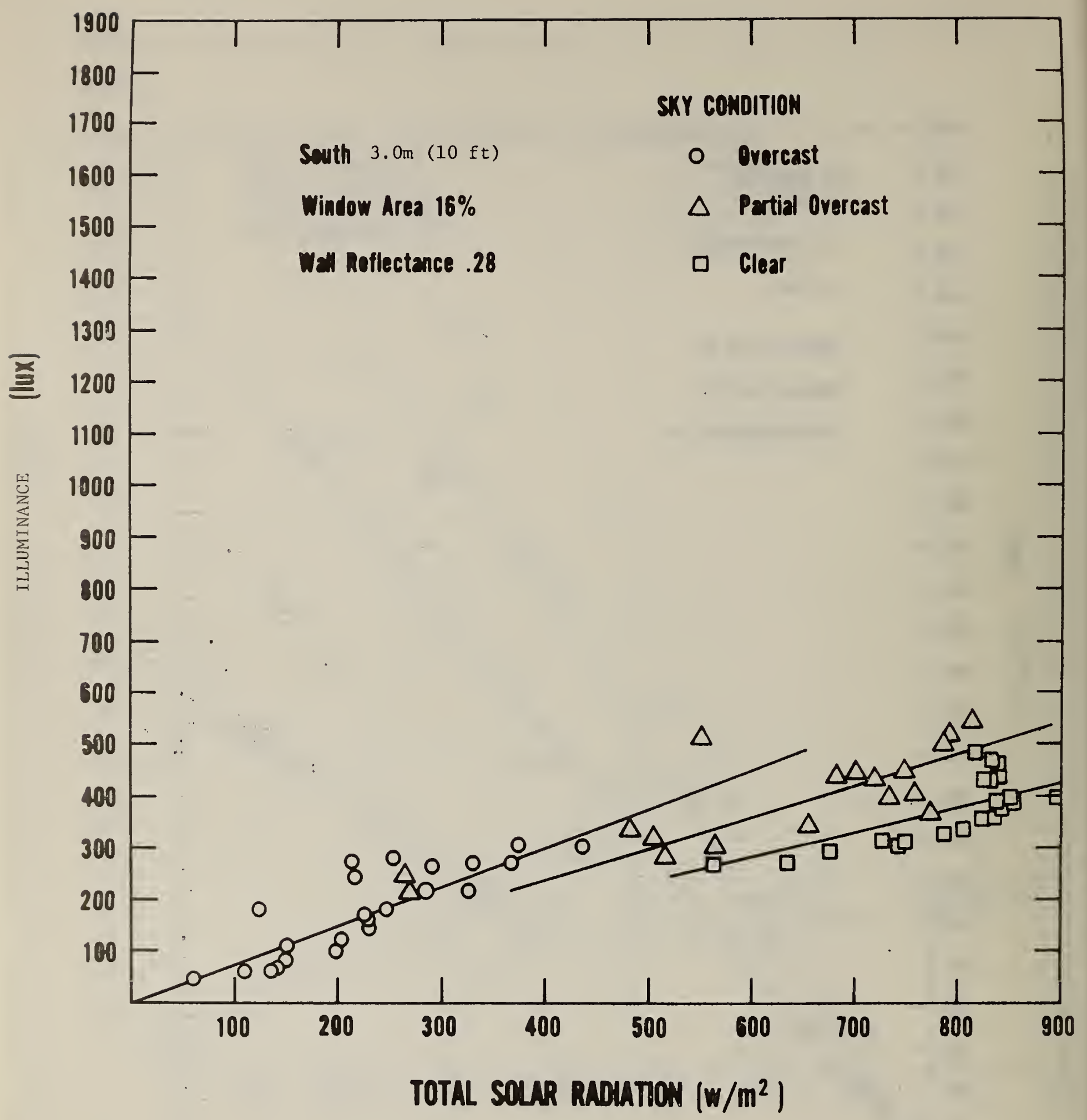

Figure 4.b Effect of sky condition on indoor illumination - south-facing window, depth $3.0 \mathrm{~m}$ 


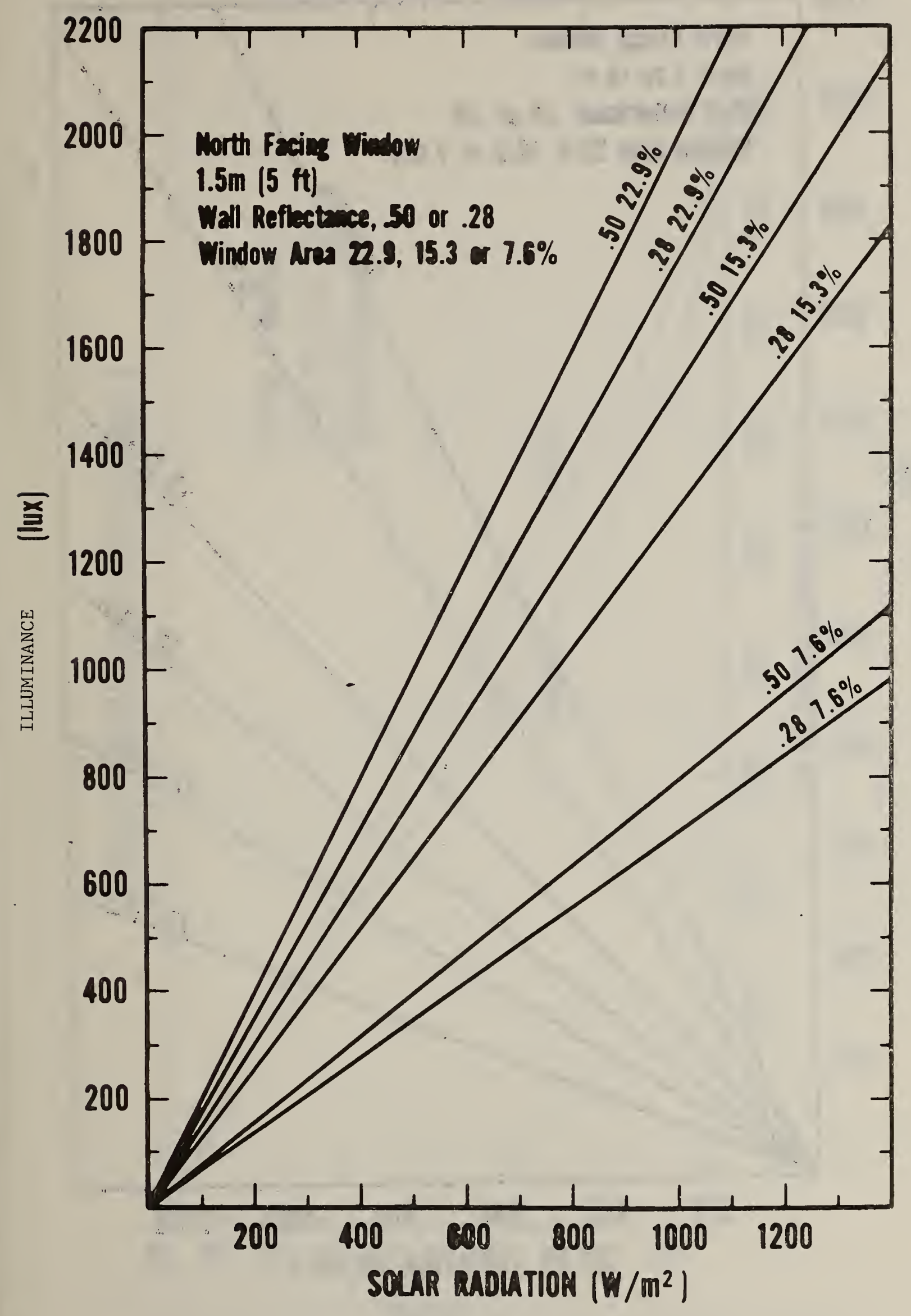

Figure 5.a Effect of window area and wall reflectance - north-facing window, depth $1.5 \mathrm{~m}$ 


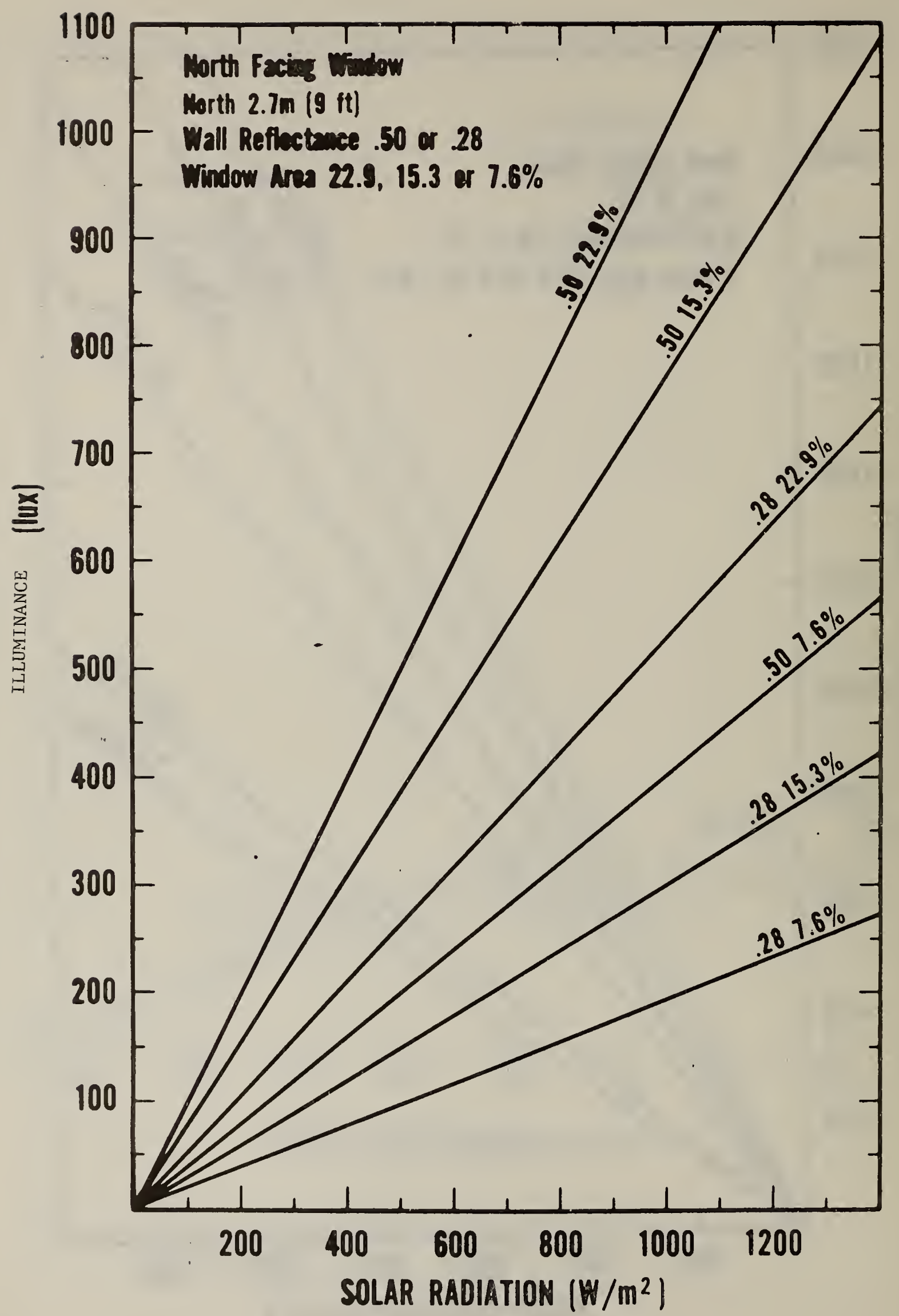

Figure 5.b Effect of window area and wall reflectance - north-facing window, depth $2.7 \mathrm{~m}$ 


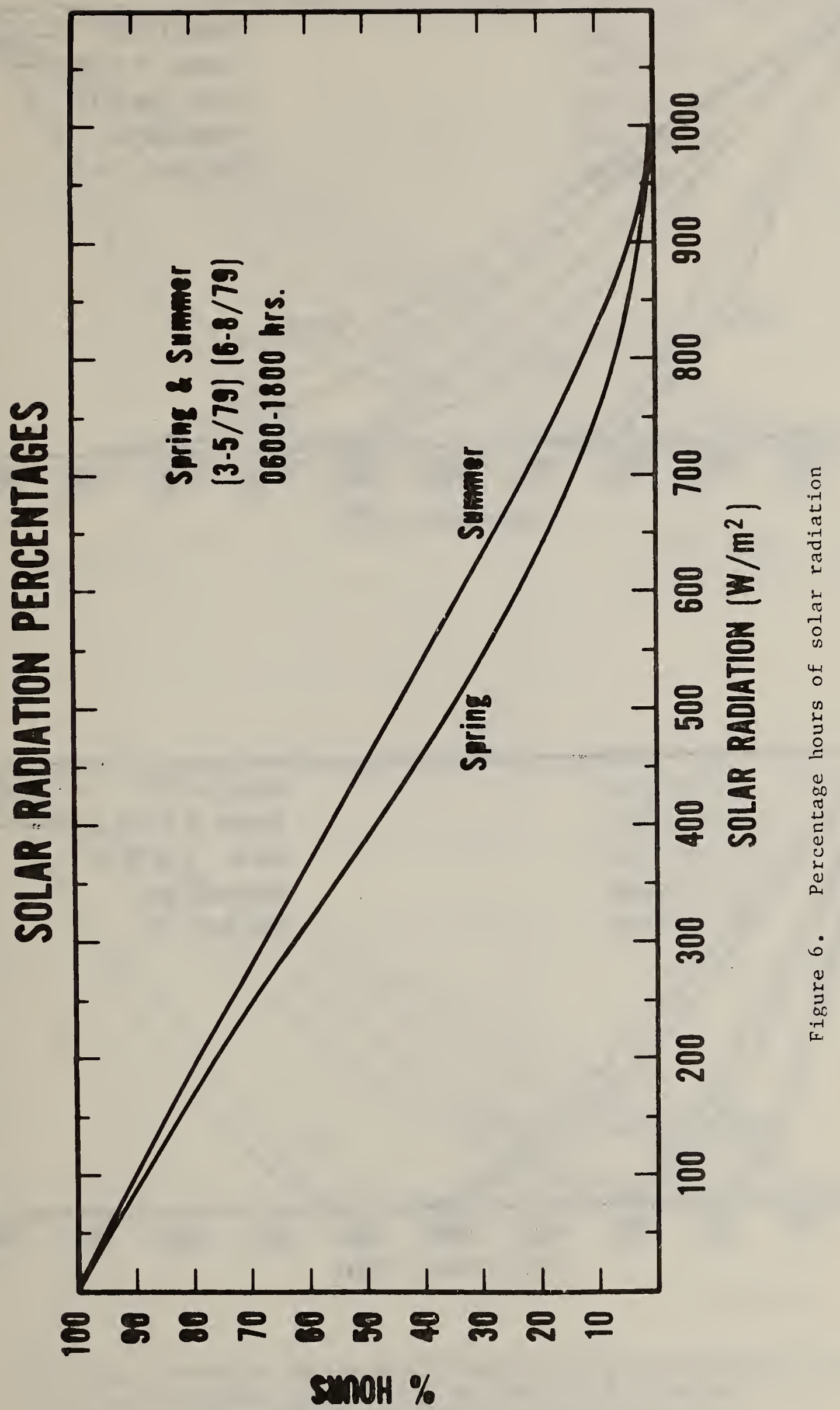




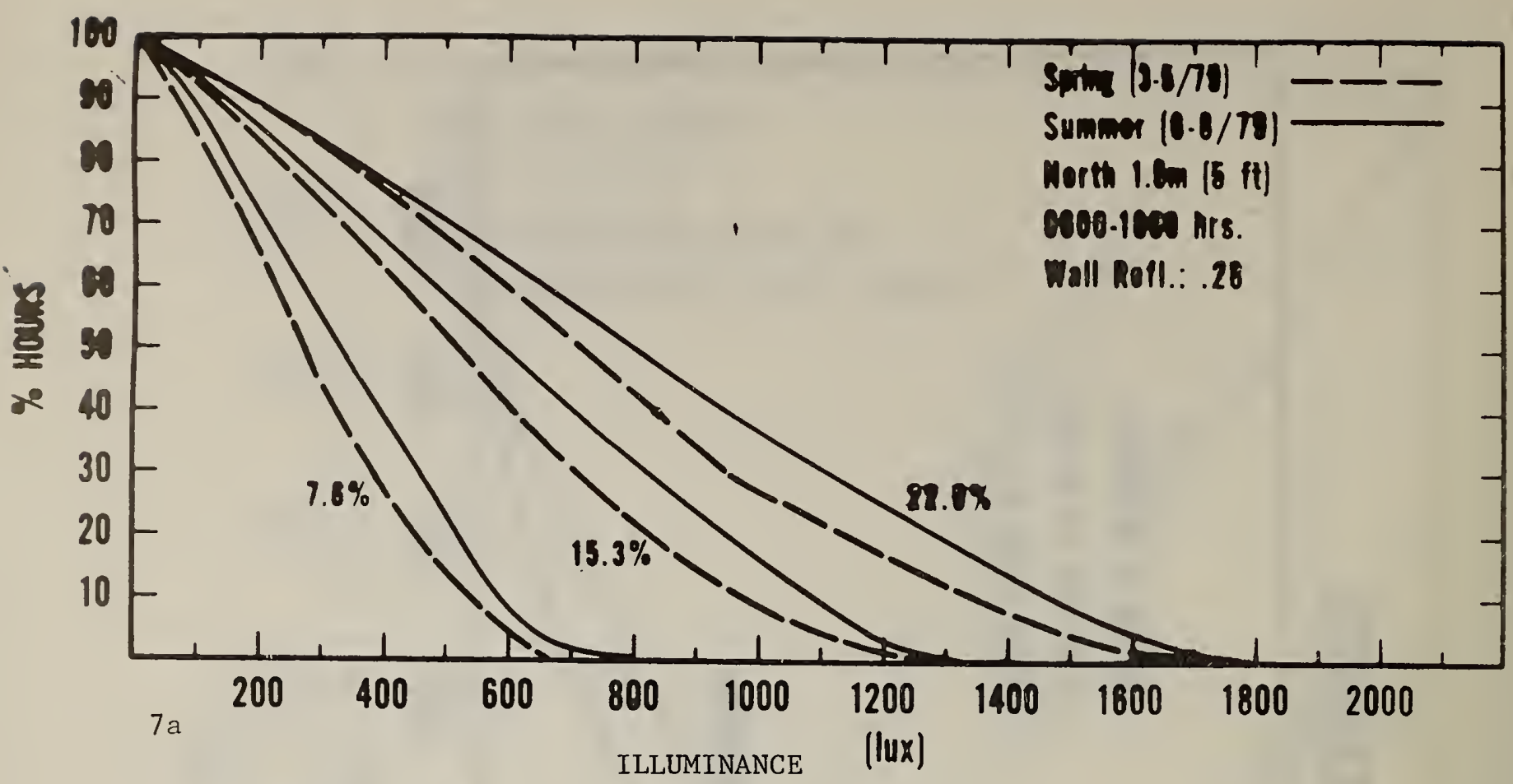

DEPTH $1.5 \mathrm{~m}$

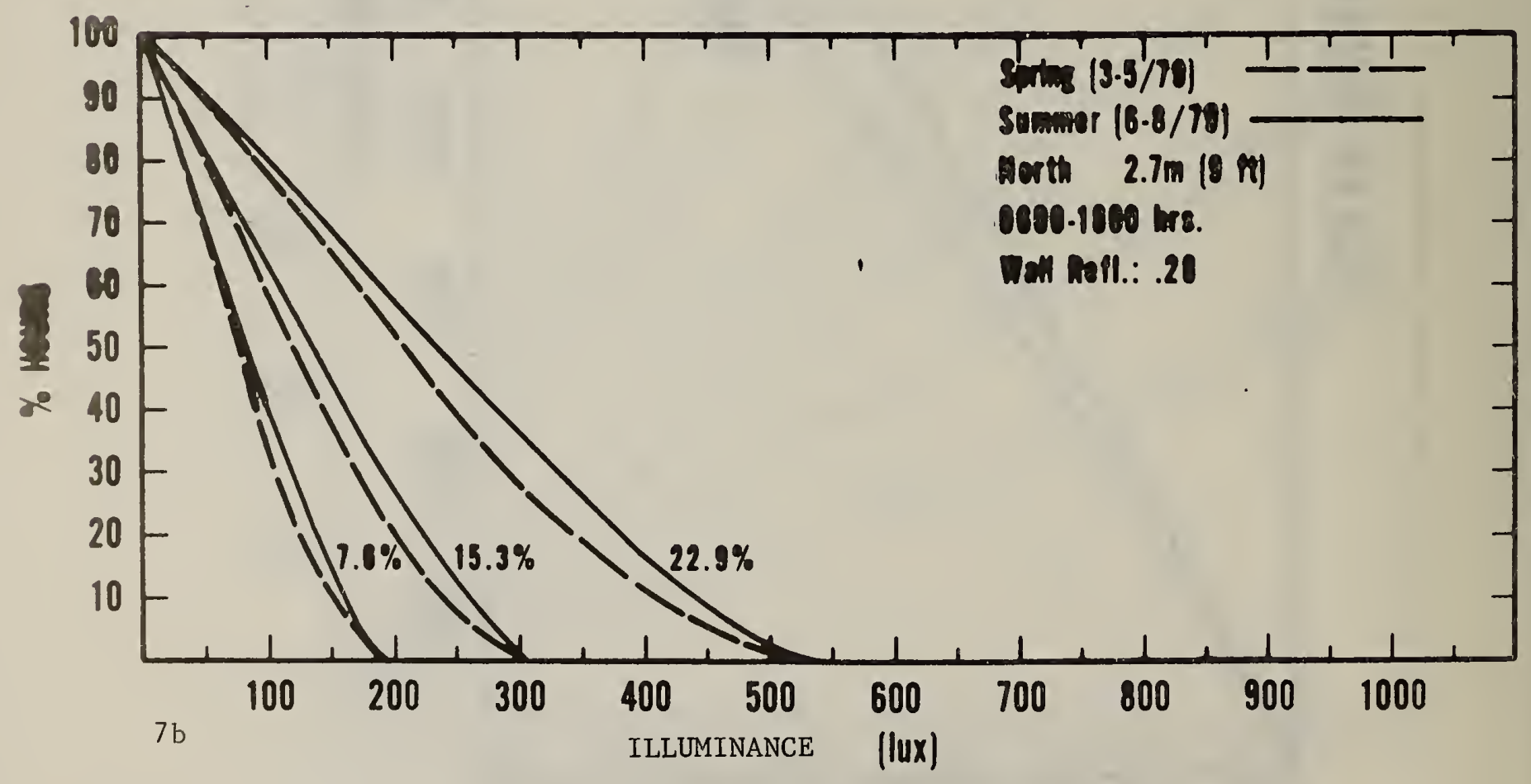

DEPTH $2.7 \mathrm{~m}$

Figure 7. Percentage hours of indoor illumination -- north-facing window, $1.5 \mathrm{~m}(5 \mathrm{ft})$ and $2.7 \mathrm{~m}(9 \mathrm{ft})$ wall reflectance 0.28 , window area $22.9,15.3$ or 7.6 percent 


\section{a) WINDOW AREA $22.9 \%$}

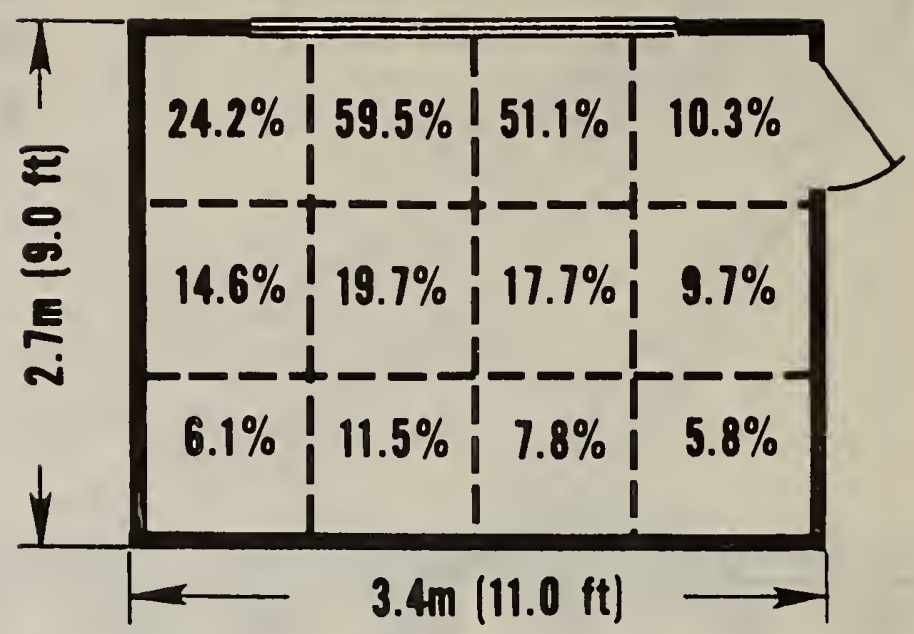

b) WINDOW APEA $15.3 \%$

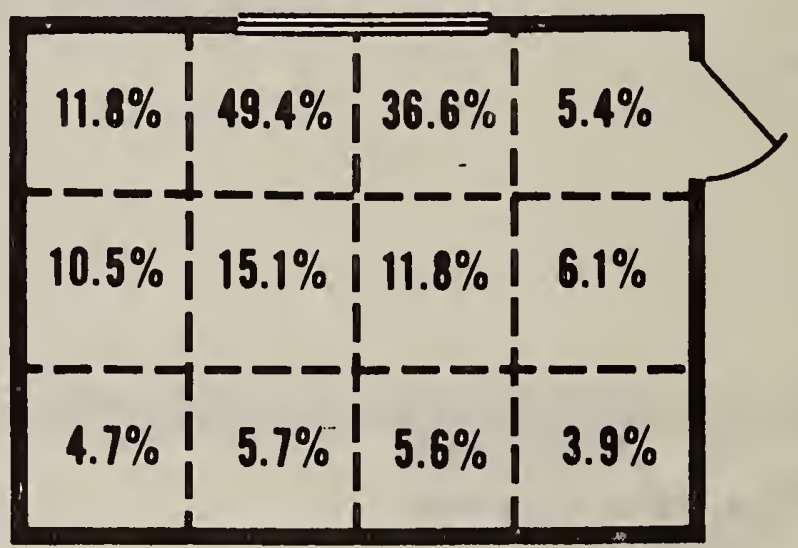

c) WWDOW AREA $7.6 \%$

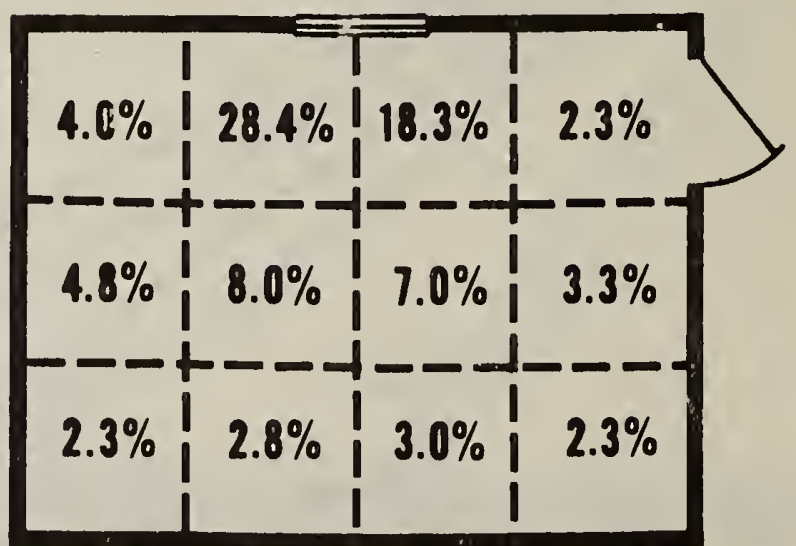

Figure 9. Indoor horizonial illumiration profiles for north-facing window, wall reflectance 0.28 and varying window areas. Percentages indicate ratio of illumination at each grid location to illumination immediately inside window 


\section{a) WINDOW AREA $22.9 \%$}

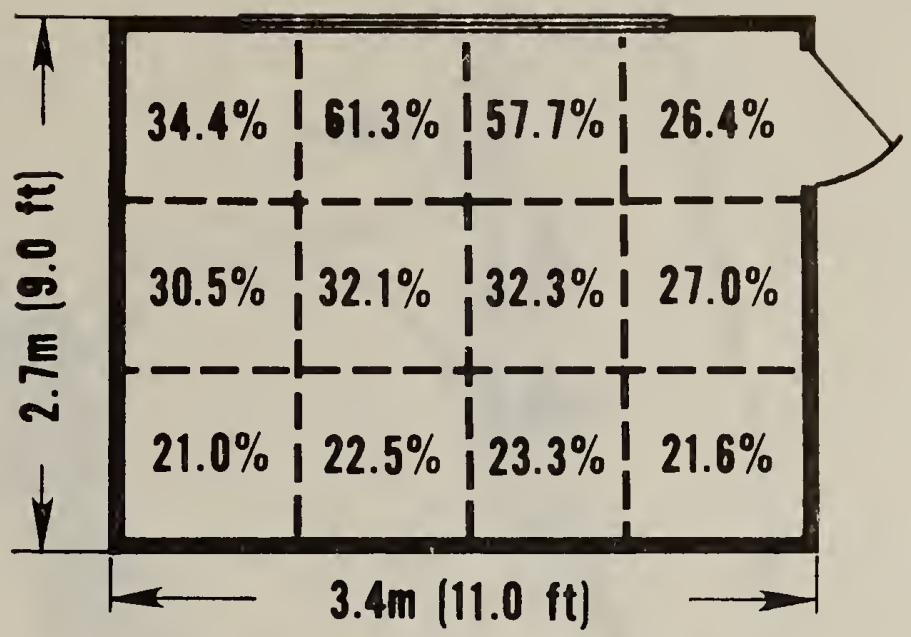

b) WINDOW AREA $15.3 \%$

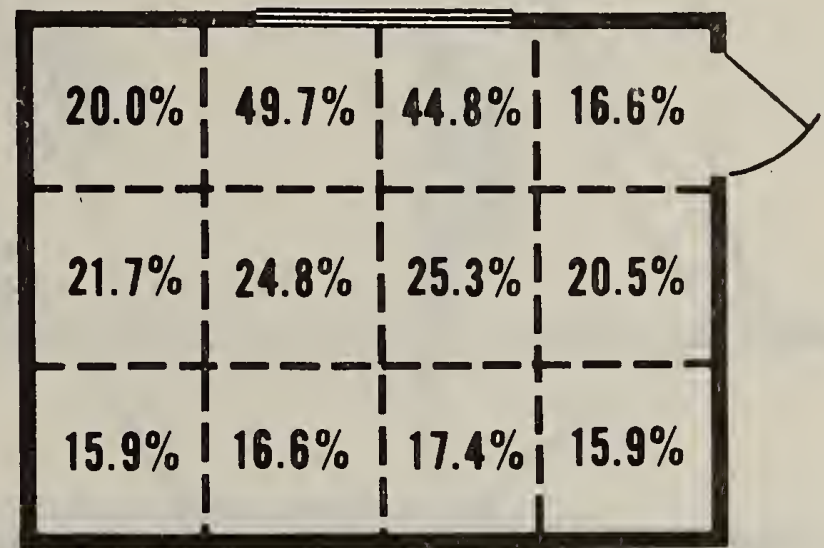

c) WINDOW AREA $7.6 \%$

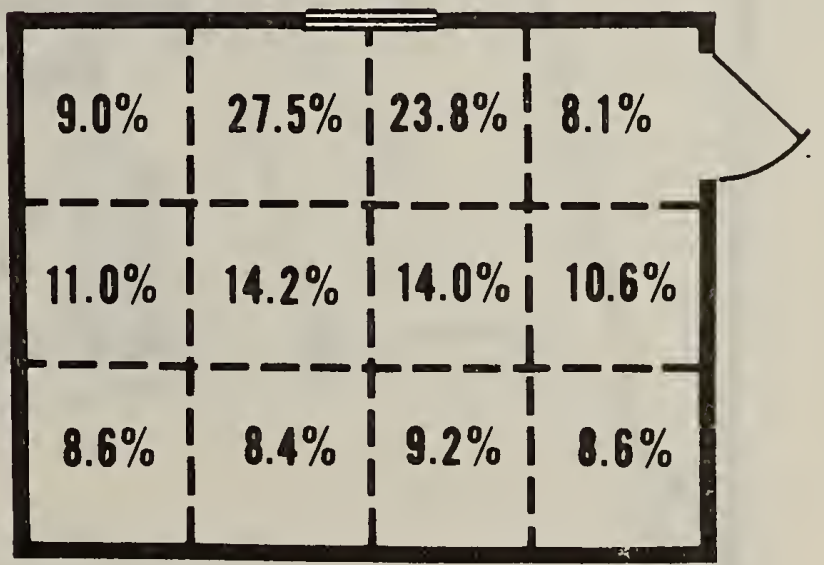

Figure 10. Indoor horizontal illumination profiles for nurth-facing window, wall reflectance 0.50 , and varying window areas. Percertages indicate ratio of illumination at the ienter of each grid location to illumination immediately inside window 

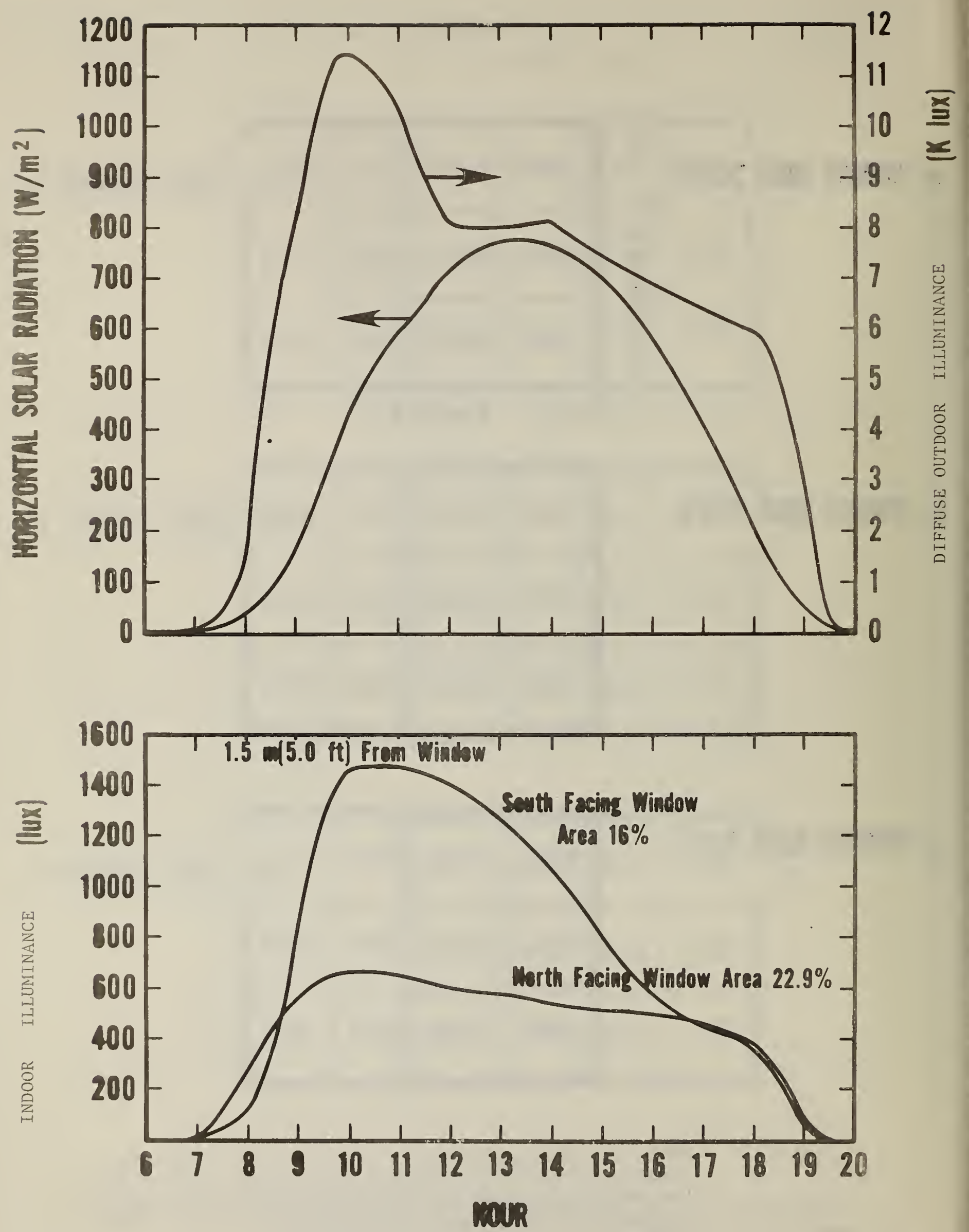

Figure 11. Daily solar radiation and illumination cycle - north and south-facing window 


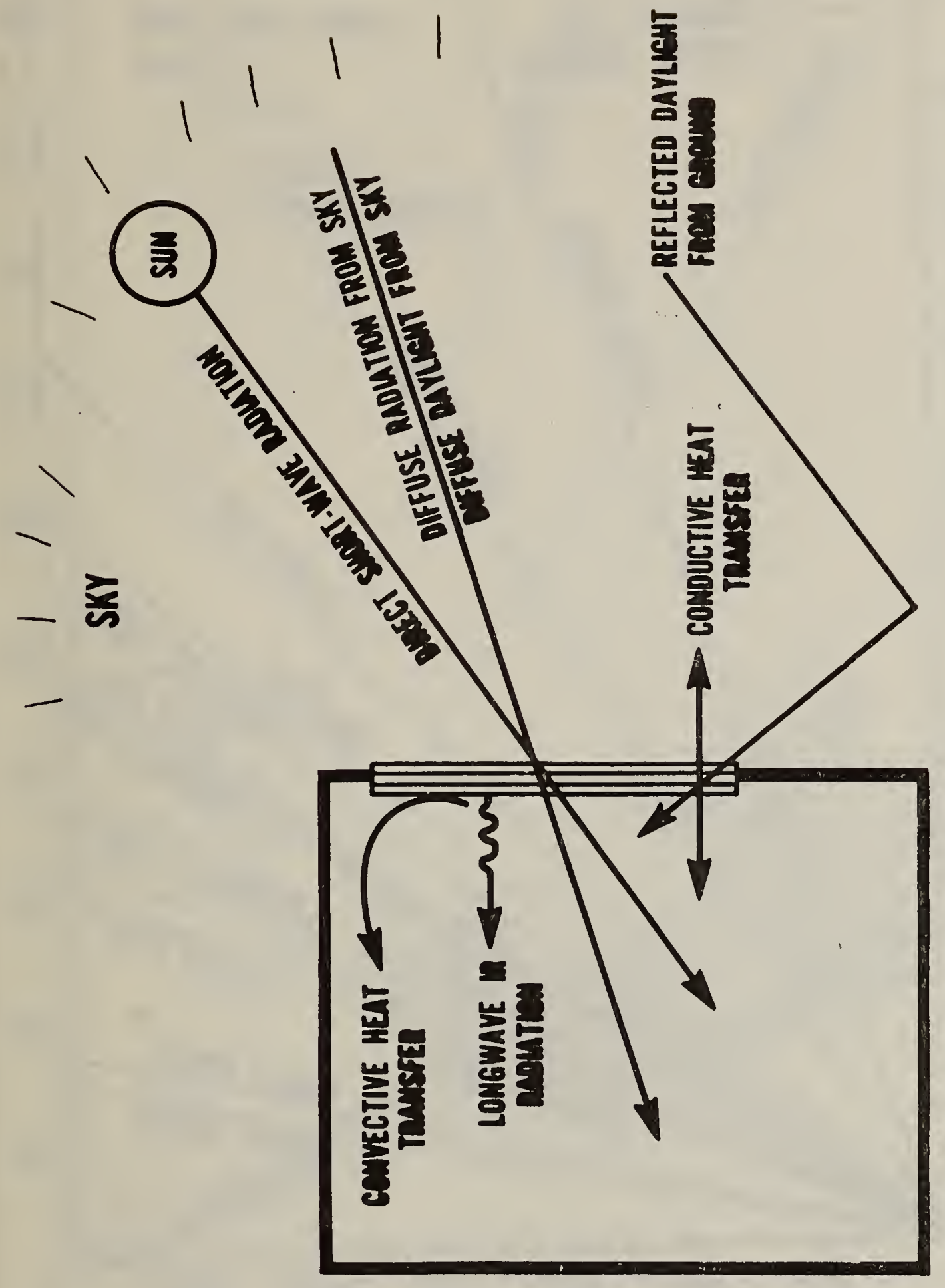

O 


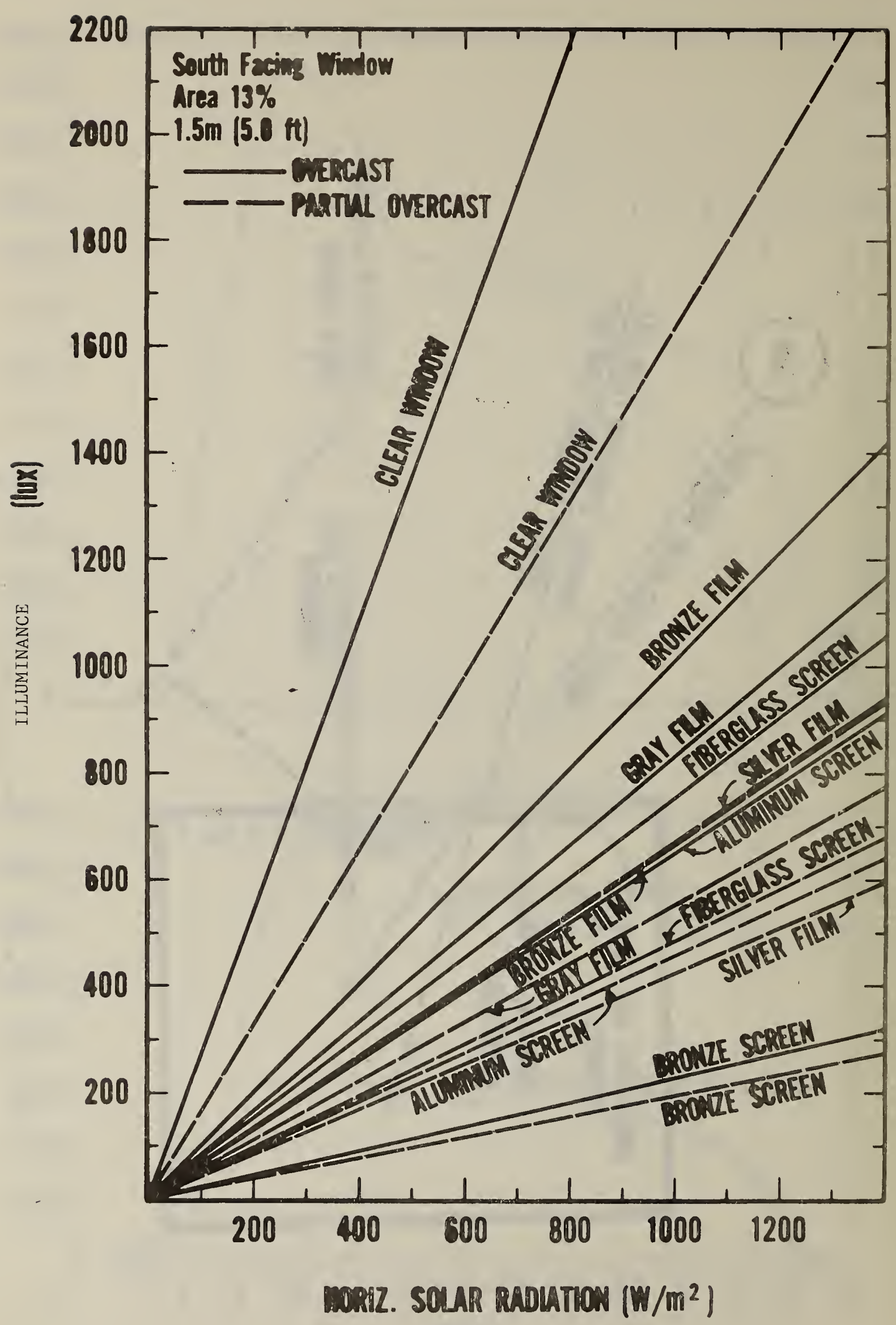

Figure 13.a Indoor illumination with window management - south-facing window, $1.5 \mathrm{~m}$ ( $5 \mathrm{ft}$ ) 


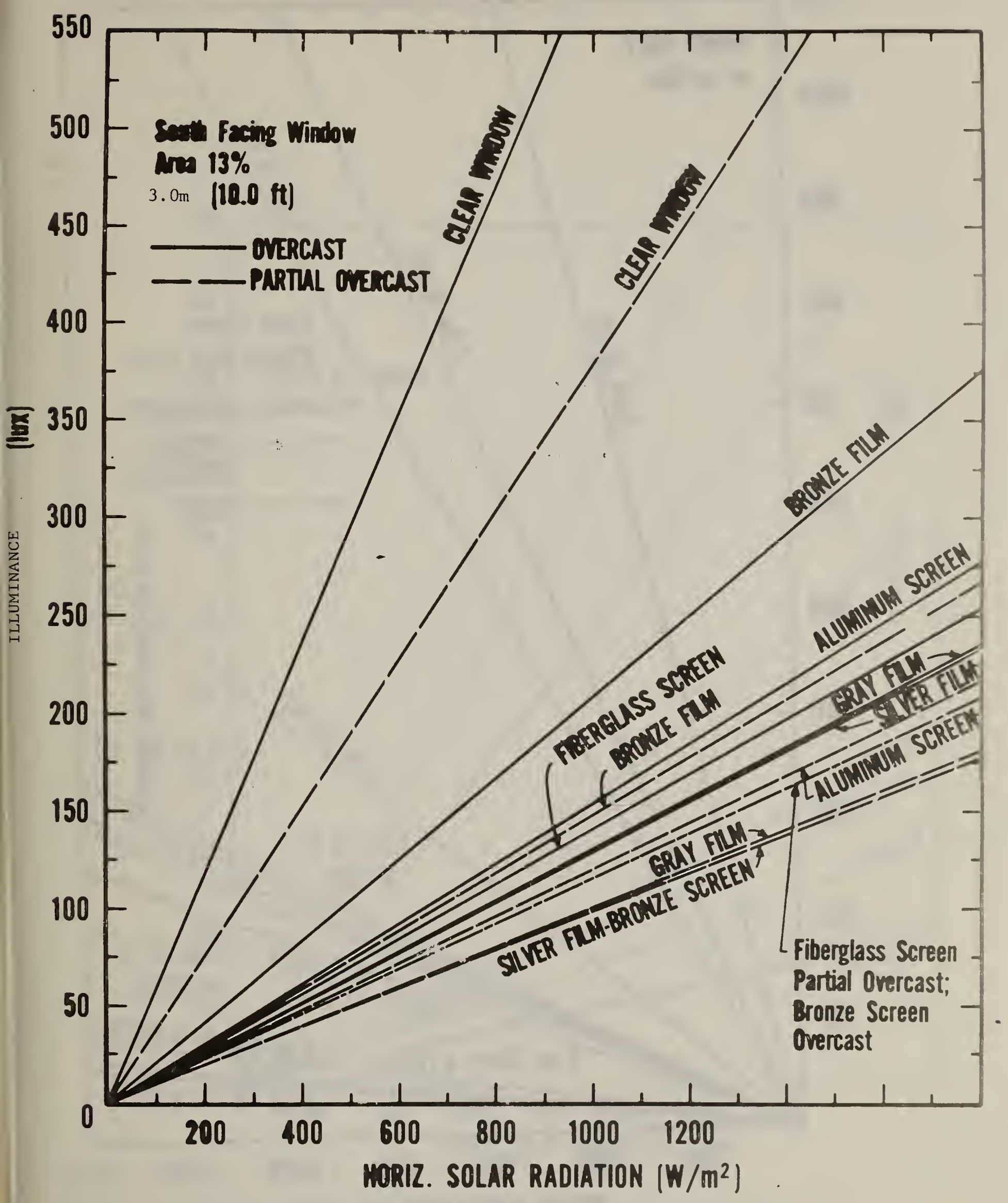

Figure 13.b Indoor illumination with window management - south-facing window, $3.0 \mathrm{~m}(10 \mathrm{ft})$ 


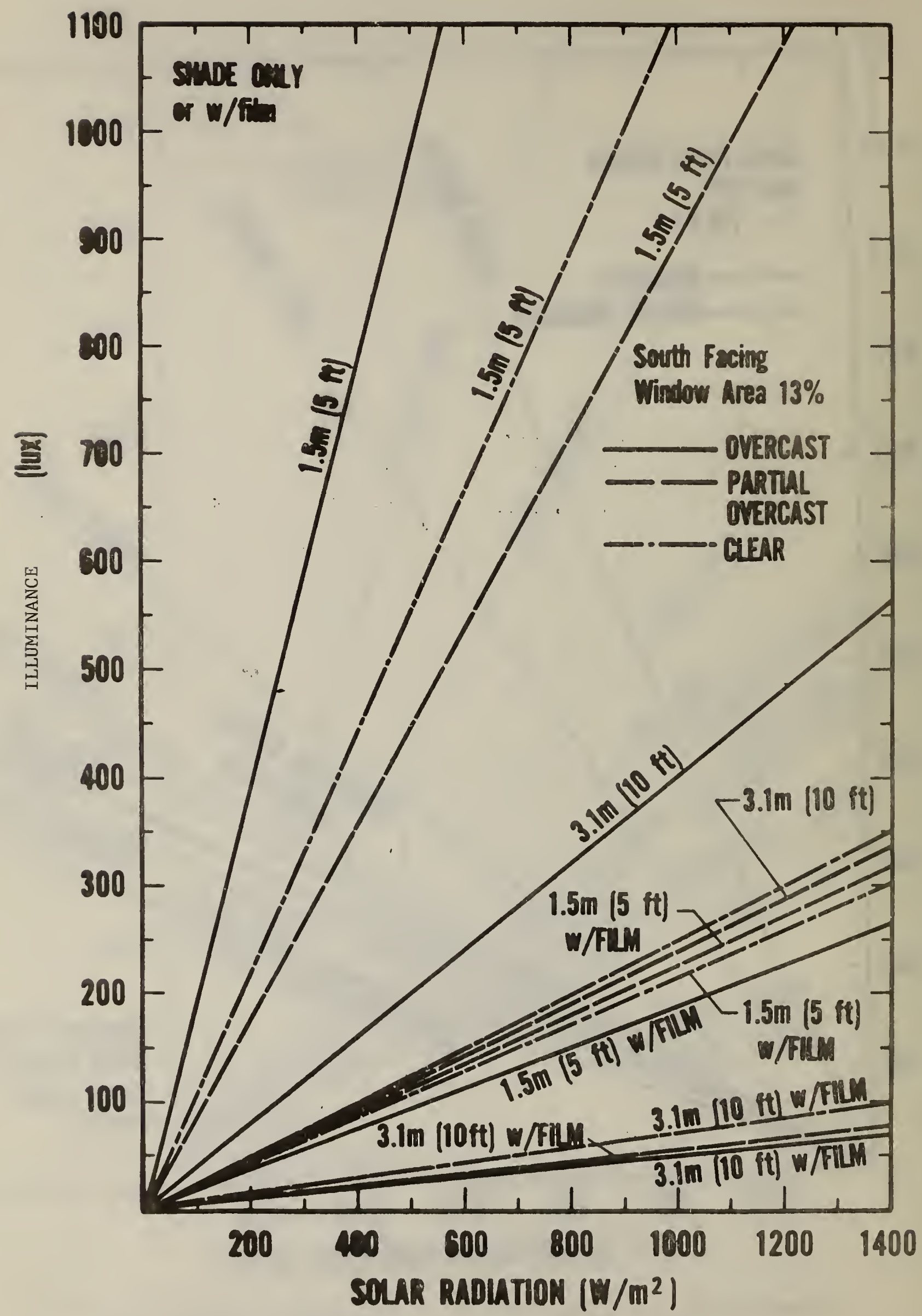

Figure 14. Indoor illumination with roll shades - south-facing window 


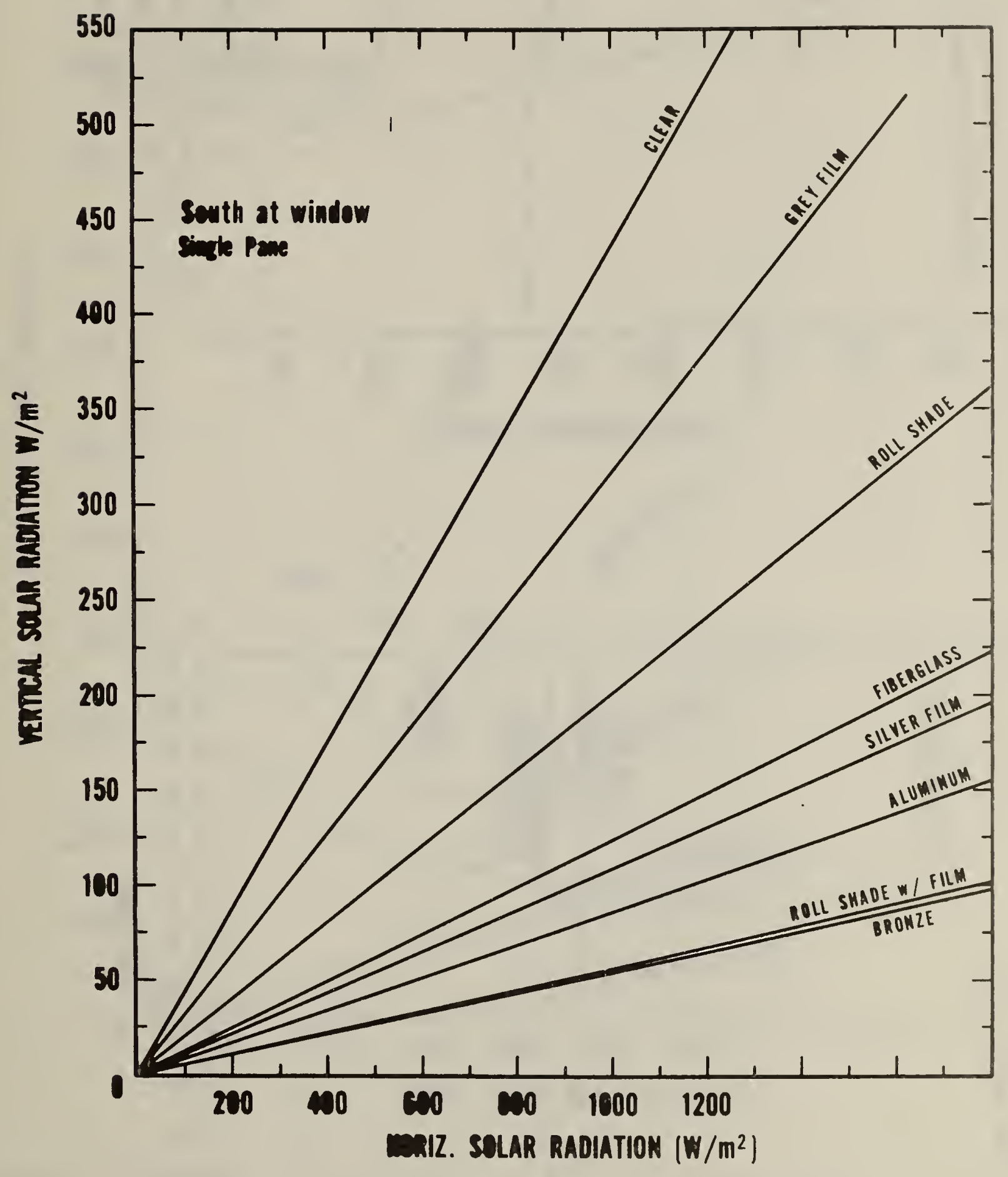

Figure 15. Vertical solar radiation at inside surface of south-facing window, with and without management 


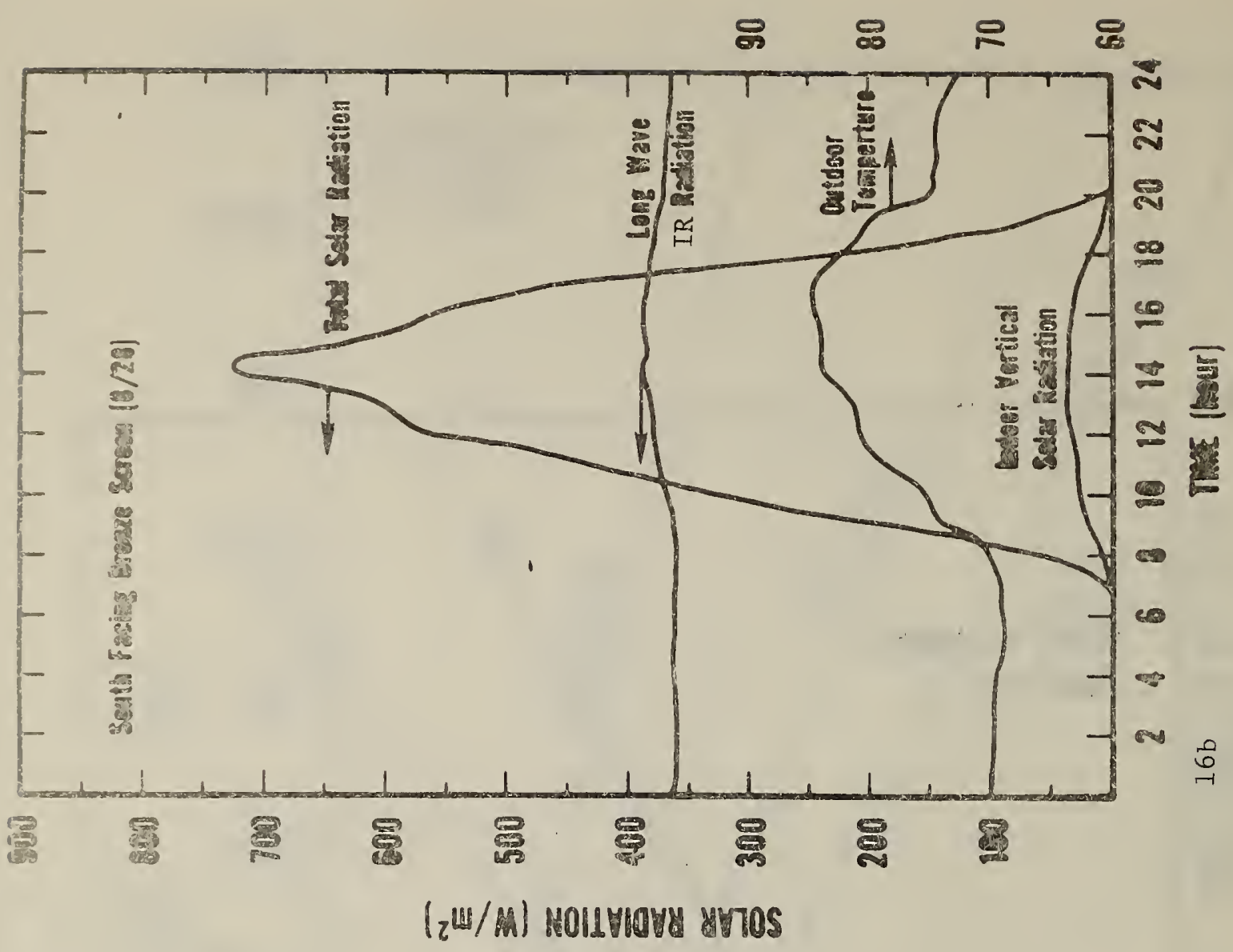

(to) dWI

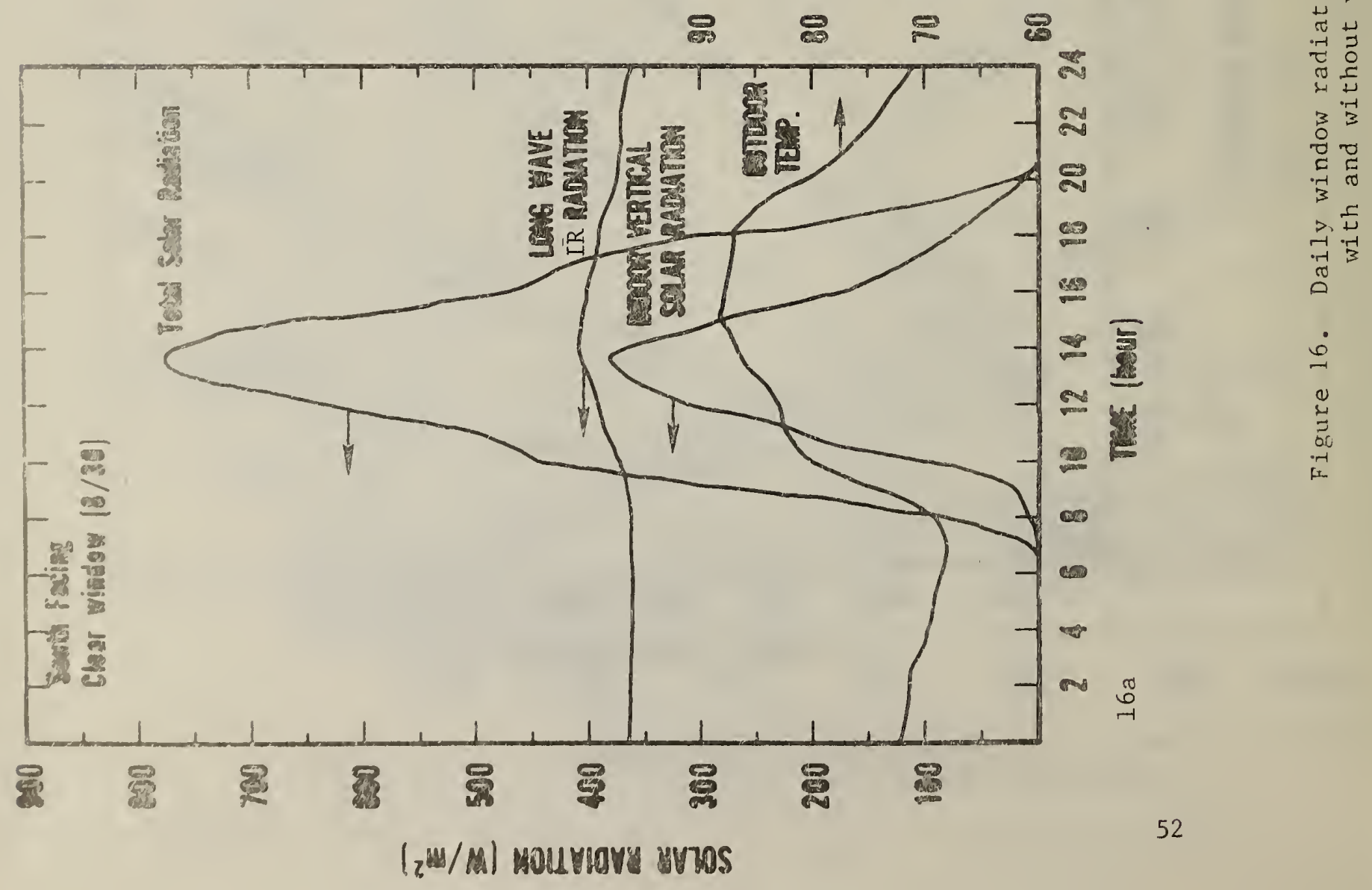




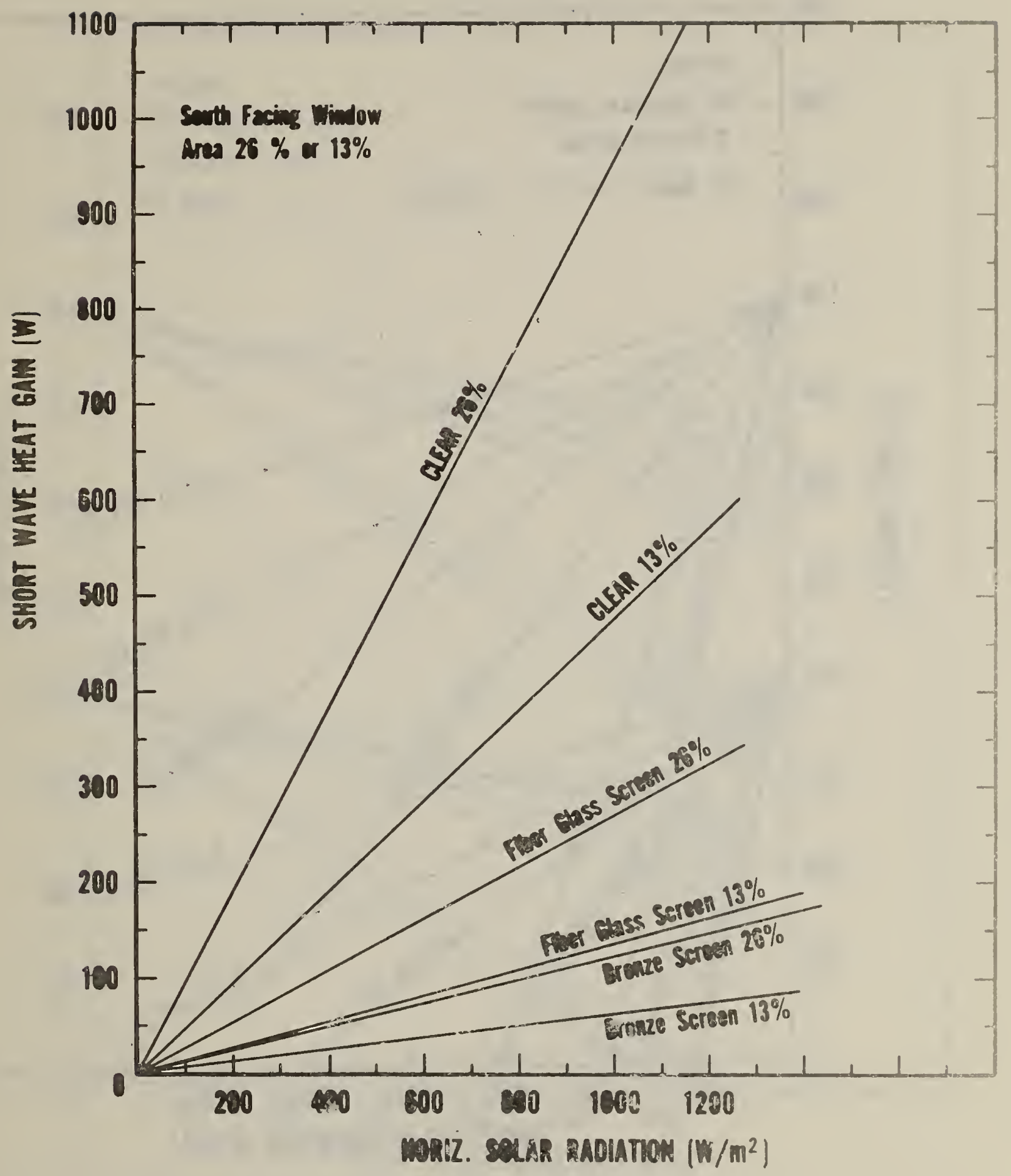

Figure 17. Short-wave solar heat gain for lest case, various window systems -- south-facing 


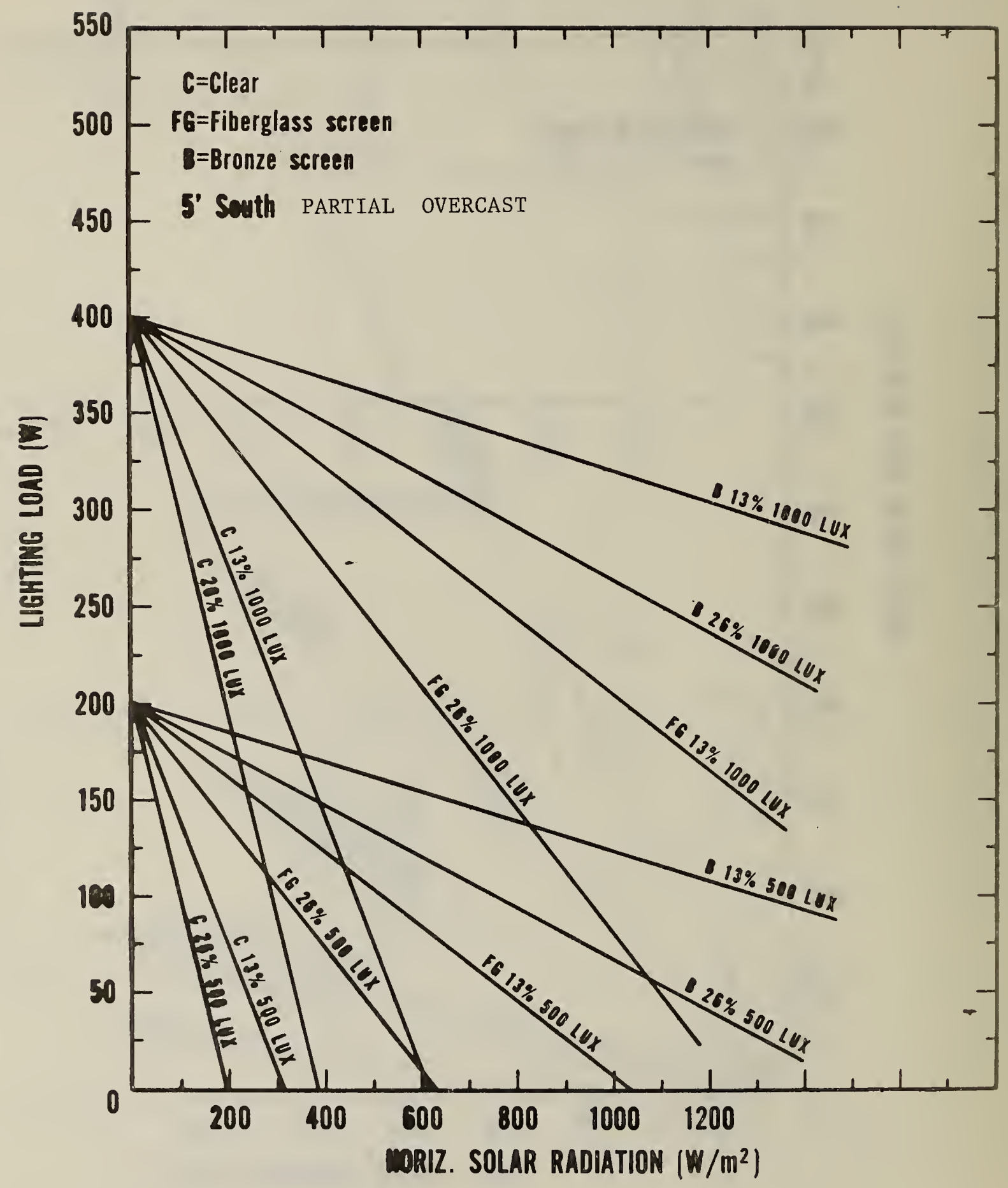

Figure 18. a Lighting load for test case, depth $1.5 \mathrm{~m}$ 


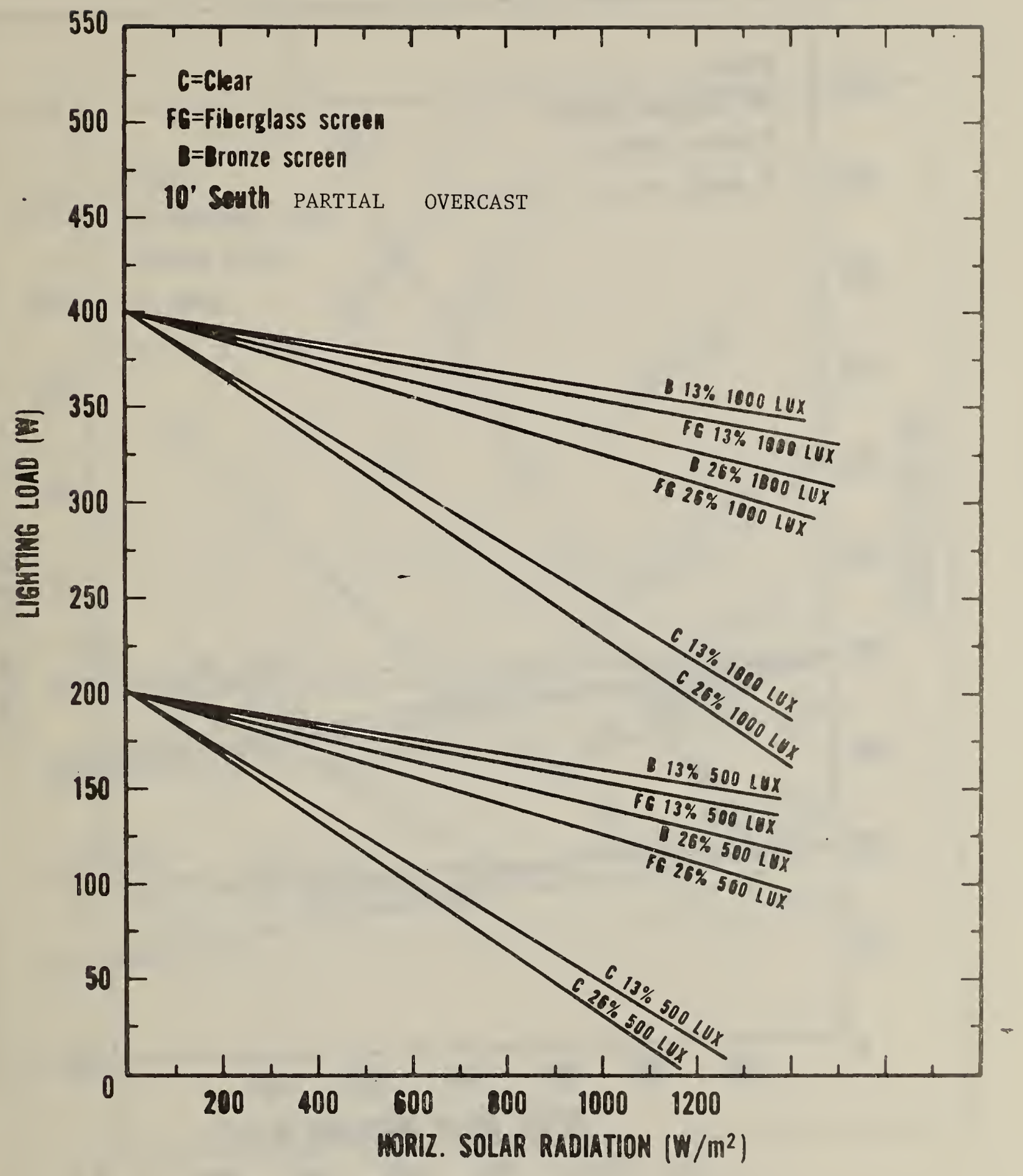

Figure 18.6 Lighting load for test case, depth $3.0 \mathrm{~m}$ 


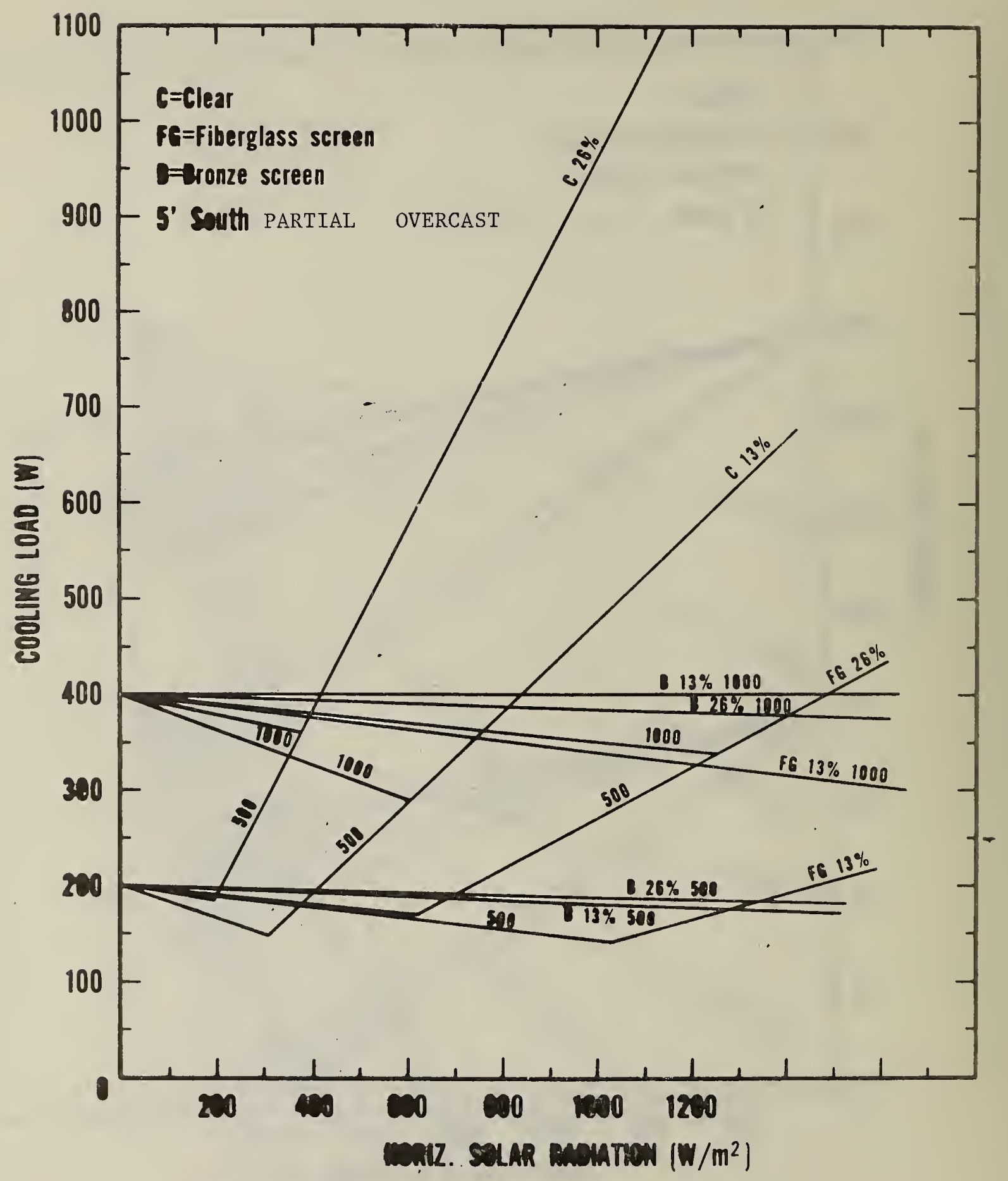

Figure 19a Cooling load for test case DEPTH $1.5 \mathrm{~m}$ 


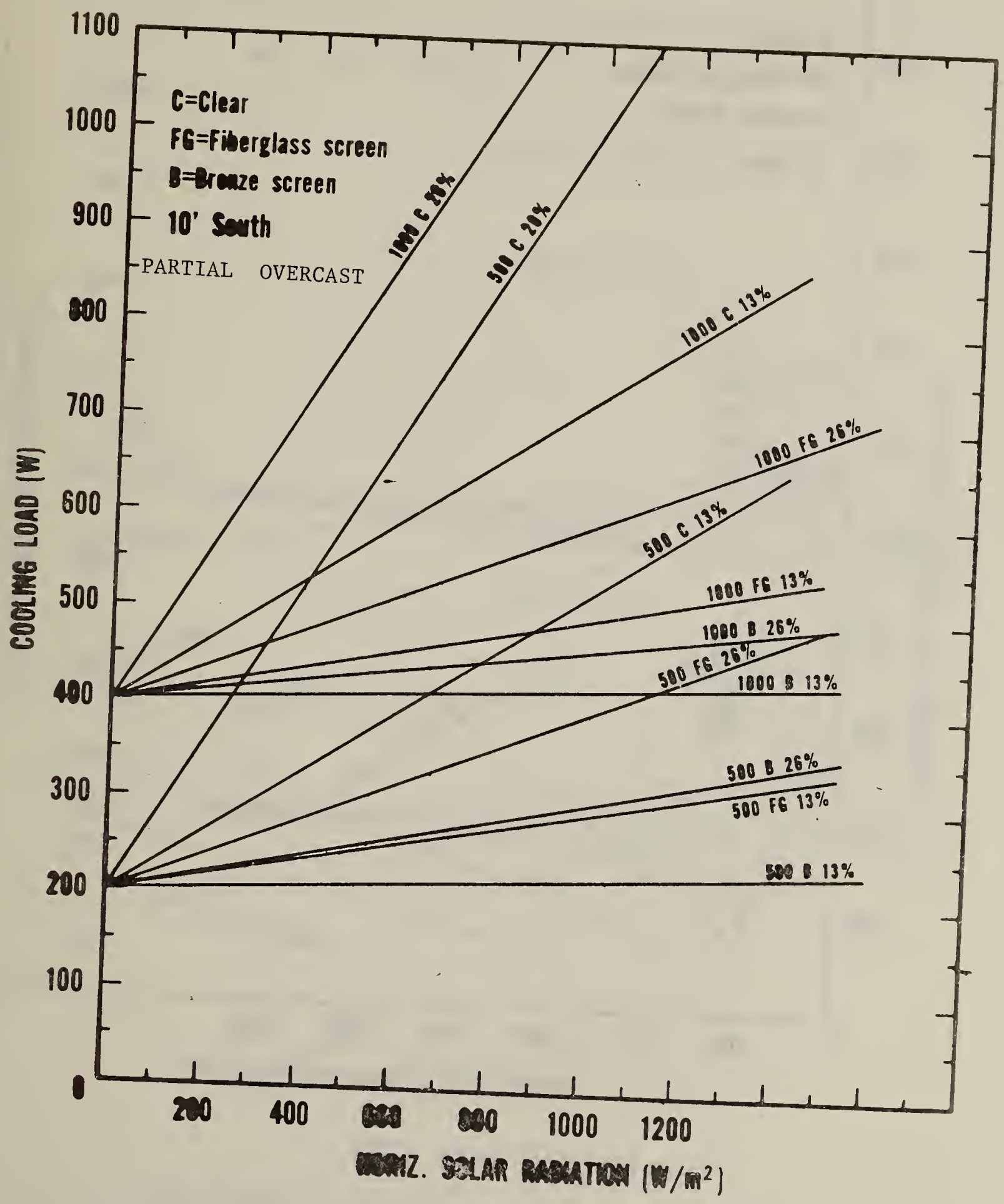

Figure $19 . \mathrm{b}$ Cooling load for test case, depth $3.0 \mathrm{~m}$ 


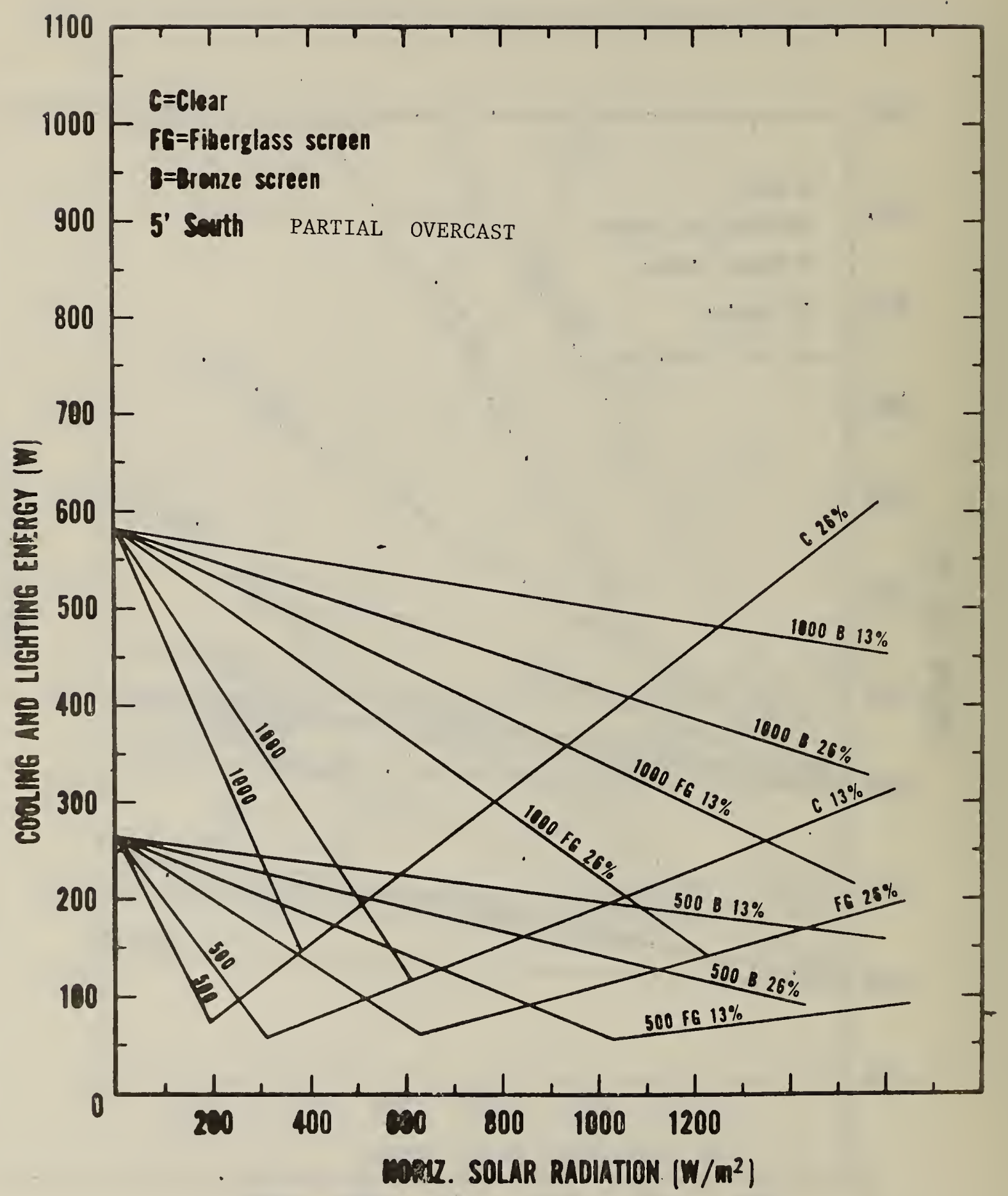

Figure 20a Cooling and lighting energy for test case DEPTH $1.5 \mathrm{~m}$ 


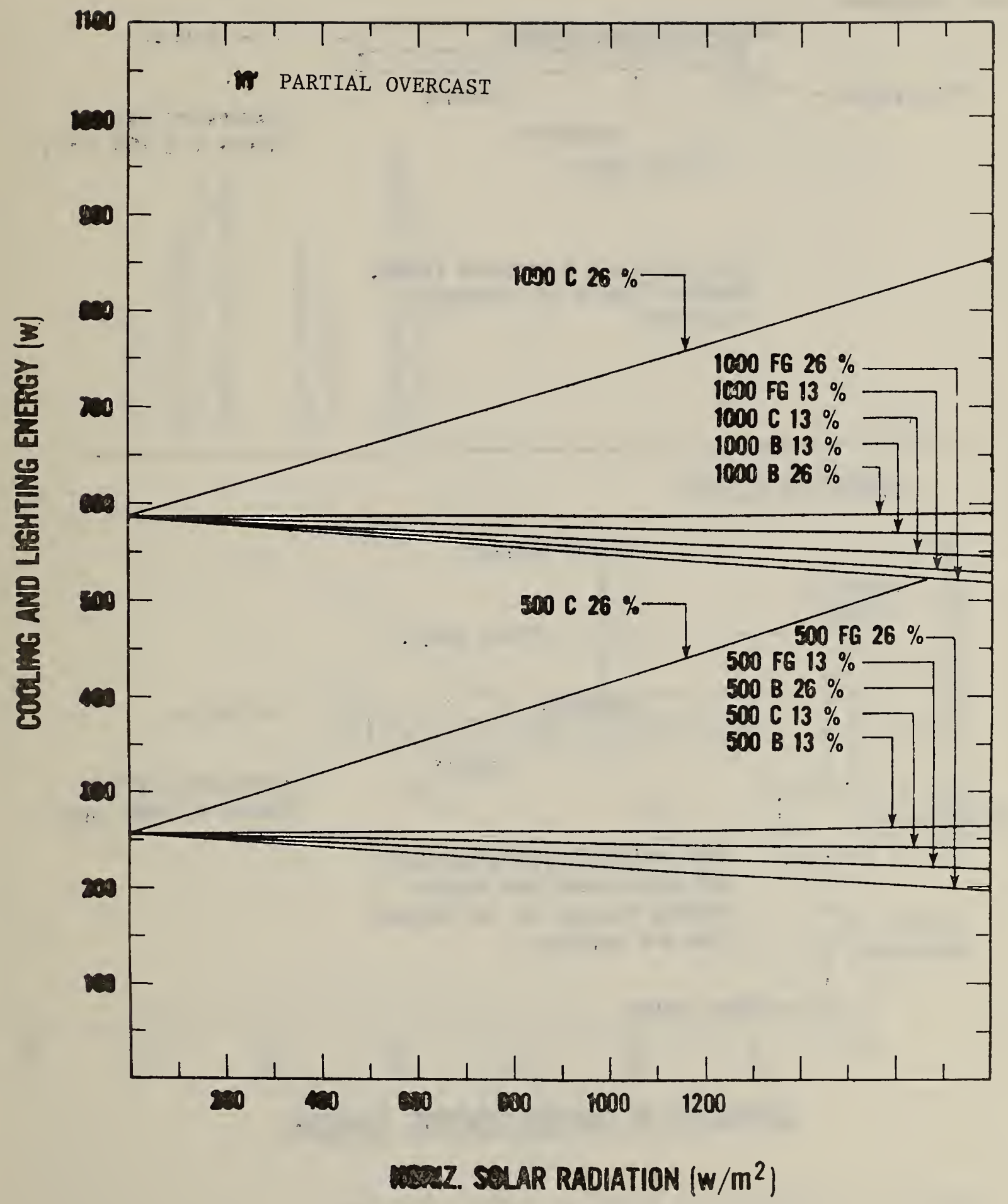

Figure 20.b Cooling and lighting energy for test case, depth $3.0 \mathrm{~m}$ 
Level adjustment

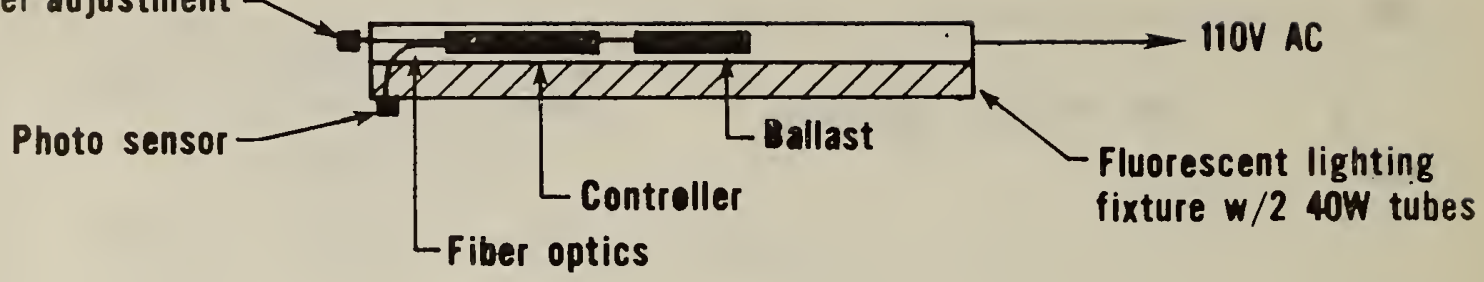

Each fixture is a complete system.

Multiple fixtures are connected in parallel.

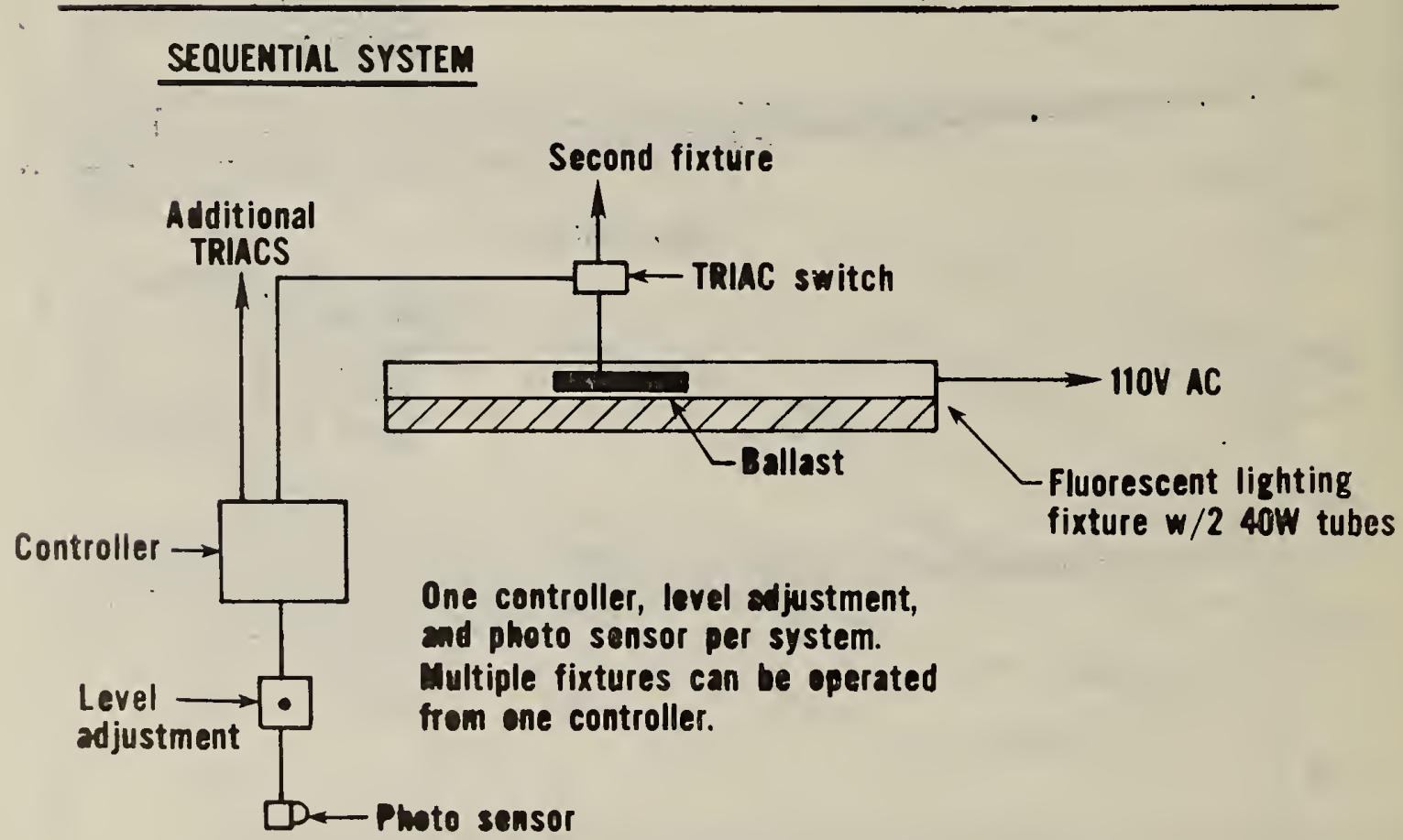

\section{SCHEMATC OF LEHTWG CONTROL SYSTEMS}

Figure 21. Schematic of lighting control systems 

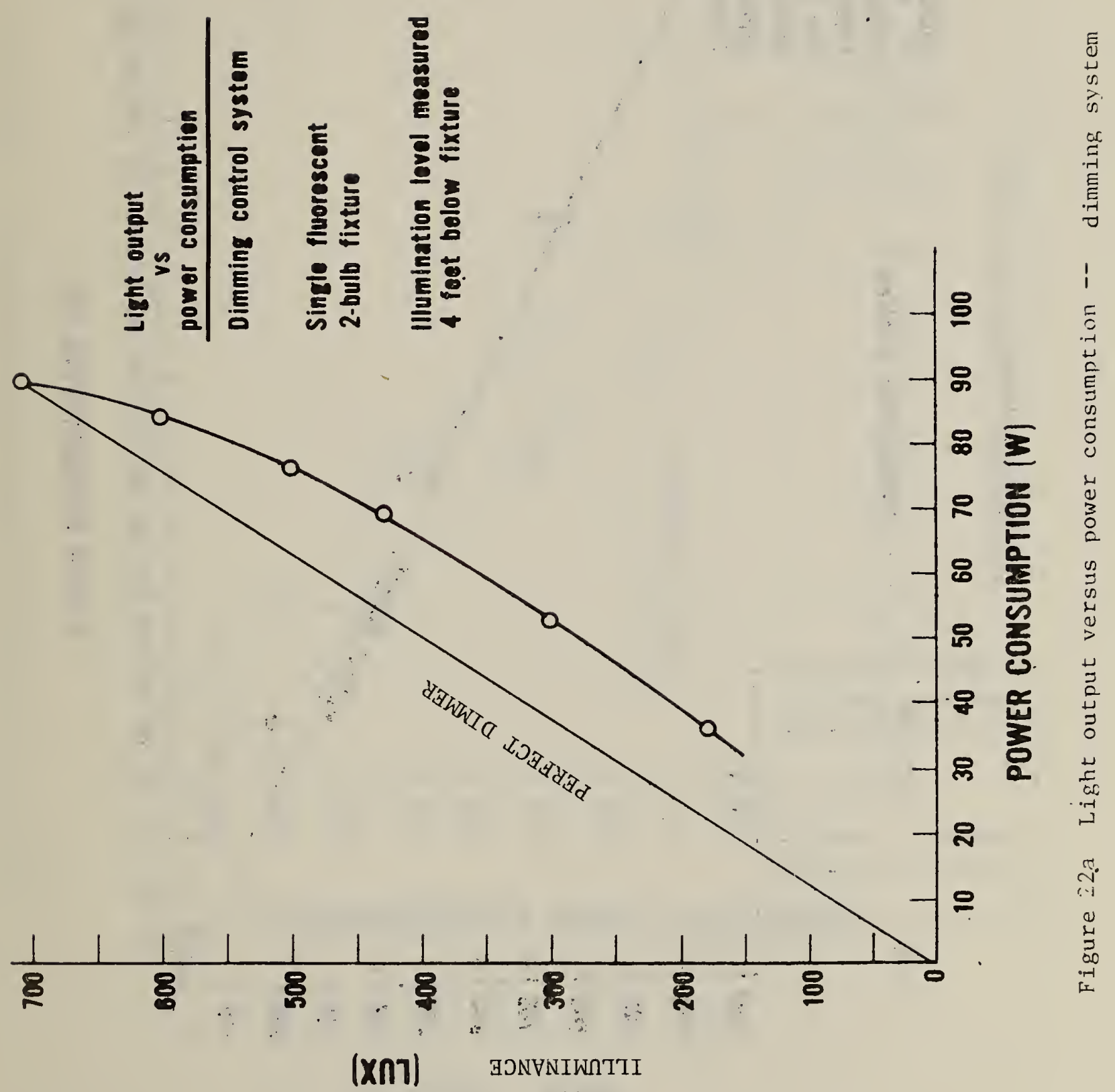


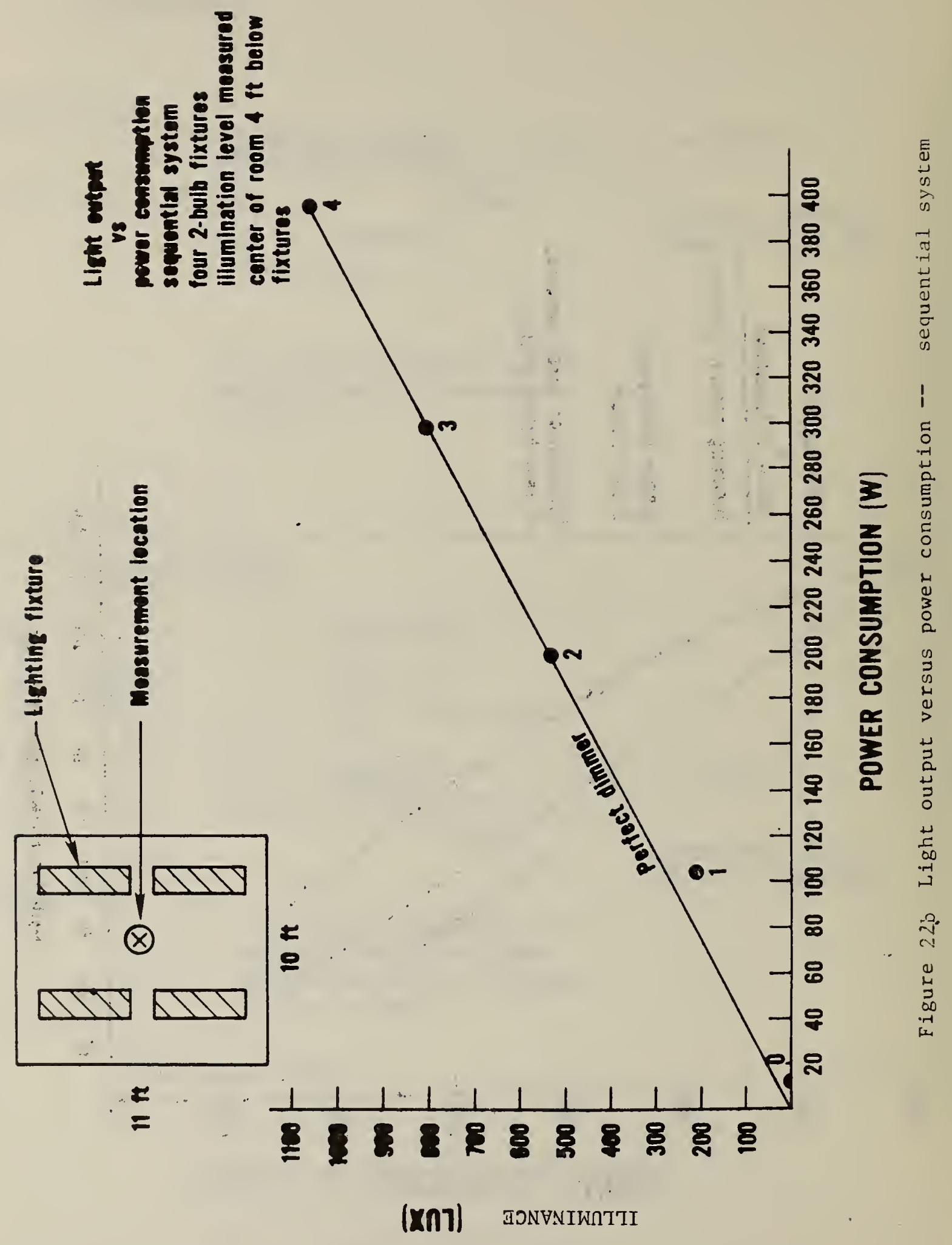




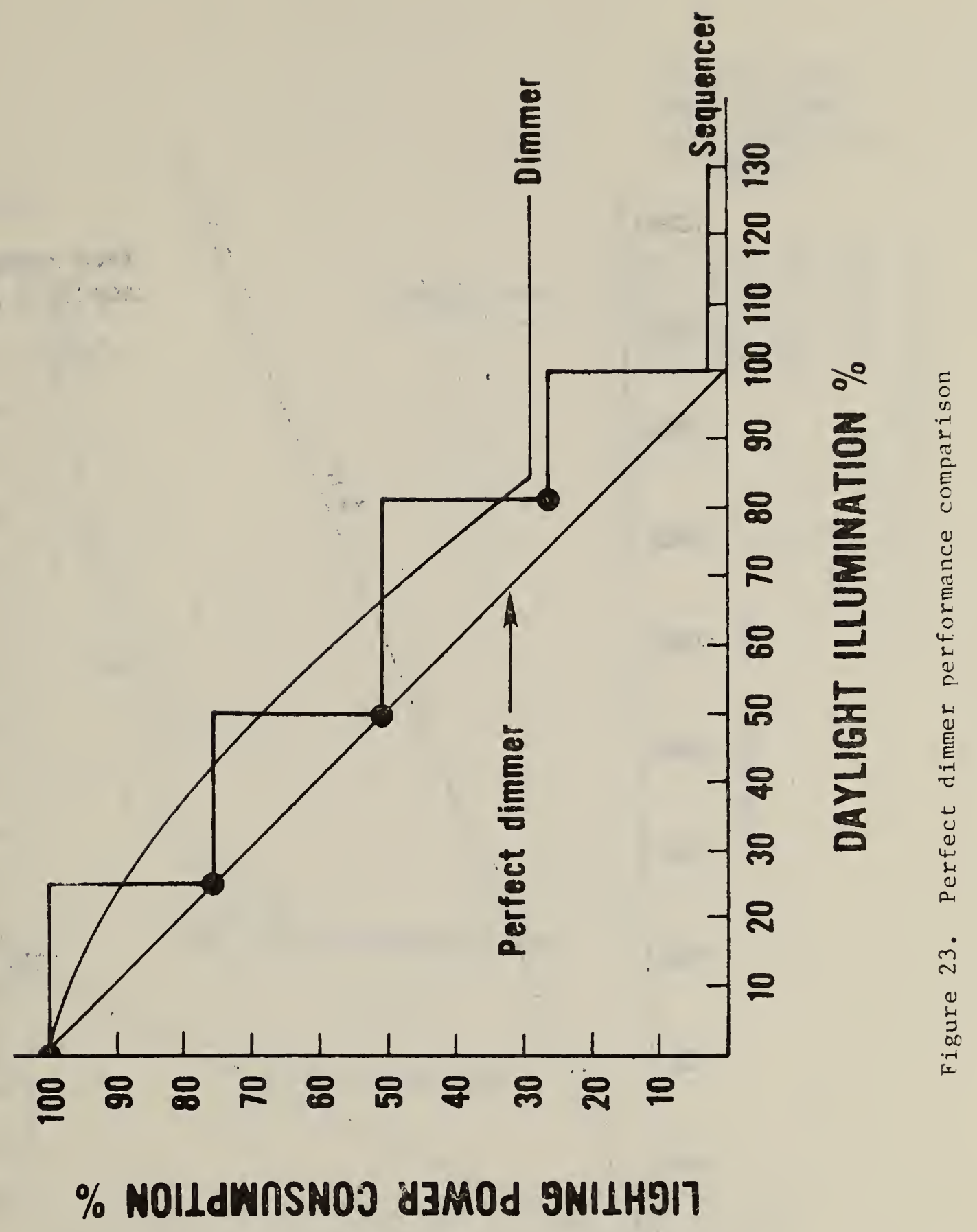




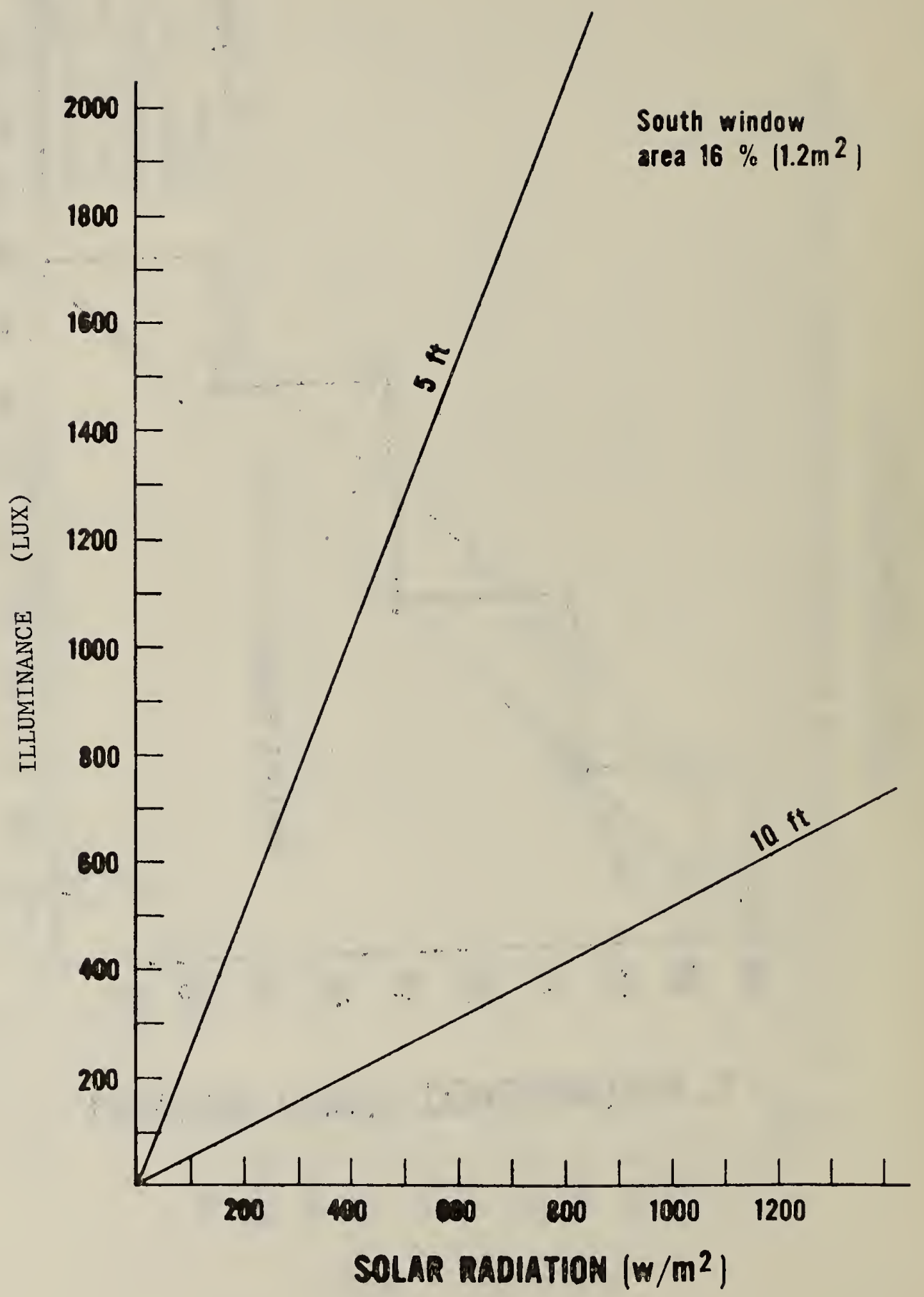

Figure 24. Average indoor 111umination for test room -- south-facing window 


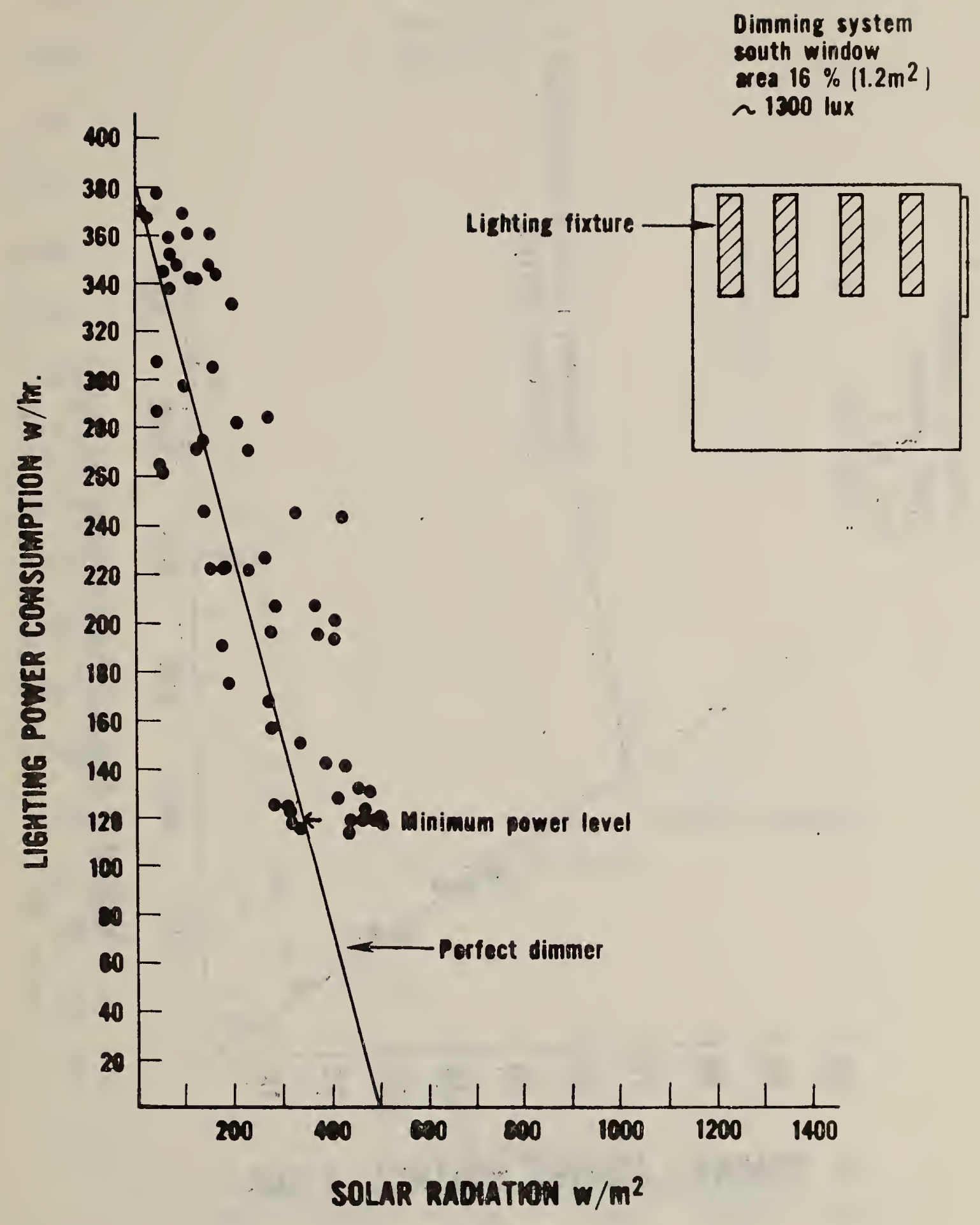

Figure 25a Lighting power consumption-dimming system system 


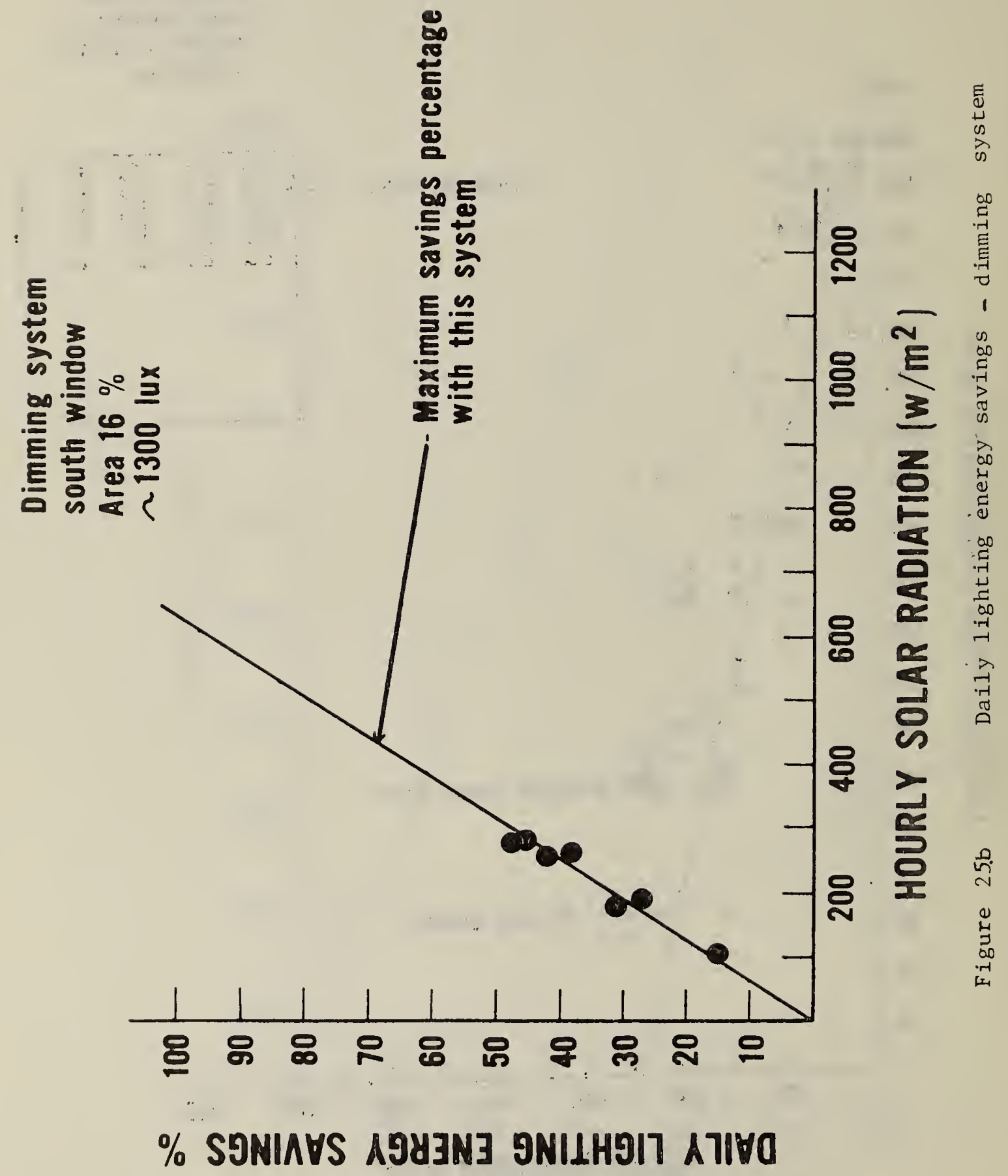




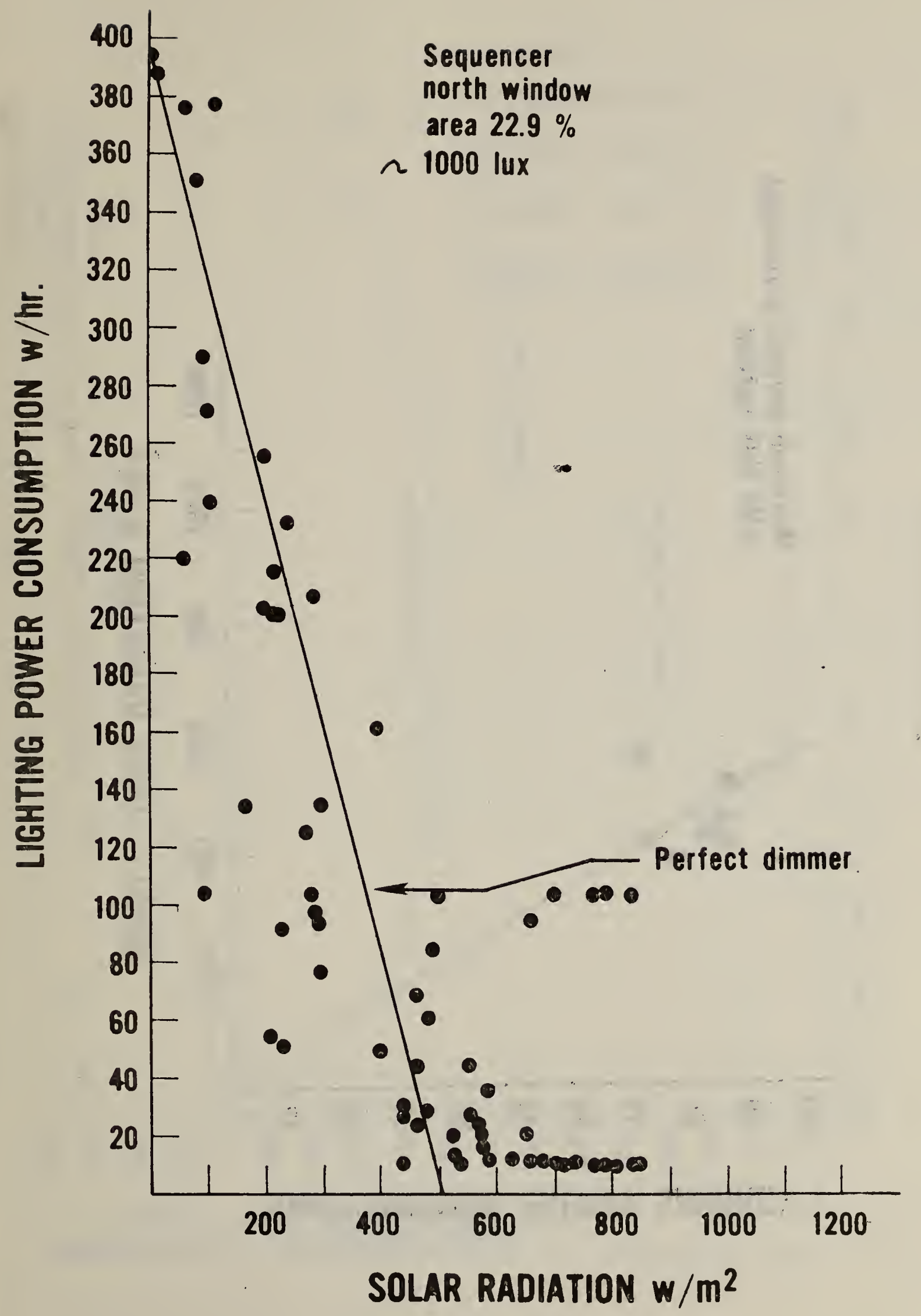

Figure 26a Lighting power consumption - sequential system 

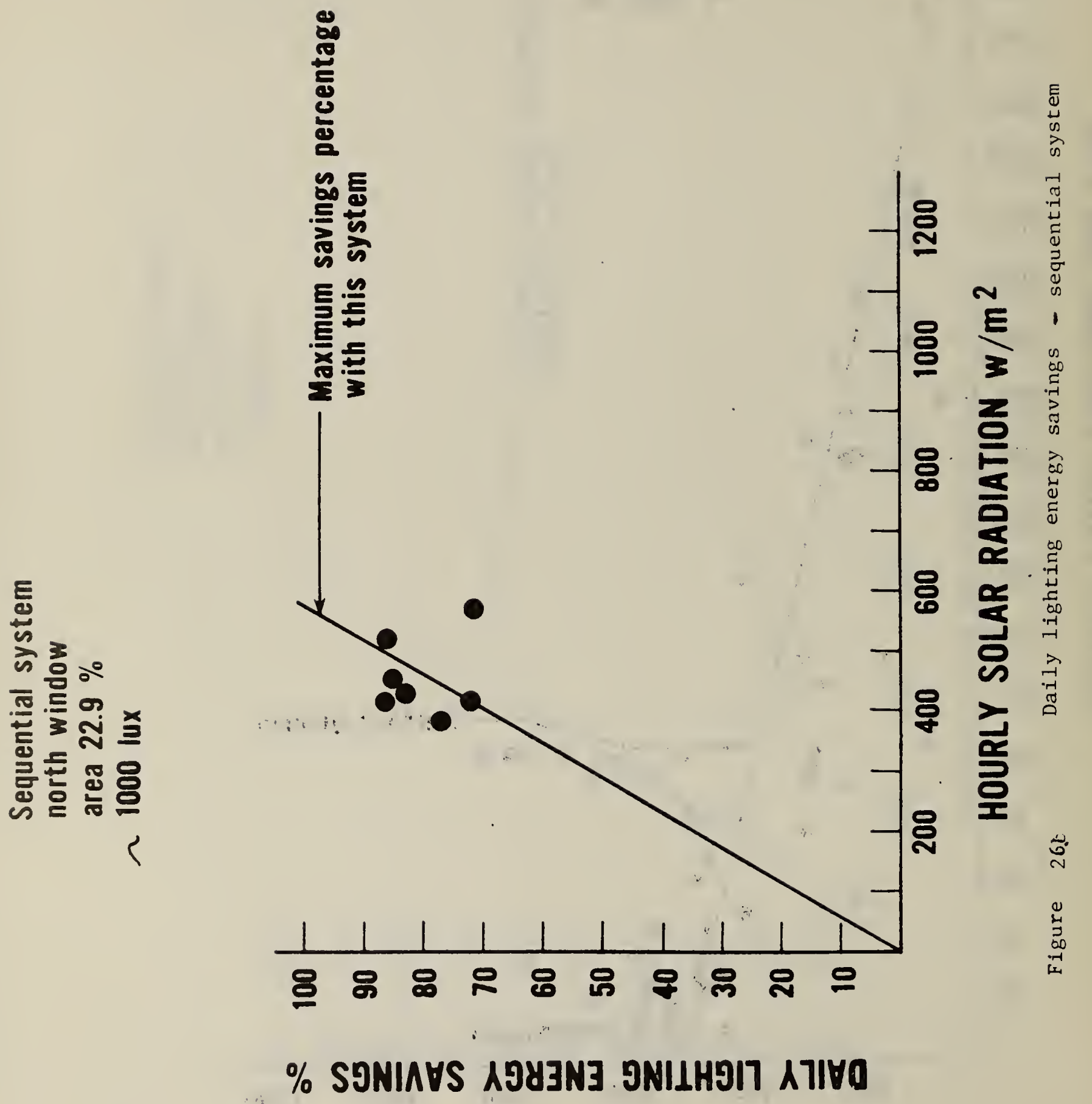

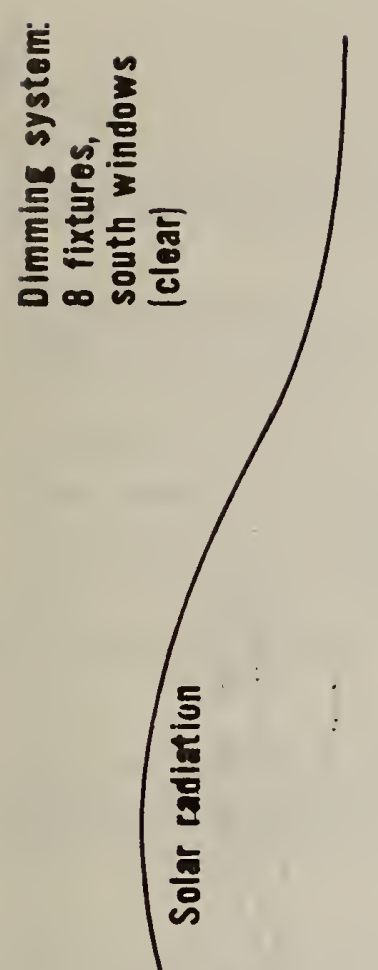

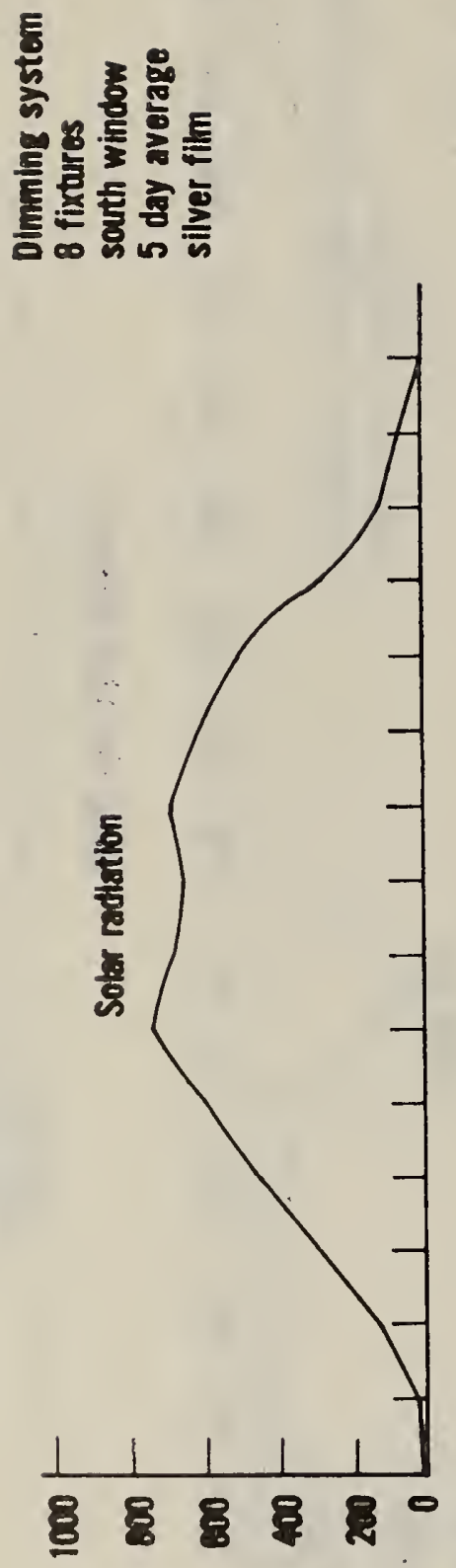

(2w/m) melmovy anos

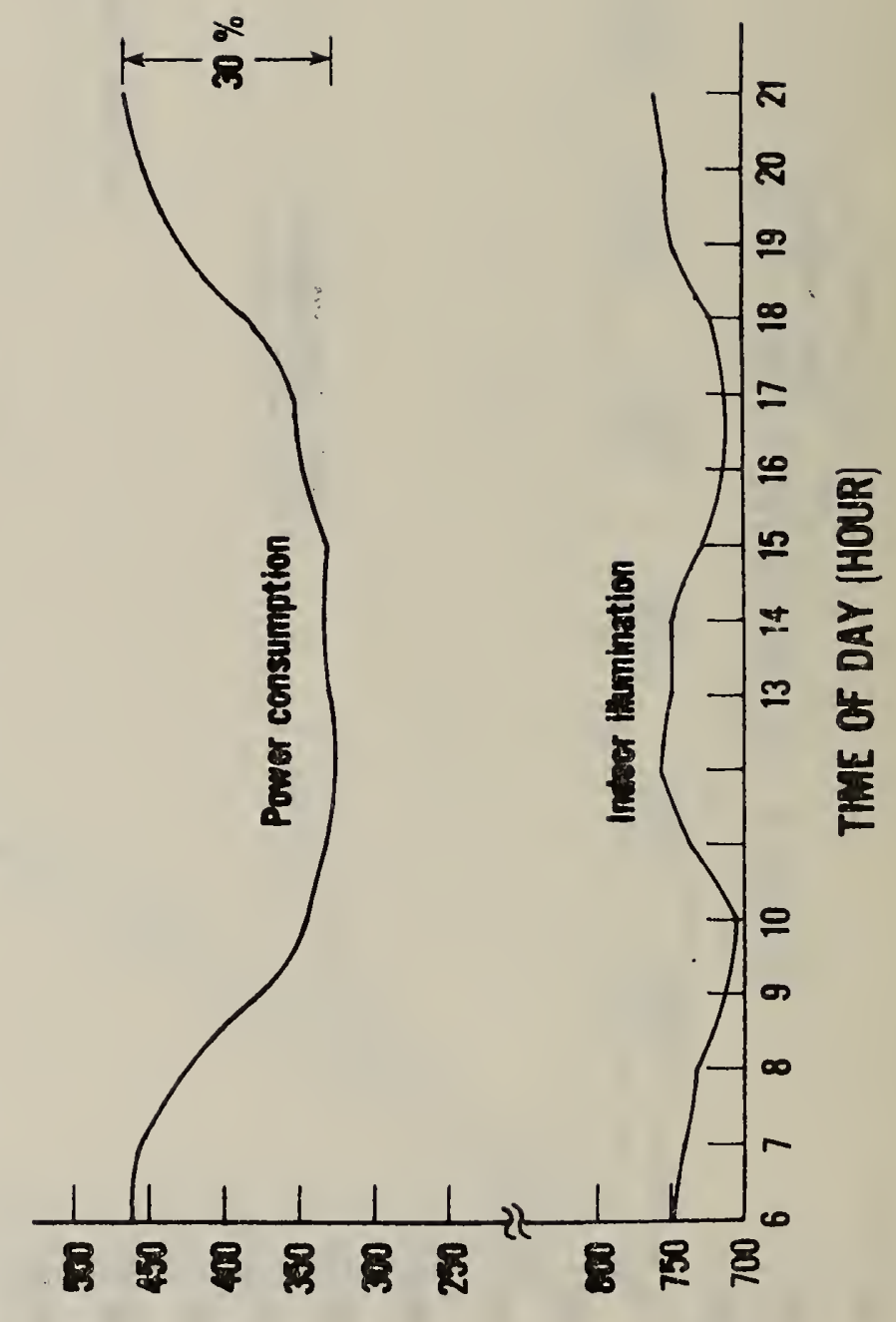

$\underset{\infty}{\infty}$

1
0
0

$\subseteq$

$+\stackrel{4-1}{4}$

$\begin{array}{ll}0 \\ \text { ते } \\ 0 & 0 \\ \text { is } & >\end{array}$

a) 3

3 in

in

3 की

ช

$\underset{\sim}{\mathbb{C}}>$

3

당

. त्- 5 ‥-1

E

की

ह 0

$+1$

is

范出

क 1

$\underbrace{\infty}_{-1} \frac{1}{0}$

出笃

0

N

[1

(Xกา) 


